\title{
GUIDELINES
}

\section{Surviving Sepsis Campaign: guidelines on the management of critically ill adults with Coronavirus Disease 2019 (COVID-19)}

Waleed Alhazzani 1,2, Morten Hylander Møller ${ }^{3,4}$, Yaseen M. Arabi ${ }^{5}$, Mark Loeb ${ }^{1,2}$, Michelle Ng Gong 6 , Eddy Fan, Simon Oczkowski ${ }^{1,2}$, Mitchell M. Levy ${ }^{8,9}$, Lennie Derde ${ }^{10,11}$, Amy Dzierba ${ }^{12}$, Bin Du ${ }^{13}$, Michael Aboodi', Hannah Wunsch ${ }^{14,15}$, Maurizio Cecconi ${ }^{16,17}$, Younsuck Koh ${ }^{18}$, Daniel S. Chertow ${ }^{19}$, Kathryn Maitland ${ }^{20}$, Fayez Alshamsi ${ }^{21}$, Emilie Belley-Cote 1,22, Massimiliano Greco ${ }^{16,17}$, Matthew Laundy ${ }^{23}$, Jill S. Morgan ${ }^{24}$, Jozef Kesecioglu ${ }^{10}$, Allison McGeer ${ }^{25}$, Leonard Mermel ${ }^{8}$, Manoj J. Mammen ${ }^{26}$ (D, Paul E. Alexander ${ }^{2,27}$, Amy Arrington ${ }^{28}$, John E. Centofanti ${ }^{29}$, Giuseppe Citerio ${ }^{30,31}$, Bandar Baw ${ }^{1,32}$, Ziad A. Memish ${ }^{33}$, Naomi Hammond ${ }^{34,35}$, Frederick G. Hayden ${ }^{36}$, Laura Evans ${ }^{37}$ and Andrew Rhodes ${ }^{38^{*}}$

(C) 2020 European Society of Intensive Care Medicine and the Society of Critical Care Medicine

\begin{abstract}
Background: The novel severe acute respiratory syndrome coronavirus 2 (SARS-CoV-2) is the cause of a rapidly spreading illness, Coronavirus Disease 2019 (COVID-19), affecting thousands of people around the world. Urgent guidance for clinicians caring for the sickest of these patients is needed.

Methods: We formed a panel of 36 experts from 12 countries. All panel members completed the World Health Organization conflict of interest disclosure form. The panel proposed 53 questions that are relevant to the management of COVID-19 in the ICU. We searched the literature for direct and indirect evidence on the management of COVID-19 in critically ill patients in the ICU. We identified relevant and recent systematic reviews on most questions relating to supportive care. We assessed the certainty in the evidence using the Grading of Recommendations, Assessment, Development and Evaluation (GRADE) approach, then generated recommendations based on the balance between benefit and harm, resource and cost implications, equity, and feasibility. Recommendations were either strong or weak, or in the form of best practice recommendations.

Results: The Surviving Sepsis Campaign COVID-19 panel issued 54 statements, of which 4 are best practice statements, 9 are strong recommendations, and 35 are weak recommendations. No recommendation was provided for 6 questions. The topics were: (1) infection control, (2) laboratory diagnosis and specimens, (3) hemodynamic support, (4) ventilatory support, and (5) COVID-19 therapy.
\end{abstract}

\footnotetext{
*Correspondence: andrewrhodes@nhs.net

${ }^{38}$ Adult Critical Care, St George's University Hospitals NHS Foundation

Trust \& St George's University of London, London, UK

Full author information is available at the end of the article
} 
Conclusion: The Surviving Sepsis Campaign COVID-19 panel issued several recommendations to help support healthcare workers caring for critically ill ICU patients with COVID-19. When available, we will provide new recommendations in further releases of these guidelines.

Keywords: Coronavirus, COVID-19, SARS CoV-2, Clinical practice guidelines, Critical illness

\section{Introduction}

At the end of 2019, a novel coronavirus, named severe acute respiratory syndrome coronavirus 2 (SARS-CoV-2), resulted in an acute respiratory illness epidemic in Wuhan, China [1]. The World Health Organization (WHO) termed this illness Coronavirus Disease 2019 (COVID-19).

By the time this guideline panel was assembled, the COVID-19 had become a pandemic and had affected over 120,000 individuals in more than 80 countries, and resulted in more than 5000 deaths worldwide [2].

The WHO and the United States Center for Disease Control and Prevention (CDC) have issued preliminary guidance on infection control, screening and diagnosis in the general population, but there is limited guidance on the acute management of critically ill patients with severe illness due to COVID-19.

\section{Guideline scope}

This guideline provides recommendations to support hospital clinicians managing critically ill adults with COVID-19 in the intensive care unit (ICU). The target users of this guideline are frontline clinicians, allied health professionals, and policymakers involved in the care of patients with COVID-19 in the ICU. The guideline applies to both high and low-middle income settings.

\section{Guideline Teams and Structure}

The Surviving Sepsis Campaign (SSC) COVID-19 subcommittee selected panel members in such a way as to obtain a balance of topic expertise, geographic location and, as far as possible, gender.

The SSC COVID-19 panel was assembled and worked within very tight timelines in order to issue recommendations in a timely manner. The panel included experts in guideline development, infection control, infectious diseases and microbiology, critical care, emergency medicine, nursing, and public health. The panel was divided into four groups: (1) infection control and testing, (2) hemodynamic support, (3) ventilatory support, and (4) therapy.
The Guidelines in Intensive Care Development and Evaluation (GUIDE) group provided methodological support throughout the guideline development process.

\section{Management of conflict of interests}

All panel members completed a conflict of interests (COI) form prior to joining the guideline panel $[3,4]$. We used the GRADEpro guideline development tool (GDT) online software (http://gdt.guidelinedevelopment.org) to administer WHO COI disclosure forms to participating panel members. Direct financial and industry-related COIs were not permitted and were considered disqualifying. The development of this guideline did not include any industry input, funding, or financial or non-financial contribution. No member of the guideline panel received honoraria or remuneration for any role in the guideline development process.

\section{Methods}

The guideline development process is summarized in Fig. 1. All actionable guideline questions were structured in the Population, Intervention, Control, and Outcome(s) (PICO) format, with explicit definitions, whereas descriptive questions were not.

Content and methods experts in each group participated in developing the guideline questions. The PICO format provided the basis for defining inclusion and exclusion criteria for the literature searches (where performed) and for identification of relevant studies.

To facilitate rapid development of recommendations, we did not perform a novel systematic prioritization of outcomes, but used the outcome prioritization informed by the ongoing SSC guideline 2020 work and expert input [5]. Accordingly, we focused on hospital mortality and serious adverse event outcomes for most questions, and for some included other outcomes deemed critical for decision making.

\section{Literature search}

For some questions, with help of professional medical librarians, we electronically searched major databases, i.e. Cochrane Central and MEDLINE, to identify relevant systematic reviews, randomized controlled trials (RCTs), observational studies, and case series. These electronic searches were performed looking for studies published 


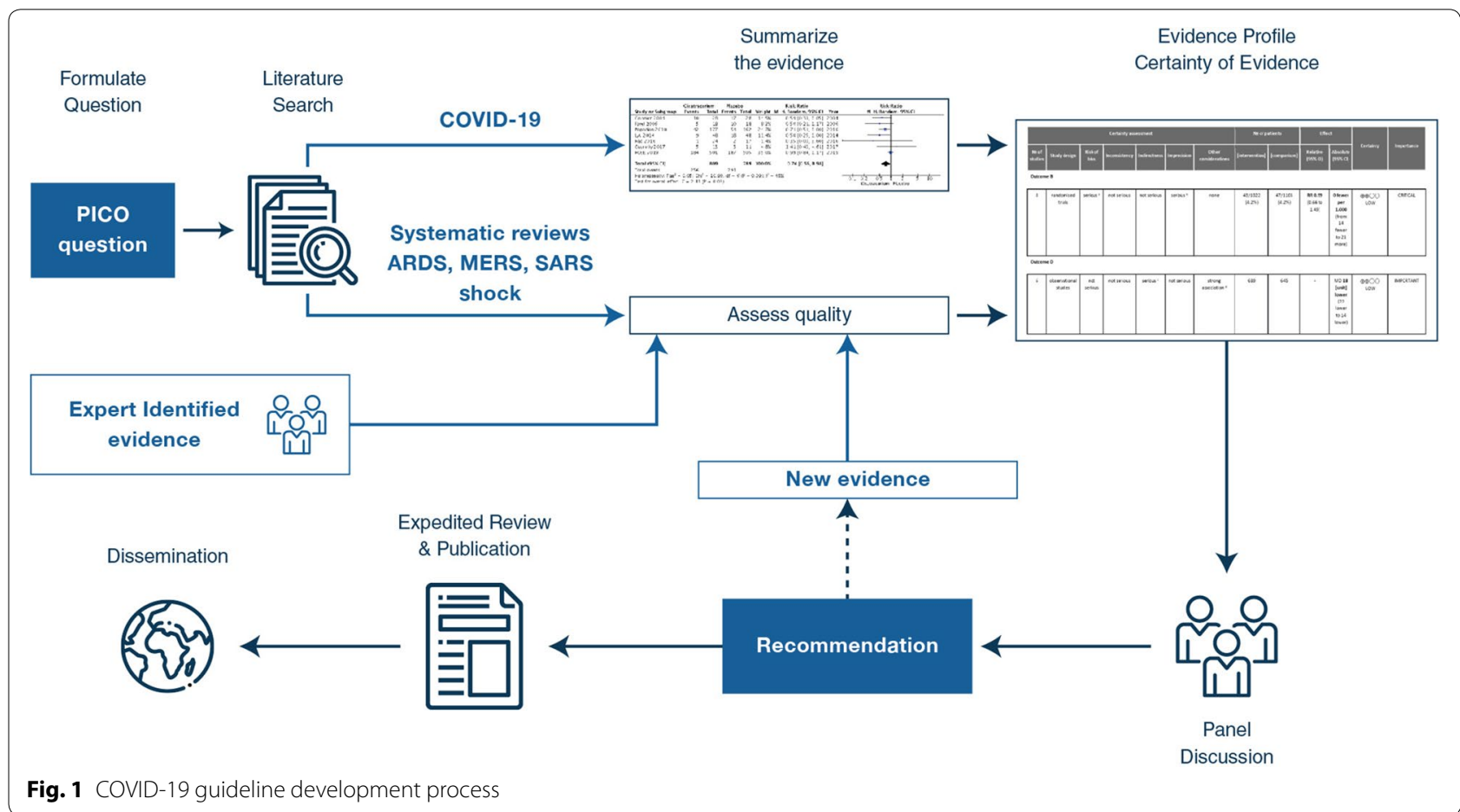

in English from inception to March 2020. To inform the recommendations on hemodynamic and ventilatory support, we used recently published systematic reviews and asked experts to identify any new relevant studies.

\section{Selection of studies and data abstraction}

For selected PICO questions, a pair of reviewers screened titles and abstracts retrieved from the bibliographic databases; for each PICO question, all potentially eligible studies were assessed for eligibility according to prespecified criteria. Content experts were asked to indicate any additional studies not identified by the search. Subsequently, pairs of reviewers independently abstracted relevant data on the corresponding PICO questions, and items relevant to risk of bias.

We obtained intention-to-treat data whenever available; otherwise we used complete case data, i.e. ignoring missing data [6].

\section{Quality of evidence}

We used the Grading of Recommendations, Assessment, Development and Evaluation (GRADE) approach to assess the quality of evidence [7], i.e. our confidence in the estimate of the effect to support a recommendation [8]. The quality of evidence was rated as high, moderate, low, or very low [9]. We used the GDT online software (http://gdt.guidelinedevelopment.org) to generate the evidence profiles (evidence summaries) [10].

\section{Using indirect evidence}

Given the recent emergence of COVID-19, we anticipated that there would be a scarcity of direct evidence, and therefore used a predefined algorithm to decide whether indirect evidence could inform a specific question (Figure S1-2).

The SSC COVID-19 panel decided which population to extrapolate evidence from based on the context of the recommendation, and the likelihood of the presence of an effect modifier (Figure S3). Accordingly, we used, as sources of indirect evidence, data on Middle East Respiratory Syndrome Coronavirus (MERS-CoV), Severe Acute Respiratory Syndrome (SARS), and other coronaviruses; in the same way, we considered, as indirect evidence, published data on supportive care in the ICU from studies on influenza and other respiratory viral infections, acute respiratory distress syndrome (ARDS) and sepsis.

\section{Recommendation formulation}

We used the principles outlined in the evidence to decision framework (EtD) to formulate recommendations, but because of the tight timelines we did not complete the online EtD tables [11]. The EtD framework covers the following domains: priority setting, magnitude of benefit and harm, certainty of the evidence, patient values, balance between desirable and undesirable effects, resources and cost, equity, acceptability and feasibility. 
Table 1 Implications of different recommendations to key stakeholders

\begin{tabular}{|c|c|c|c|c|}
\hline Recommendation & Meaning & Implications to patients & Implications to clinicians & Implications to policymakers \\
\hline $\begin{array}{l}\text { Strong recommendation or } \\
\text { Best practice statement }\end{array}$ & $\begin{array}{l}\text { Must do or } \\
\text { Must avoid }\end{array}$ & $\begin{array}{l}\text { Almost all individuals in this } \\
\text { situation would want the } \\
\text { recommended intervention, } \\
\text { and only a small proportion } \\
\text { would not want it }\end{array}$ & $\begin{array}{l}\text { Most individuals should receive } \\
\text { the recommended course } \\
\text { of action }\end{array}$ & $\begin{array}{l}\text { Can be adapted as policy in most } \\
\text { situations, including the use as } \\
\text { performance indicators }\end{array}$ \\
\hline Weak recommendation & $\begin{array}{l}\text { Consider doing or } \\
\text { Consider avoiding }\end{array}$ & $\begin{array}{l}\text { The majority of individuals in } \\
\text { this situation would want the } \\
\text { recommended intervention, } \\
\text { but many would not }\end{array}$ & $\begin{array}{l}\text { Different choices are likely to } \\
\text { be appropriate for different } \\
\text { patients, and the recommen- } \\
\text { dation should be tailored } \\
\text { to the individual patient's } \\
\text { circumstances. Such as } \\
\text { patients', family's, or substi- } \\
\text { tute decision maker's values } \\
\text { and preferences }\end{array}$ & Policies will likely be variable \\
\hline
\end{tabular}

Each of the four subgroups drafted the preliminary recommendations. We use the wording "we recommend" for strong recommendations and "we suggest" for suggestions (i.e. weak recommendations). The implications of the recommendation strength are presented in Table 1. The final list of recommendations was developed by panel discussion and consensus; voting on recommendations was not required. We present the guideline statements and recommendations in Table 2.

\section{Updating the recommendations}

We will have periodic automated electronic searches sent to assigned panel members every week to identify relevant new evidence as it emerges. Accordingly, we will issue further guideline releases in order to update the recommendations, if needed, or formulate new ones.

\section{Infection Control}

\section{Risk of SARS-CoV-2 transmission}

A recent report from the Chinese Center of Disease Control and Prevention described 72,314 cases of COVID-19 from China, of which 44,672 were laboratory confirmed. Among laboratory-confirmed cases, 1716 (3.8\%) were healthcare workers, most of whom, 63\% (1080 of 1716), acquired the infection in Wuhan. The report describes that $14.8 \%$ (247 of 1668) of infected healthcare workers had severe or critical illness, and that 5 died [12]. In Italy, as of March 15, 2020, there are 2026 documented COVID-19 cases among healthcare workers [13]. Although incidence data is not available, these data point to a considerable burden of infection among healthcare workers. The risk of patient-to-patient transmission in the ICU is currently unknown, therefore, adherence to infection control precautions is paramount.

Healthcare workers should follow the infection control policies and procedures already in place at their healthcare institutions. We provide the following recommendations and suggestions as considerations rather than a requirement to change institutional infection control policies.

\section{Recommendation \\ 1. For healthcare workers performing aerosol-generating proce- dures* $^{*}$ on patients with COVID-19 in the ICU, we recommend using fitted respirator masks (N95 respirators, FFP2, or equivalent), as opposed to surgical/medical masks, in addition to other personal protective equipment (i.e. gloves, gown, and eye protection, such as a face shield or safety goggles) \\ Best practice statement. \\ *Aerosol-generating procedures in the ICU include: endotracheal intubation, bronchoscopy, open suctioning, administration of nebulized treatment, manual ventilation before intubation, physical proning of the patient, disconnecting the patient from the ventila- tor, non-invasive positive pressure ventilation, tracheostomy, and cardiopulmonary resuscitation}

\section{Rationale}

Respirator masks are designed to block 95-99\% of aerosol particles. The N95 type conforms to United States Federal Drug Agency standards, and the FFP2 conforms to European standards-European Committee for Standards standards). Staff should be fit tested for each different type. Surgical masks (also known as medical masks) are designed to block large particles, droplets and sprays, but are less effective in blocking small particle aerosols $(<5$ $\mu \mathrm{m})[14]$.

This recommendation is based on a consensus of recommendations from the $\mathrm{CDC}, \mathrm{WHO}$, and other public health organizations, along with epidemiologic data demonstrating that aerosol-generating procedures increased risk to healthcare workers during the SARS epidemic. Powered air purifying respirators (PAPRs) can be used by healthcare workers who failed N95 mask fit testing and when N95s are in limited supply. 
Table 2 Recommendations and statements

Recommendation

Strength

\section{INFECTION CONTROL AND TESTING}

1 For healthcare workers performing aerosol-generating procedures* on patients with COVID-19 in the ICU, we recommend using fitted respirator masks (N95 respirators, FFP2, or equivalent), as opposed to surgical/medical masks, in addition to other personal protective equipment (i.e. gloves, gown, and eye protection, such as a face shield or safety goggles)

2 We recommend performing aerosol-generating procedures on ICU patients with COVID-19 in a negative pressure room

3 For healthcare workers providing usual care for non-ventilated COVID-19 patients, we suggest using surgical/medical masks, as opposed to respirator masks, in addition to other personal protective equipment (i.e. gloves, gown, and eye protection, such as a face shield or safety goggles)

$4 \quad$ For healthcare workers who are performing non-aerosol-generating procedures on mechanically ventilated (closed Weak circuit) patients with COVID-19, we suggest using surgical/medical masks, as opposed to respirator masks, in addition to other personal protective equipment (i.e. gloves, gown, and eye protection, such as a face shield or safety goggles)

5 For healthcare workers performing endotracheal intubation on patients with COVID-19, we suggest using videoguided laryngoscopy, over direct laryngoscopy, if available

6 For COVID-19 patients requiring endotracheal intubation, we recommend that endotracheal intubation be performed by the healthcare worker who is most experienced with airway management in order to minimize the number of attempts and risk of transmission

7.1 For intubated and mechanically ventilated adults with suspicion of COVID-19: For diagnostic testing, we suggest obtaining lower respiratory tract samples in preference to upper respiratory tract (nasopharyngeal or oropharyngeal) samples

7.2 For intubated and mechanically ventilated adults with suspicion of COVID-19: With regard to lower respiratory samples, Weak we suggest obtaining endotracheal aspirates in preference to bronchial wash or bronchoalveolar lavage samples

\section{HEMODYNAMICS}

8 In adults with COVID-19 and shock, we suggest using dynamic parameters skin temperature, capillary refilling time, Weak and/or serum lactate measurement over static parameters in order to assess fluid responsiveness

9 For the acute resuscitation of adults with COVID-19 and shock, we suggest using a conservative over a liberal fluid Weak strategy

10 For the acute resuscitation of adults with COVID-19 and shock, we recommend using crystalloids over colloids

11 For the acute resuscitation of adults with COVID-19 and shock, we suggest using buffered/balanced crystalloids over unbalanced crystalloids

12 For the acute resuscitation of adults with COVID-19 and shock, we recommend against using hydroxyethyl Strong starches

13 For the acute resuscitation of adults with COVID-19 and shock, we suggest against using gelatins Weak

14 For the acute resuscitation of adults with COVID-19 and shock, we suggest against using dextrans Weak

15 For the acute resuscitation of adults with COVID-19 and shock, we suggest against the routine use of albumin for Weak initial resuscitation

16 For adults with CoVID-19 and shock, we suggest using norepinephrine as the first-line vasoactive agent, over other Weak agents

17 If norepinephrine is not available, we suggest using either vasopressin or epinephrine as the first-line vasoactive agent, Weak over other vasoactive agents, for adults with COVID-19 and shock

18 For adults with COVID-19 and shock, we recommend against using dopamine if norepinephrine is available

Strong

19 For adults with COVID-19 and shock, we suggest adding vasopressin as a second-line agent, over titrating norepi- Weak nephrine dose, if target mean arterial pressure (MAP) cannot be achieved by norepinephrine alone

20 For adults with COVID-19 and shock, we suggest titrating vasoactive agents to target a MAP of 60-65 mmHg, rather Weak than higher MAP targets

21 For adults with COVID-19 and shock with evidence of cardiac dysfunction and persistent hypoperfusion despite fluid resuscitation and norepinephrine, we suggest adding dobutamine, over increasing norepinephrine dose

22 For adults with COVID-19 and refractory shock, we suggest using low-dose corticosteroid therapy ("shock-reversal"), Weak over no corticosteroid

Remark: A typical corticosteroid regimen in septic shock is intravenous hydrocortisone $200 \mathrm{mg}$ per day administered either as an infusion or intermittent doses

\section{VENTILATION}

23 In adults with COVID-19, we suggest starting supplemental oxygen if the peripheral oxygen saturation $\left(\mathrm{SpO}_{2}\right)$ is $<92 \%$, Weak and recommend starting supplemental oxygen if $\mathrm{SpO}_{2}$ is $<90 \%$ 
Table 2 (continued)

Recommendation

Strength

24 In adults with COVID-19 and acute hypoxemic respiratory failure on oxygen, we recommend that $\mathrm{SpO}_{2}$ be maintained no higher than $96 \%$

25 For adults with COVID-19 and acute hypoxemic respiratory failure despite conventional oxygen therapy, we suggest using HFNC over conventional oxygen therapy

26 In adults with COVID-19 and acute hypoxemic respiratory failure, we suggest using HFNC over NIPPV

27 In adults with COVID-19 and acute hypoxemic respiratory failure, if HFNC is not available and there is no urgent indication for endotracheal intubation, we suggest a trial of NIPPV with close monitoring and short-interval assessment for worsening of respiratory failure

28 We were not able to make a recommendation regarding the use of helmet NIPPV compared with mask NIPPV. It is an option, but we are not certain about its safety or efficacy in COVID-19

29 In adults with COVID-19 receiving NIPPV or HFNC, we recommend close monitoring for worsening of respiratory status, Best practice statement and early intubation in a controlled setting if worsening occurs

30 In mechanically ventilated adults with COVID-19 and ARDS, we recommend using low tidal volume (Vt) ventilation (Vt Strong $4-8 \mathrm{~mL} / \mathrm{kg}$ of predicted body weight), over higher tidal volumes $(\mathrm{Vt}>8 \mathrm{~mL} / \mathrm{kg}$ )

31 For mechanically ventilated adults with COVID-19 and ARDS, we recommend targeting plateau pressures (Pplat) of $<30 \mathrm{~cm} \mathrm{H}_{2} \mathrm{O}$

32 For mechanically ventilated adults with COVID-19 and moderate to severe ARDS, we suggest using a higher PEEP strategy, over a lower PEEP strategy.

Remarks: If using a higher PEEP strategy (i.e. PEEP $>10 \mathrm{~cm} \mathrm{H}_{2} \mathrm{O}$ ), clinicians should monitor patients for barotrauma

33 For mechanically ventilated adults with COVID-19 and ARDS, we suggest using a conservative fluid strategy over a liberal fluid strategy

34 For mechanically ventilated adults with COVID-19 and moderate to severe ARDS, we suggest prone ventilation for 12-16 $\mathbf{~ h}$, over no prone ventilation

35.1 For mechanically ventilated adults with COVID-19 and moderate to severe ARDS: we suggest using, as needed, inter- Weak mittent boluses of neuromuscular blocking agents (NMBA), over continuous NMBA infusion, to facilitate protective lung ventilation

35.2 In the event of persistent ventilator dyssynchrony, the need for ongoing deep sedation, prone ventilation, or persistently high plateau pressures, we suggest using a continuous NMBA infusion for up to $48 \mathrm{~h}$

36 In mechanically ventilated adults with COVID-19 ARDS, we recommend against the routine use of inhaled nitric oxide

37 In mechanically ventilated adults with COVID-19, severe ARDS and hypoxemia despite optimizing ventilation and other rescue strategies, we suggest a trial of inhaled pulmonary vasodilator as a rescue therapy; if no rapid improvement in oxygenation is observed, the treatment should be tapered off

38 For mechanically ventilated adults with COVID-19 and hypoxemia despite optimizing ventilation, we suggest using recruitment maneuvers, over not using recruitment maneuvers

39 If recruitment maneuvers are used, we recommend against using staircase (incremental PEEP) recruitment maneuvers Strong

40 In mechanically ventilated adults with COVID-19 and refractory hypoxemia despite optimizing ventilation, use of rescue Weak therapies, and proning, we suggest using venovenous (VV) ECMO if available, or referring the patient to an ECMO center

Remark: Due to the resource-intensive nature of ECMO, and the need for experienced centers and healthcare workers, and infrastructure, ECMO should only be considered in carefully selected patients with COVID-19 and severe ARDS

\section{THERAPY}

41 In mechanically ventilated adults with COVID-19 and respiratory failure (without ARDS), we suggest against the routine use of systemic corticosteroids

42 In mechanically ventilated adults with COVID-19 and ARDS, we suggest using systemic corticosteroids, over not using Weak corticosteroids

Remark: The majority of our panel support a weak recommendation (i.e. suggestion) to use steroids in the sickest patients with COVID-19 and ARDS. However, because of the very low-quality evidence, some experts on the panel preferred not to issue a recommendation until higher quality direct evidence is available

43 In mechanically ventilated patients with COVID-19 and respiratory failure, we suggest using empiric antimicrobials/ antibacterial agents, over no antimicrobials

Remark: if the treating team initiates empiric antimicrobials, they should assess for de-escalation daily, and re-evaluate the duration of therapy and spectrum of coverage based on the microbiology results and the patient's clinical status

44 For critically ill adults with COVID-19 who develop fever, we suggest using acetaminophen/paracetamol for temperature control, over no treatment

45 In critically ill adults with COVID-19, we suggest against the routine use of standard intravenous immunoglobulins (IVIG)

46 In critically ill adults with COVID-19, we suggest against the routine use of convalescent plasma

47.1 In critically ill adults with COVID-19: we suggest against the routine use of lopinavir/ritonavir

Strong

Weak

Weak

Weak

No recommendation

Strong

Strong

Weak

Weak

Weak

Weak

Weak

Weak

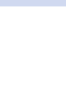


Table 2 (continued)

\section{Recommendation}

47.2 There is insufficient evidence to issue a recommendation on the use of other antiviral agents in critically ill adults with COVID-19

48 There is insufficient evidence to issue a recommendation on the use of recombinant rIFNs, alone or in combination with antivirals, in critically ill adults with COVID-19

49 There is insufficient evidence to issue a recommendation on the use of chloroquine or hydroxychloroquine in critically ill adults with COVID-19

50 There is insufficient evidence to issue a recommendation on the use of tocilizumab in critically ill adults with COVID-19

No recommendation

No recommendation

\section{Recommendation}

2. We recommend performing aerosol-generating procedures on ICU patients with COVID-19 in a negative pressure room. Best practice statement

\section{Rationale}

Negative pressure rooms are an engineering control intended to prevent the spread of contagious airborne pathogens from room to room (e.g. measles, and tuberculosis). The main goal is to avoid the accidental release of pathogens into a larger space and open facility, thereby protecting healthcare workers and patients in a hospital setting. Negative air pressure is created in the patient's room to keep the pathogen inside and avoid its diffusion. By adopting this precaution when aerosol-generating procedures like tracheal intubation, bronchoscopies, or non-invasive positive pressure ventilation (NIPPV) are performed within the room, there is a lower risk of crosscontamination among rooms and infection for staff and patients outside the room. Negative pressure is created and maintained by a ventilation system that allows extra air to enter the isolated room by differential pressure, and be exhausted directly to the outside or be filtered through a high-efficiency particulate air (HEPA) filter directly before recirculation. Moreover, the presence of unnecessary staff in the room should be avoided.

Negative pressure rooms have proven to be an effective measure that helped to avoid cross-contamination during the SARS epidemic [15]. Accordingly, for aerosolgenerating procedures, the WHO guidance on COVID19 recommends the use of negative pressure rooms with a minimum of 12 air changes per hour or at least $160 \mathrm{~L} /$ second/patient in facilities with natural ventilation [16]. Bronchoscopies are among the procedures at highest risk of aerosolization, and their use should be minimized. Non-invasive ventilation is also at high risk of aerosolization, and strategies have been described to contain the risk [17] of virus spread, also according to a previous report on SARS infection [18].
Where this is not feasible, a portable HEPA filter should be used in the room wherever possible. A HEPA filter is a mechanical air filter, used for isolation where maximum reduction or removal of submicron particulate matter from air is required. HEPA filters have been demonstrated to reduce virus transmission in simulated settings [19].

\section{Recommendations \\ 3. For healthcare workers providing usual care for non-ventilated COVID- 19 patients, we suggest using surgical/medical masks, as opposed to respirator masks, in addition to other personal protective equipment (i.e. gloves, gown, and eye protection, such as a face shield or safety goggles). \\ Weak recommendation, low-quality evidence. \\ 4. For healthcare workers who are performing non-aerosol-generating procedures on mechanically ventilated (closed circuit) patients with COVID-19, we suggest using surgical/medical masks, as opposed to respirator masks, in addition to other personal protective equipment (i.e. gloves, gown, and eye protection, such as a face shield or safety goggles). \\ Weak recommendation, low-quality evidence.}

\section{Rationale}

Our recommendations are in line with the WHO guidance, and with the current evidence, which suggests that surgical/medical masks are probably not inferior to N95 respirators for providing protection against laboratory confirmed seasonal respiratory viral infections (e.g. influenza, but not measles). We updated the most recent systematic review and meta-analysis of RCTs [20], and identified one new RCT [21]. Overall, 4 RCTs (5549 individuals) randomized healthcare workers to N95 respirators or medical masks [21-25]. The use of medical masks, as opposed to N95 respirators, did not increase laboratory-confirmed respiratory infection (OR 1.06, 95\% CI 0.90-1.25). Although the point estimates suggest that use of medical masks was associated with increased risk of influenza-like illness (OR 1.31, 95\% CI 0.94, 1.85) and clinical respiratory infection (OR 1.49, 95\% CI $0.98-$ $2.28)$, the differences were not statistically significant. A 
recent systematic review and meta-analysis reached similar conclusions [26].

Only one RCT reported on coronavirus. On testing for seasonal coronavirus (OC43, HKU1, 229E, NL63) by means of PCR in this non-cluster RCT, 4.3\% (9/212) of nurses in the medical mask group had RT-PCR confirmed coronavirus infection as compared with 5.7\% $(12 / 210)$ in the N95 respirator group [22].

When making these recommendations, the panel considered the lack of convincing evidence that N95 respirators improve clinical outcomes, the cost and resources associated with N95 mask use, and the need to preserve the N95 respirator supply for aerosol-generating procedures. Therefore, the panel issued a suggestion to use medical masks in this context. However, SARS-CoV-2 appears to be more easily transmissible and lethal than seasonal influenza. Specifically, an early estimate of the reproductive number $\left(\mathrm{R}_{0}\right)$ of SARS-CoV-2, the average number of people an infected person subsequently infects as a function of biological properties of the pathogen in combination with social and environmental factors, is 2.3 [27]. By comparison, the estimated average $R_{0}$ for the 1918 influenza pandemic that resulted in an estimated 50 million deaths globally was 1.8 , and the estimated average $R_{0}$ for seasonal influenza is 1.28 [28]. Therefore, a minimum of a surgical/medical mask is recommended for healthcare workers caring for non-ventilated COVID-19 patients and for healthcare workers who are performing non-aerosol-generating procedures on mechanically ventilated (closed circuit) patients with COVID-19. When scarcity is not an issue, use of a fitted respirator use of a fitted respirator mask is a reasonable option.

\section{Recommendation}

5. For healthcare workers performing endotracheal intubation on patients with COVID-19, we suggest using video-guided laryngoscopy, over direct laryngoscopy, if available.

Weak recommendation, low-quality evidence.

\section{Rationale}

There is no direct evidence comparing the use of videolaryngoscopy with direct laryngoscopy for intubation of patients with COVID-19. While SARS-CoV-2 appears to be predominantly spread by large respiratory droplets, intubation is likely a small particle (less than $5 \mu \mathrm{m}$ ) aerosol-generating procedure, which increases the risk of transmission to healthcare workers [29]. Intubation is particularly risky given the close contact of healthcare workers with the patient's airway and respiratory secretions. Thus, techniques that can reduce the number of attempts at endotracheal intubation and the duration of the procedure and minimize the proximity between the operator and the patient, should be prioritized, potentially reducing the risk of complications in hypoxic COVID-19 patients. In a systematic review including 64 studies and 7044 patients, video-laryngoscopy reduced the risk of failed intubation (OR 0.35, 95\% CI 0.19-0.65), without a significant impact upon the proportion of successful first-pass attempts (OR 0.79, 95\% CI 0.48-1.3), hypoxia (OR 0.39, 95\% CI 0.11.44), or time for tracheal intubation [30,31]. In patients with difficult airways, the first-attempt success rate may be improved with video-laryngoscopy [32].

Thus, in settings where video-laryngoscopy is available and staff are skilled in its use, we suggest that it be used, in preference to direct laryngoscopy, to maximize the chances of success. Recognizing that not all centers will have rapid access to video-laryngoscopy or skilled users, this recommendation is conditional.

\section{Recommendation \\ 6. For COVID-19 patients requiring endotracheal intubation, we rec- ommend that endotracheal intubation be performed by the health- \\ care worker who is most experienced with airway management in order to minimize the number of attempts and risk of transmission. Best practice statement.}

\section{Rationale}

Similar to the reasoning above, factors that maximize the chances of first pass success should be used when intubating patients with suspected or confirmed COVID-19. Thus, we recommend that the healthcare operator with the most experience and skill in airway management should be the first to attempt intubation.

\section{Laboratory diagnosis and specimens}

\section{Indications for testing ICU patients for SARS CoV-2}

The WHO recently declared a COVID-19 pandemic. Accordingly, every critically ill patient arriving with evidence of respiratory infection should be considered potentially infected with SARS-CoV-2. Real-time polymerase chain reaction (RT-PCR) is the gold standard for similar viral infections, including SARS [33]. Notably, COVID-19 poses several diagnostic challenges due to an extended incubation period (approximately 2 weeks) that includes a prolonged interval (approximately 5 days) of viral shedding prior to the onset of symptoms. Moreover, the duration of asymptomatic shedding is not only variable but may also differ based on the anatomic level (upper versus lower) of the infection in the respiratory system [1, 34]. Accordingly, the performance of biomolecular assay may vary by site of sampling. 


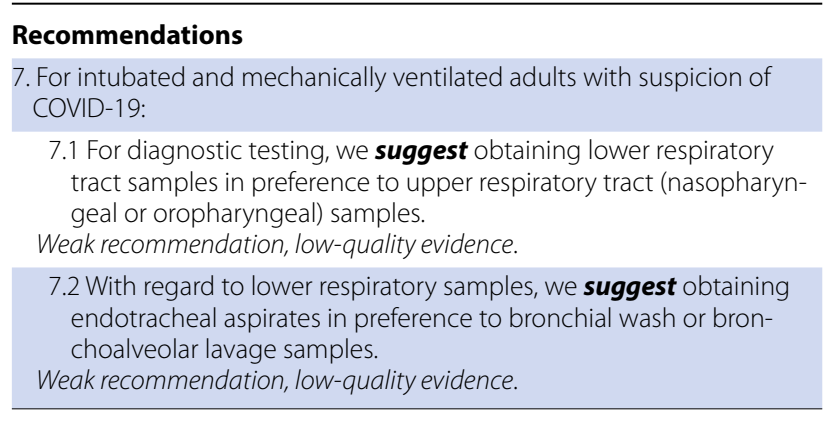

\section{Rationale}

COVID-19 diagnosis is based on RT-PCR testing of respiratory samples from nasopharyngeal and oropharyngeal swabs, and of lower respiratory tract samples whenever possible. Bronchoalveolar lavage should be limited and performed only if indicated and with adequate precautions, due to the risk of aerosolization and consequent exposure of healthcare professionals. Similarly, sputum induction should be avoided due to increased risk of aerosolization. Tracheal aspirate specimens appear to carry a lower risk of aerosolization, and can sometimes be obtained without disconnecting the patient from the ventilator.

The procedures involved in laboratory RT-PCR testing for SARS-CoV-2 using a number of assays currently in use are well described [35]. Despite the generally high sensitivity and specificity of RT-PCR-based assays [36], it may not be enough to rely on oropharyngeal swabs specimens alone for SARS-CoV-2 diagnosis due to their low negative predictive value. In a recent study, only 9 out of 19 (47\%) oropharyngeal swabs from COVID-19 patients tested positive by RT-PCR [37]. Similar data were reported using RT-PCR during the 2002-2003 SARS epidemic [38]. Using seroconversion as the "gold standard" for SARS diagnosis, RT-PCR assays performed on nasopharyngeal and throat specimens were positive only 65 and $70 \%$ of the time, respectively. However, no false positives were observed indicating assay specificity of $100 \%$. Similarly, in a study accounting for CT scan findings among suspected COVID-19 cases, 48\% with negative oropharyngeal or nasal swabs were considered highly likely cases, and 33\% were considered probable cases [39]. Consequently, a single negative swab from the upper airway does not rule out SARS-CoV-2 infection and repeated sampling from multiple sites, including the lower airway, will increase diagnostic yield. Similarly, given that coinfection with other viral pathogens has been observed, a positive test for another respiratory virus does not rule out COVID-19, and should not delay testing if there is a high suspicion of COVID-19 [40]. Given this high specificity, a single positive swab confirms the diagnosis of COVID-19 and is enough to trigger infection control precautions and appropriate treatment of the patient.

Lower respiratory tract specimens are considered to give a higher diagnostic yield than upper respiratory specimens in patients with pneumonia, consistent with what was observed for SARS [41], and should therefore be obtained whenever possible.

\section{Supportive care \\ A. Hemodynamic support}

\section{Shock and cardiac injury in COVID-19 patients}

The reported prevalence of shock in adult patients with COVID-19 is highly variable (from 1 to 35\%), depending on the patient population studied, the severity of illness, and the definition of shock. In a recent report summarizing the epidemiological characteristics of 44,415 Chinese patients with COVID-19, 2087 (5\%) were diagnosed as critical cases, defined as severe hypoxemia and/or the presence of other organ failure, including shock [12]. In another Chinese study of 1099 patients with COVID-19 with similar severity of illness, only $12(1.1 \%)$ developed shock [1]. In hospitalized patients, the incidence is likely higher [42] (Table 3), and may reach 20-35\% among patients in the ICU $[42,43]$.

Cardiac injury (elevation of cardiac injury biomarkers above the 99th percentile upper reference limit) has

Table 3 Epidemiological characteristics in recent COVID-19 reports

\begin{tabular}{|c|c|c|c|c|c|c|c|}
\hline Study & $n$ & $\begin{array}{l}\text { ICU admission } \\
(\%)\end{array}$ & $\begin{array}{l}\text { Cardiac Injury } \\
(\%)\end{array}$ & Shock (\%) & NIPPV (\%) & Invasive MV (\%) & CFR (\%) \\
\hline Huang et al. [44] & 41 & 32 & 12 & 7 & 24 & 5 & 15 \\
\hline Chen et al. [65] & 99 & 23 & - & 4 & 13 & 4 & 11 \\
\hline Wang et al. [43] & 138 & 26 & 7 & 9 & 11 & 12 & - \\
\hline Guan et al. [1] & 1099 & - & - & 1 & 5.1 & 2.3 & 1 \\
\hline Yang et al. [42] & 52 & 100 & 23 & 35 & 55.8 & 42.3 & 62 \\
\hline Zhou et al. [45] & 191 & 26 & 17 & 20 & 14 & 17 & 28 \\
\hline
\end{tabular}

CFR case fatality rate, ICU intensive care unit, NIPPV non-invasive positive pressure ventilation 
been reported in 7-23\% of patients with COVID-19 in Wuhan, China [42-45]. While the prevalence of cardiac injury may correlate with the prevalence of shock, a lack of systematic screening for cardiac dysfunction in hemodynamically stable patients means that this association cannot be taken as certain (Table 3).

The prognosis of patients with COVID-19 and shock has not been systematically reported. In a study of 150 patients from 2 hospitals in Wuhan, China, shock was a major reason for death in $40 \%$, and may, at least in part, be due to fulminant myocarditis [46].

Studies on risk factors associated with shock in patients with COVID-19 are lacking. The majority of those that are available report unadjusted estimates [12, 42, 46]. Despite methodological limitations, these studies suggest that older age, comorbidities (especially diabetes and cardiovascular disease including hypertension), lower lymphocyte count, higher D-dimer level, and possibly cardiac injury are risk factors to consider.

\section{Fluid therapy}

\section{Recommendation \\ 8. In adults with COVID-19 and shock, we suggest using dynamic parameters skin temperature, capillary refilling time, and/or serum lactate measurement over static parameters in order to assess fluid responsiveness. \\ Weak recommendation, low-quality evidence.}

\section{Rationale}

There is no direct evidence addressing the optimal resuscitation strategy in patients with COVID-19 and shock, therefore the panel based this recommendation on indirect evidence drawn from critically ill patients in general.

In a systematic review and meta-analysis of $13 \mathrm{RCTs}$ $(n=1652)$ examining the effect of dynamic assessment of fluid therapy on important patient outcomes in adult ICU patients requiring fluid resuscitation [47], the use of dynamic assessment to guide fluid therapy was found to reduce mortality (RR $0.59,95 \%$ CI $0.42-0.83$ ), ICU length of stay (MD -1.16 days, $95 \% \mathrm{CI}-1.97$ to -0.36 ) and duration of mechanical ventilation $(-2.98 \mathrm{~h}, 95 \%$ CI -5.08 to -0.89 ). Of note, only one trial focused on patients with septic shock. Dynamic parameters used in these trials included stroke volume variation (SVV), pulse pressure variation (PPV), and stroke volume change with passive leg raising or fluid challenge. Among the examined dynamic parameters, passive leg raising followed by PPV and SVV appears to predict fluid responsiveness with highest accuracy [48]. The static parameters included components of early goal-directed therapy, e.g. central venous pressure (CVP) and mean arterial pressure (MAP).
The use of serum lactate levels to guide resuscitation of patients with shock has been summarized in a systematic review and meta-analysis of 7 RCTs $(n=1301)$ [49]. Compared with central venous oxygen saturation (ScVO2) guided therapy, early lactate clearance-directed therapy was associated with a reduction in mortality (RR $0.68,95 \%$ CI $0.56-0.82$ ), shorter ICU length of stay (MD 1.64 days, $95 \% \mathrm{CI}-3.23$ to -0.05$)$, and shorter duration of mechanical ventilation (MD - 10.22 h, 95\% CI - 15.94 to -4.50 ). However, a high lactate level does not always indicate hypovolemia; it may also be caused by mitochondrial dysfunction, liver failure, beta-agonists, mesenteric ischemia, or epinephrine.

In the ANDROMEDA-SHOCK trial, capillary refill testing (CRT) every 30 min was associated with a nonsignificant reduction in mortality (HR 0.75 , 95\% CI $0.55-$ 1.02) compared with serum lactate measurement every $2 \mathrm{~h}$ [50]. CRT is a simple and easy test that can be used in almost any setting. Given the possible improvements in mortality, length of stay, and duration of mechanical ventilation that they may produce, as well as their availability, we suggest using dynamic parameters skin temperature, capillary refilling time, and/or lactate measurement over static parameters to assess fluid responsiveness in patients with COVID-19 and shock.

\section{Recommendation}

9. For the acute resuscitation of adults with COVID-19 and shock, we suggest using a conservative over a liberal fluid strategy. Weak recommendation, low-quality evidence.

\section{Rationale}

No direct evidence exists on patients with COVID-19 and shock, therefore the panel used indirect evidence from critically ill patients with sepsis and ARDS to inform this recommendation.

A recent systematic review of 9 RCTs $(n=637$ patients) comparing restricted versus liberal fluid volumes in the initial resuscitation of patients with sepsis found no statistically significant difference in mortality (RR 0.87, 95\% CI $0.69-1.10$ ) and serious adverse events (RR 0.91, 95\% CI 0.78-1.05) [51]. However, all assessed outcomes favored conservative fluid therapy (lower volumes). Importantly, the quantity and quality of evidence were both judged to be very low, suggesting that more research is needed.

Correspondingly, in a 2017 meta-analysis of 11 RCTs $(\mathrm{n}=2051$ patients), adults and children with ARDS or sepsis managed according to a conservative fluid strategy in the post-resuscitation phase of critical illness had more ventilator-free days and shorter ICU stays than patients managed according to a liberal fluid strategy [52] (see section on respiratory support for more details). 
In 2011, a large RCT of 3141 febrile African children (FEAST) found that children randomized to fluid boluses with saline or albumin had increased mortality compared with children not receiving fluid boluses [53].

In the absence of data demonstrating a benefit of the use of liberal fluid strategies in critically ill patients with sepsis or ARDS, and considering that the majority of COVID-19 patients in the ICU develop ARDS, we suggest an initial conservative approach to fluid resuscitation in patients with COVID-19 and shock.

\section{Recommendation}

10. For the acute resuscitation of adults with COVID-19 and shock

we recommend using crystalloids over colloids.

Strong recommendation, moderate quality evidence.

\section{Rationale}

Since there exists no direct evidence on shock in patients with COVID-19, the panel based this recommendation on indirect evidence from critically ill patients in general.

In a systematic review of 69 RCTs ( $n=30,020$ patients) that compared the use of crystalloids versus colloids in critically ill patients [54], no outcomes favored the use of colloids. Considering that some colloids are harmful (see below), all colloids are more costly than crystalloids, and availability of colloids is limited in some settings (e.g. some low- and middle-income countries), we recommend using crystalloids for fluid resuscitation in patients with COVID-19 and shock.

\section{Recommendation}

11. For the acute resuscitation of adults with COVID-19 and shock

we suggest using buffered/balanced crystalloids over unbalanced crystalloids.

Weak recommendation, moderate quality evidence.

\section{Rationale}

No direct evidence addresses this question in patients with COVID-19 and shock; the panel therefore based this recommendation on indirect evidence from critically ill patients in general.

A systematic review and meta-analysis of 21 RCTs ( $\mathrm{n}=20,213$ patients) comparing intravenous buffered (balanced) crystalloid solutions versus $0.9 \%$ saline for resuscitation of critically ill adults and children [55] reported no significant differences in hospital mortality (OR 0.91, 95\% CI 0.83-1.01) or acute kidney injury (OR 0.92 , 95\% CI 0.84-1.00) between the treatments. However, the point estimates for both outcomes suggest a potential for benefit from buffered crystalloid solutions.
In the absence of apparent harm, and considering the roughly equivalent costs, we suggest using buffered crystalloid solutions over unbalanced crystalloid solutions for resuscitation of patients with COVID-19 and shock. In settings with limited availability of buffered solutions, $0.9 \%$ saline remains a reasonable alternative.

\section{Recommendation \\ 12. For the acute resuscitation of adults with COVID-19 and shock, we recommend against using hydroxyethyl starches. \\ Strong recommendation, moderate quality evidence.}

\section{Rationale}

Given the absence of direct evidence on patients with COVID-19 and shock, the panel based this recommendation on indirect evidence from critically ill patients in general.

A systematic review of 69 RCTs $(n=30,020$ patients) compared the use of crystalloids versus colloids in critically ill patients; 24 of these RCTs $(n=11,177$ patients) compared the use of crystalloids with the use of starches [54]. When the data were pooled, no statistically significant difference in mortality was observed at the end of follow-up (RR 0.97, 95\% CI 0.86-1.09), within 90 days (RR 1.01, 95\% CI 0.90-1.14), or within 30 days (RR 0.99, 95\% CI 0.90-1.09). The authors, however, reported an increased risk of blood transfusion (RR 1.19, 95\% CI 1.02-1.39) and renal replacement therapy (RRT) with starches (RR 1.30, 95\% CI 1.14-1.48). Given the risk of clinically significant harm and of the apparent absence of benefits from the use of hydroxyethyl starches, we recommend against their use for resuscitation of patients with COVID-19 and shock.

\section{Recommendation}

13. For the acute resuscitation of adults with COVID-19 and shock, we suggest against using gelatins.

Weak recommendation, low-quality evidence.

\section{Rationale}

Since no study has evaluated this question in patients with COVID-19 and shock, the panel based this recommendation on indirect evidence from critically ill patients in general.

In a systematic review of 69 RCTs $(n=30,020$ patients) comparing crystalloid versus colloid use in critically ill patients, crystalloids were compared with gelatins in 6 RCTs $(n=1698)$ [54]. No statistically significant difference in all-cause mortality was observed at the end of the follow-up (RR 0.89, 95\% CI 0.74-1.08), 
within 90 days (RR $0.89,95 \%$ CI $0.73-1.09$ ), or within 30 days (RR 0.92, 95\% CI 0.74-1.16), although point estimates favored the use of crystalloids. Considering the absence of any benefit of gelatins, and their higher costs, we suggest against using gelatins for resuscitation of patients with COVID-19 and shock.

\section{Recommendation \\ 14. For the acute resuscitation of adults with COVID-19 and shock, we suggest against using dextrans. \\ Weak recommendation, low-quality evidence.}

\section{Rationale}

Given the absence of direct evidence on patients with COVID-19 and shock, the panel based this recommendation on indirect evidence from critically ill patients in general.

A systematic review and meta-analysis on crystalloid versus colloid use in critically ill patients identified 19 trials comparing crystalloids with dextrans $(n=4736)$ [54]. It reported similar mortality rates at the end of follow-up (RR 0.99, 95\% CI 0.88-1.11) and within 90 days (RR 0.99, 95\% CI 0.87-1.12), but a possibly increased risk of blood transfusion in the dextran arm (RR 0.92, 95\% CI 0.77-1.10).

In view of a possible increased risk of blood transfusion (bleeding) and higher costs associated with dextrans, we suggest against their use for resuscitation of patients with COVID-19 and shock.

\section{Recommendation}

15. For the acute resuscitation of adults with COVID-19 and shock,
we suggest against the routine use of albumin for initial resuscitation.
Weak recommendation, moderate quality evidence.

\section{Rationale}

Since there is no direct evidence on patients with COVID19 and shock, the panel based this recommendation on indirect evidence from critically ill patients in general.

A systematic review and meta-analysis identified 20 RCTs $(n=13,047)$ comparing albumin with crystalloid use [54]. It demonstrated no significant difference in all-cause mortality at the end of the follow-up (RR 0.98, 95\% CI 0.92-1.06), within 90 days (RR 0.98, 95\% CI 0.921.04 ), or within 30 -days (RR $0.99,95 \%$ CI $0.93-1.06)$. The risks of blood transfusion (RR 1.31, 95\% CI 0.95-1.80) and RRT (RR 1.11, 95\% CI 0.96-1.27) were also similar.

In the absence of a benefit of albumin, and considering its cost and limited availability, we suggest against its routine use for the initial resuscitation of patients with COVID-19 and shock.

\section{Vasoactive agents}

\section{Recommendation}

16. For adults with COVID-19 and shock, we suggest using norepinephrine as the first-line vasoactive agent, over other agents. Weak recommendation, low-quality evidence.

\section{Rationale}

There is no direct evidence on patients with COVID-19 and shock, therefore the panel based this recommendation on indirect evidence from critically ill patients in general.

A systematic review of 28 RCTs ( $n=3497$ patients) and a clinical practice guideline from 2016 summarized the available body of evidence on the best first-line vasopressor for patients with shock $[56,57]$.

As norepinephrine is the most widely studied vasoactive agent with a low a priori risk of undesirable effects, we suggest using norepinephrine as the first-line vasoactive agent in patients with COVID-19 and shock.

\section{Recommendation}

17. If norepinephrine is not available, we suggest using either vasopressin or epinephrine as the first-line vasoactive agent, over other vasoactive agents, for adults with COVID-19 and shock

Weak recommendation, low-quality evidence.

\section{Rationale}

In the absence of direct evidence on patients with COVID19 and shock, the panel based this recommendation on indirect evidence from critically ill patients in general. In a systematic review of $28 \mathrm{RCTs}(\mathrm{n}=3497$ patients) norepinephrine was compared with both vasopressin and epinephrine, but no trials directly compared the two options [57]. If norepinephrine is not available, we suggest using either vasopressin or epinephrine, as both agents have been assessed in RCTs without showing clear evidence of harm. Factors determining the choice between vasopressin and epinephrine may include availability and contraindications to the two agents. With vasopressin, digital ischemia may be a concern; with epinephrine, tachycardia and excess lactate production may be considerations.

\section{Recommendation \\ 18. For adults with COVID-19 and shock, we recommend against \\ using dopamine if norepinephrine is available. \\ Strong recommendation, high quality evidence.}

\section{Rationale}

Because no direct evidence addresses this question in patients with COVID-19 and shock, the panel based this recommendation on indirect evidence from critically ill patients.

A 2016 Cochrane systematic review found 6 RCTs $(\mathrm{n}=1400)$ comparing norepinephrine and dopamine in 
patients with shock [57]. When pooled, the results showed no significant difference in all-cause mortality, but the point estimate favored norepinephrine (RR 1.07, 95\% CI 0.99-1.16), and an increased risk of arrhythmias (RR 2.34, 95\% CI 1.46-3.78) was found in the dopamine arm.

On the basis of an increased risk of harm, including a possible increased risk of mortality in patients treated with dopamine, we recommend against using dopamine in patients with COVID-19 and shock where norepinephrine or alternatives are available (see recommendation 17).

\section{Recommendation}

19. For adults with COVID-19 and shock, we suggest adding vasopressin as a second-line agent, over titrating norepinephrine dose, if target mean arterial pressure (MAP) cannot be achieved by norepinephrine alone.

Weak recommendation, moderate quality evidence.

\section{Rationale}

In the absence of data on patients with COVID-19 and shock, the panel based this recommendation on indirect evidence from critically ill patients in general.

In a recent clinical practice guideline, the use of vasopressin and vasopressin analogs in critically ill adults with distributive shock was assessed [58]. Analyzing 25 RCTS $(\mathrm{n}=3737$ patients), the authors found low certainty of a reduction in mortality (RR 0.91, 95\% CI 0.85-0.99), high certainty of a reduction in atrial fibrillation (RR 0.77, 95\% CI 0.67-0.88), and moderate certainty of an increased risk of digital ischemia (RR 2.56, 95\% CI 1.24-5.25) with the addition of vasopressin or its analogs to catecholamines. Another recent systematic review reached similar conclusion [59]. In view of these findings, we suggest adding vasopressin as a second-line agent, over titrating norepinephrine dose, if target MAP cannot be achieved by norepinephrine alone in patients with COVID-19 and shock.

\section{Recommendation}

20. For adults with COVID-19 and shock, we suggest titrating vasoactive agents to target a MAP of $60-65 \mathrm{mmHg}$, rather than higher MAP targets.

Weak recommendation, moderate quality evidence.

\section{Rationale}

No direct evidence informs this recommendation; it is based on indirect evidence from critically ill patients.

A recent individual patient-data meta-analysis of $2 \mathrm{RCTs}$ $(\mathrm{n}=894$ patients) comparing higher versus lower blood pressure targets for vasopressor therapy in adult patients with shock reported no significant difference in 28-day mortality (OR $1.15,95 \%$ CI $0.87-1.52$ ), 90-day mortality (OR 1.08, 95\% CI 0.84-1.44), myocardial injury (OR 1.47, 95\% CI 0.64-3.56), or limb ischemia (OR 0.92, 95\% CI $0.36-2.10)$ [60]. The risk of arrhythmias was increased in patients allocated to the higher target group (OR 2.50, 95\% CI 1.35-4.77). Correspondingly, the recently published 65 trial reports an absolute risk difference in mortality of $3 \%$ (RR 0.93, 95\% CI 0.85-1.03) in favor of a MAP target of 60-65 $\mathrm{mmHg}$ (lower target), as compared to a standard of care MAP target (higher target) [61].

With an indication of improved outcome with lower MAP targets (and no firm indication of harm), we suggest titrating vasoactive agents to a target of $60-65 \mathrm{mmHg}$.

\section{Recommendation \\ 21. For adults with COVID-19 and shock with evidence of cardiac dysfunction and persistent hypoperfusion despite fluid resus- citation and norepinephrine, we suggest adding dobutamine, over increasing norepinephrine dose. \\ Weak recommendation, very low-quality evidence.}

\section{Rationale}

In the absence of direct evidence in patients with COVID19 and shock, the panel used indirect evidence from critically ill patients to inform this recommendation. In a clinical practice guideline from 2018 assessing the optimal inotropic agent in patients with acute circulatory failure (shock), no RCTs comparing dobutamine vs. placebo or no treatment were identified [62]. Based on a physiological rationale, we suggest adding dobutamine, over no treatment, in patients with COVID-19 and shock with evidence of cardiac dysfunction and persistent hypoperfusion despite fluid resuscitation and high doses of norepinephrine. The use of dobutamine in shock, including in COVID-19 patients with shock, is a research priority.

\section{Recommendation \\ 22. For adults with COVID-19 and refractory shock, we suggest using low-dose corticosteroid therapy ("shock-reversal"), over no corticoster- oid therapy. \\ Weak recommendation, very low-quality evidence. \\ Remark: A typical corticosteroid regimen in septic shock is intravenous hydrocortisone $200 \mathrm{mg}$ per day administered either as an infusion or intermittent doses.}

\section{Rationale}

Since no data exist on the use of steroids in patients with COVID-19 and shock, the panel based this recommendation on indirect evidence from critically ill patients in general. Both a 2018 systematic review of 22 RCTs ( $n=7297$ patients) comparing low-dose corticosteroid therapy versus no corticosteroid therapy in adult patients with septic shock [63] and a clinical practice guideline [64] report no significant difference in short-term mortality (RR $0.96,95 \%$ CI $0.91-1.02$ ), long-term mortality (RR $0.96,95 \%$ CI $0.90-1.02$ ), or serious adverse events (RR 0.98, 95\% CI 0.90-1.08). However, time to resolution of shock and length of stay in ICU and in hospital were shorter with corticosteroid therapy. 
As time to resolution of shock and length of stay (especially in ICU) are important cost considerations, we suggest using low-dose corticosteroid therapy in patients with COVID-19 and refractory shock. Below, we provide further guidance on patients with COVID-19 and respiratory failure in the absence of refractory shock.

\section{B. Ventilatory support}

The prevalence of hypoxic respiratory failure in patients with COVID-19 is 19\% [12]. Recent reports from China showed that 4-13\% of COVID-19 patients in these studies received non-invasive positive pressure ventilation (NIPPV), and that $2.3-12 \%$ required invasive mechanical ventilation (Table 3 ) [1, 12, 42, 43, 65]. Although the true incidence of hypoxic respiratory failure in patients with COVID-19 is not clear, it appears that about $14 \%$ will develop severe disease requiring oxygen therapy, and 5\% will require ICU admission and mechanical ventilation [12]. Another study reported on 52 critically ill COVID-19 patients; $67 \%$ of these patients had ARDS, 33 (63.5\%) received high-flow nasal cannula (HFNC), 56\% invasive mechanical ventilation, and $42 \%$ NIPPV [42].

\section{Risk factors for respiratory failure}

Risk factors associated with respiratory failure requiring mechanical ventilation are not clearly described in published reports, although from the limited available data, risk factors associated with a critical illness/ICU admission included older age ( $>60$ years), male gender, and the presence of underlying comorbidities such as diabetes, malignancy, and immunocompromised state [1, 12, 42, 43]. The CDC reported an overall case-fatality rate (CFR) of $2.3 \%$, with a CFR of $14.8 \%$ in patients aged 80 years or older. In critically ill patients, the CFR was $49.0 \%$, and it was higher than $50 \%$ in those who received invasive mechanical ventilation. The presence of pre-existing comorbid conditions such as cardiovascular disease, diabetes, chronic respiratory disease, hypertension, and cancer were associated with higher risk of death [12].

\section{Recommendations}

23. In adults with COVID-19, we suggest starting supplemental oxygen if the peripheral oxygen saturation $\left(\mathrm{SpO}_{2}\right)$ is $<92 \%$ (weak recommendation, low-quality evidence), and recommend starting supplemental oxygen if $\mathrm{SpO}_{2}$ is $<90 \%$

Strong recommendation, moderate quality evidence.

24. In adults with COVID-19 and acute hypoxemic respiratory failure on oxygen, we recommend that $\mathrm{SpO}_{2}$ be maintained no higher than $96 \%$. Strong recommendation, moderate quality evidence.

\section{Rationale}

A recent study described the disease course of 1009 patients with COVID-19 in China and showed that $41 \%$ of all hospitalized patients and over $70 \%$ of those with severe disease required supplemental oxygen [1]. In critically ill patients, hypoxia can be detrimental and is associated with poor outcomes [66]. There are no randomized or non-randomized studies on the use of oxygen in adults with COVID-19. However, the panel used indirect evidence from the acutely ill population to inform the recommendations.

A systematic review and meta-analysis of $25 \mathrm{RCTs}$ $(16,037$ patients) showed that a liberal oxygen strategy is associated with increased risk of hospital mortality (RR1.21, 95\% CI 1.03-1.43) in acutely ill patients [67]. Furthermore, a meta-regression showed a linear association between risk of death and higher $\mathrm{SpO}_{2}$ targets [67]. The median $\mathrm{SpO}_{2}$ in the liberal oxygen group was 96\% (IQR 96-98) across all trials. A recent clinical practice guideline recommended that $\mathrm{SpO}_{2}$ be maintained no higher than $96 \%$ [68].

Subsequent trials provided further guidance on oxygenation targets. The ICU-ROX trial randomized 1000 critically ill patients to receive either conservative oxygen (based on a protocol to dial down oxygen) or usual care. This trial showed no difference in 180-day mortality between the two groups (OR 1.05, 95\% CI 0.81-1.37) [69]. The ICU-ROX trial did not compare hyperoxia with a conservative oxygen strategy; instead it compared usual care with a conservative oxygen strategy.

The recent $\mathrm{LOCO} 2$ trial randomized patients with ARDS to a conservative oxygen arm (target $\mathrm{SpO}_{2} 88 \%$ to $92 \%$ ) or a liberal oxygen arm (target $\mathrm{SpO}_{2} \geq 96 \%$ ). The trial was stopped early for futility and possible harm after 61 deaths had occurred in 205 included patients for 28-day mortality [risk difference (RD) 7.8\%, 95\% CI; -4.8-20.6] [70]. At 90 days, the conservative oxygen arm had a higher risk of death (RD 14.0\%, 95\% CI, 0.7-27.2).

Considering the associated patient harm at the extremes of $\mathrm{SpO}_{2}$ targets and the increased cost of liberal oxygen use, as well as the potential to reduce equity if oxygen resources are depleted, the panel issued a strong recommendation against using oxygen to target $\mathrm{SpO}_{2}>96 \%$, and a strong recommendation to avoid lower values $\left(\mathrm{SpO}_{2}<90 \%\right)$. Therefore, a reasonable $\mathrm{SpO}_{2}$ range for patients receiving oxygen is $92-96 \%$.

\footnotetext{
Recommendation

25. For adults with COVID-19 and acute hypoxemic respiratory failure despite conventional oxygen therapy, we suggest using HFNC over conventional oxygen therapy.

Weak recommendation, low-quality evidence.
} 


\section{Rationale}

As there is no direct evidence on patients with COVID19 , the panel used indirect evidence from the critically ill population to inform this recommendation. In an RCT comparing HFNC with conventional oxygen therapy in patients with acute hypoxic respiratory failure, HFNC resulted in reduced 90-day mortality (OR 0.42, 95\% CI 0.21-0.85), but did not reduce the risk of intubation [71]. A systematic review and meta-analysis of 9 RCTs (2093 patients) showed that HFNC reduces intubation compared with conventional oxygen (RR 0.85, 95\% CI 0.740.99), but does not affect the risk of death or ICU length of stay [72-74]. Even though the evidence on mortality and length of stay was not as strong, the reduction in the need for intubation is an important finding, particularly from the perspective of pandemics such as COVID-19, where resources such as critical care beds and ventilators may become limited. In addition, in SARS, there are reports of increased transmission of disease to healthcare workers, especially nurses, during endotracheal intubation (OR 6.6, 95\% Cl 2.3-18.9) [29, 75, 76]. Although this is a finding based mostly on retrospective observational studies, HFNC does not seem to confer an increased risk of transmission of disease. In studies evaluating bacterial environmental contamination, HFNC presented a contamination risk similar to that of conventional oxygen [77]. In SARS, healthcare workers exposed to HFNC were not at increased risk of developing disease [75]. Finally, patients may find HFNC more comfortable than, or at least as comfortable as, conventional oxygen therapy $[71,74]$. Although some authors advised avoiding the use of HFNC in patients with COVID-19 due to the fear of disease transmission, studies supporting this advice are lacking [78]. Although some have proposed that patients wear face masks while on HFNC therapy, we are uncertain about the efficacy and safety of this approach. This question could be addressed in future studies.

\section{Recommendation}

26. In adults with COVID-19 and acute hypoxemic respiratory failure, we suggest using HFNC over NIPPV.

Weak recommendation, low-quality evidence.

\section{Rationale}

In adults with COVID-19 and acute respiratory failure, we suggest the use of HFNC over NIPPV. In an RCT comparing HFNC with NIPPV in patients with acute hypoxic respiratory failure, HFNC resulted in reduced mortality at 90 days (HR 2.50, 95\% CI 1.31-4.78), but did not significantly affect the need for intubation (50\% failure rate in NIPPV vs $47 \%$ in conventional oxygen and $40 \%$ in HFNC groups; $p=0.18$ ) [71]. Another meta-analysis comparing HFNC with NIPPV showed HFNC to decrease the need for intubation of patients, yet without significantly reducing mortality or ICU length of stay [72]. Additionally, patients may find HFNC more comfortable than NIPPV [71]. Given the evidence for a decreased risk of intubation with HFNC compared with NIPPV in acute hypoxemic respiratory failure, and studies suggesting that NIPPV may carry a greater risk of nosocomial infection of healthcare providers, we suggest HFNC over NIPPV. However, any patients receiving HFNC or NIPPV should be monitored closely and cared for in a setting where intubation can be facilitated in the event of decompensation, as the failure rate may be high and emergency intubation in an uncontrolled setting may increase the risk of nosocomial infection of healthcare providers $[79,80]$.

\section{Recommendation \\ 27. In adults with COVID-19 and acute hypoxemic respiratory failure, if HFNC is not available and there is no urgent indication for endotra- cheal intubation, we suggest a trial of NIPPV with close monitoring and short-interval assessment for worsening of respiratory failure. Weak recommendation, low-quality evidence. \\ 28. We were not able to make a recommendation regarding the use of helmet NIPPV compared with mask NIPPV. It is an option, but we are not certain about its safety or efficacy in COVID-19. \\ 29. In adults with COVID-19 receiving NIPPV or HFNC, we recommend close monitoring for worsening of respiratory status, and early intuba- tion in a controlled setting if worsening occurs. \\ Best practice statement}

\section{Rationale}

In adults presenting with hypoxic respiratory failure from COVID-19, there is no direct evidence to support the use of NIPPV; furthermore, some prior studies suggested that it may be associated with an increased risk of infection transmission to healthcare workers. Metaanalyses of RCTs showed reductions in both intubation and mortality risks with NIPPV in hypoxic respiratory failure. However, these meta-analyses included studies focused on immunocompromised, acute cardiogenic pulmonary edema, or post-operative patients; their findings may therefore be less applicable to COVID-19 patients, in whom acute hypoxemic respiratory failure and ARDS are more common presentations. [43, 81-83] In acute hypoxemic respiratory failure with an etiology other than cardiogenic pulmonary edema, NIPPV has a high failure rate. In one RCT, failure was reported in $49 \%$ of patients with hypoxic respiratory failure ventilated with 
NIPPV; these patients therefore required intubation [71]. In addition, patients with hypoxic respiratory failure randomized to NIPPV had higher mortality $(28 \%, 95 \%$ CI 21-37\%) than those treated with conventional oxygen therapy $(23 \%, 95 \%$ CI $16-33 \%)$ or HFNC $(13 \%, 95 \%$ CI $7-20 \%)(p=0.02)$.

In a cohort of Middle East Respiratory Syndrome (MERS) patients, NIPPV was not associated with improved mortality or length of stay, compared with patients who were intubated without trying NIPPV [79]. However, NIPPV was associated with a high failure rate (92.4\%), leading to intubation. Patients who received NIPPV prior to intubation had increased inhaled nitric oxide requirements and increased mortality [79]. Failure rates in other pandemics, such as influenza, H1N1 and SARS, range from 10 to $70 \%$, while demonstrations of efficacy mainly come from case series and observational studies rather than RCTs, leading to practice variation. In China, the use of NIPPV for pandemic respiratory infection is common, whereas guidelines from Europe, Hong Kong, and the US advise against NIPPV as a first-line therapy in H1N1 [84]. There are additional concerns over the use of NIPPV in respiratory pandemics like COVID19: NIPPV may aggravate severe forms of lung injury as a result of injurious transpulmonary pressures and large tidal volumes $[85,86]$, and may delay initiation of invasive mechanical ventilation, leading to emergency or more unstable intubations that can increase the risk of transmission to the healthcare team [85]. In addition, NIPPV is an aerosol-generating procedure that can increase the risk of transmission of disease to healthcare workers [29]. Several other studies and meta-analyses of SARS have also highlighted the risk of nosocomial spread of the disease with NIPPV [76, 87].

The balance between benefit and harm when using NIPPV in adults with COVID-19 is unclear. If, in certain COVID-19 patients, other forms of respiratory failure, such as acute hypercapnic respiratory failure or acute cardiogenic pulmonary edema, are known to be the cause of respiratory failure, NIPPV may be beneficial $[88,89]$. However, because limited experience with NIPPV in pandemics suggests a high failure rate, we recommend that any patient receiving NIPPV be monitored closely and cared for in a setting where intubation can be facilitated in the event of decompensation $[79,80]$. However, when resources become stretched, there may be insufficient ability to provide invasive ventilation, and even a moderate chance of success with NIPPV may justify its use.

If NIPPV is used, helmet NIPPV is an attractive option, if available. A single-center RCT showed decreased intubation and improved mortality from NIPPV delivered by helmet in ARDS patients [90]. Of particular importance in the setting of a pandemic such as COVID-19, NIPPV by helmet has also been shown to reduce exhaled air dispersion, whereas face masks were insufficient [91]. However, helmet NIPPV is more expensive, and without direct evidence of benefit in COVID-19 patients, resources should not be utilized to acquire this equipment if is not already available. Figure 2 summarizes the recommendations on HFNC and NIPPV in patients with COVID-19.

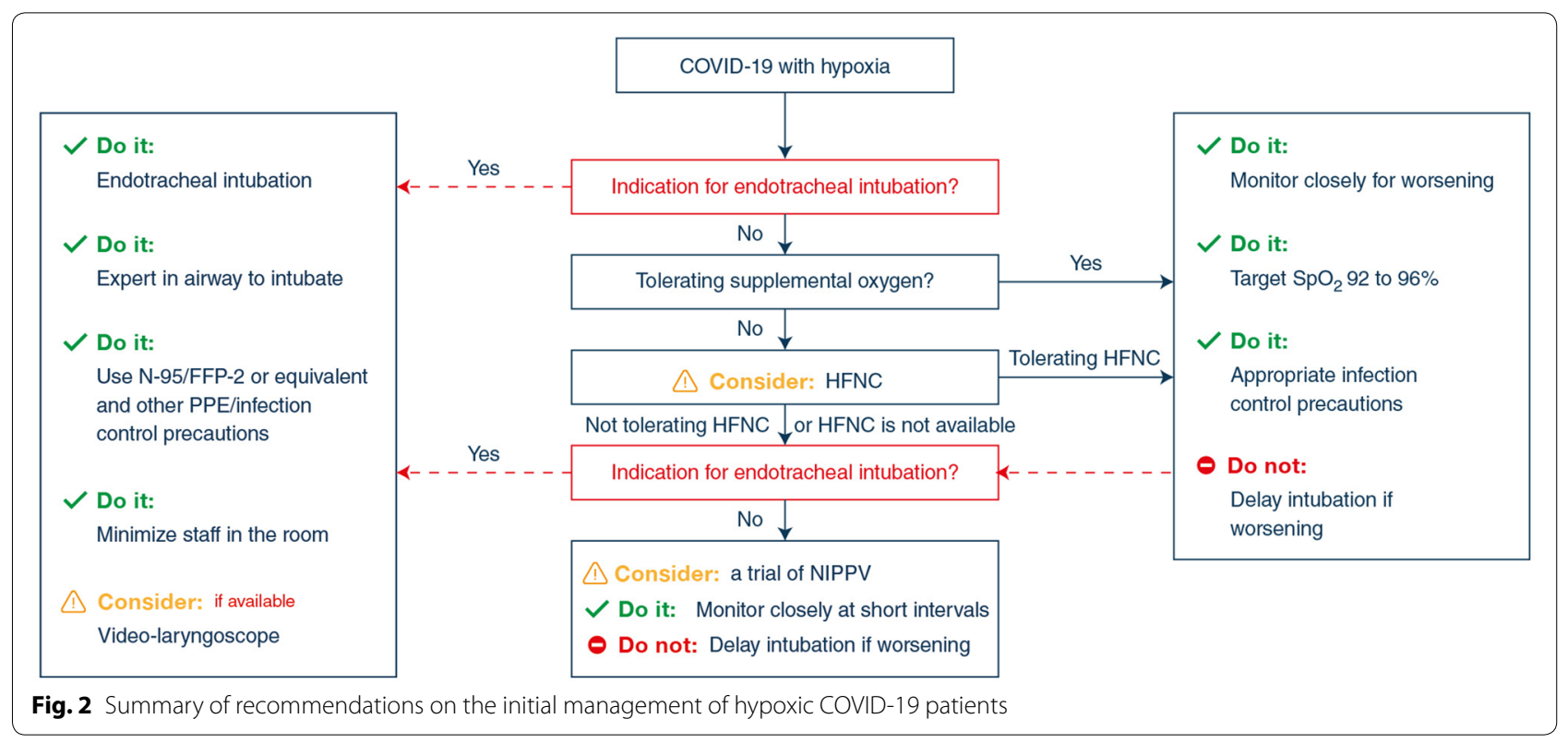




\section{Invasive Mechanical Ventilation}

\section{Recommendation \\ 30. In mechanically ventilated adults with COVID-19 and ARDS, we recommend using low tidal volume $(\mathrm{Vt})$ ventilation (Vt 4-8 $\mathrm{mL} / \mathrm{kg}$ of predicted body weight), over higher tidal volumes ( $\mathrm{Vt}>8 \mathrm{~mL} / \mathrm{kg})$. Strong recommendation, moderate quality evidence.}

\section{Rationale}

Currently there are no studies addressing mechanical ventilation strategies in COVID-19 patients. However, the panel of experts believes that mechanically ventilated patients with COVID-19 should be managed similarly to other patients with acute respiratory failure in the ICU.

While mechanical ventilation is a potentially life-saving intervention, it can worsen lung injury and, through ventilator-induced lung injury (VILI), contribute to multiorgan failure in patients with ARDS [86]. One of the main ventilator strategies to minimize VILI is low $\mathrm{Vt}$ ventilation.

A systematic review and meta-analysis of RCTs found an inverse association between larger $\mathrm{Vt}$ gradient and mortality [92]. In addition, authors found that using a protocolized low Vt strategy with high PEEP (9 RCTs and 1629 patients) reduced the risk of death ( $R R, 0.80$, 95\% CI, 0.66-0.98) [92]. Our analysis of 5 RCTs (1181 patients) showed a reduction in hospital mortality with low Vt ventilation (RR 0.73, 95\% CI 0.63-0.85) [93-98]. On the basis of the available body of evidence, several guidelines recommended using low $\mathrm{Vt}(4-8 \mathrm{~mL} / \mathrm{kg}$ of predicted body weight) in patients with ARDS $[99,100]$.

The panel judged the magnitude of benefit to be moderate, the cost to be low, and the intervention to be acceptable and feasible to implement, and they therefore issued a strong recommendation to use low Vt $(4-8 \mathrm{~mL} /$ $\mathrm{kg}$ predicted body weight) when ventilating patients with ARDS (Fig. 3).

\section{Practical considerations}

The ARDSNet study protocol set the initial $\mathrm{Vt}$ at $6 \mathrm{~mL} / \mathrm{kg}$ which can be increased to $8 \mathrm{~mL} / \mathrm{kg}$ if the patient is double triggering or if inspiratory airway pressure decreases below PEEP [95].

Strict adherence to target Vt in spontaneously breathing patients with ARDS is a challenge; patient-ventilator dyssynchrony is not uncommon [101].

\section{Recommendation}

31. For mechanically ventilated adults with COVID-19 and ARDS, we recommend targeting plateau pressures (Pplat) of $<30 \mathrm{~cm} \mathrm{H}_{2} \mathrm{O}$ Strong recommendation, moderate quality evidence.

\begin{tabular}{|c|c|c|c|}
\hline COVID-19 with mild ARDS & i & COVID-19 with Mod to Severe ARDS & Rescue/Adjunctive therapy \\
\hline $\begin{array}{l}\text { Do: } \\
V t 4-8 \mathrm{ml} / \mathrm{kg} \text { and } \mathrm{P}_{\text {plat }}<30 \mathrm{~cm} \mathrm{H}_{2} \mathrm{O}\end{array}$ & $\begin{array}{c}1 \\
1 \\
1 \\
1\end{array}$ & $\begin{array}{l}1 \text { CONSIDER: } \\
\text { Higher PEEP }\end{array}$ & $\begin{array}{l}\text { ? Uncertain: } \\
\text { Antivirals, chloroquine, anti-IL6 }\end{array}$ \\
\hline $\begin{array}{l}\checkmark \text { Do: } \\
\text { Investigate for bacterial infection }\end{array}$ & $\begin{array}{l}1 \\
1 \\
1 \\
1\end{array}$ & $\begin{array}{l}\text { (1) CONSIDER: } \\
\text { NMBA boluses to facilitate ventilation targets }\end{array}$ & $\begin{array}{l}\text { A CONSIDER: if proning, high } \mathrm{P}_{\text {plt, }} \text { asynchrony } \\
\text { I } \\
\text { NMBA infusion for } 24 \mathrm{~h}\end{array}$ \\
\hline $\begin{array}{l}\checkmark \text { Do: } \\
\text { Target SpO2 92\% - 96\% }\end{array}$ & $\begin{array}{c}1 \\
1 \\
1 \\
1\end{array}$ & $\begin{array}{l}\text { (1) CONSIDER: if PEEP responsive } \\
\text { Traditional Recruitment maneuvers }\end{array}$ & $\begin{array}{l}\text { A CONSIDER: } \\
\text { Prone ventilation } 12-16 \mathrm{~h}\end{array}$ \\
\hline $\begin{array}{l}\text { (1) CONSIDER: } \\
\text { Conservative fluid strategy }\end{array}$ & $\begin{array}{c}1 \\
1 \\
1 \\
1\end{array}$ & $\begin{array}{l}\triangle \text { CONSIDER: } \\
\text { Prone ventilation } 12-16 \mathrm{~h}\end{array}$ & 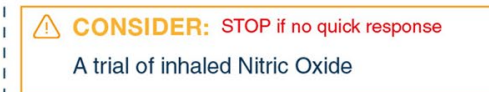 \\
\hline $\begin{array}{l}\text { (1) CONSIDER: } \\
\text { Empiric antibiotics }\end{array}$ & $\begin{array}{c}1 \\
1 \\
1\end{array}$ & $\begin{array}{l}\text { (1) CONSIDER: if proning, high } \mathrm{P}_{\mathrm{plt}} \text {, asynchrony } \\
\text { NMBA infusion for } 24 \mathrm{~h}\end{array}$ & 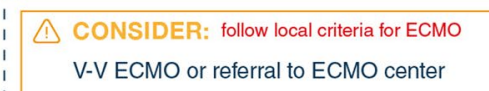 \\
\hline $\begin{array}{l}\text { ? Uncertain: } \\
\text { Systematic corticosteroids }\end{array}$ & 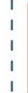 & $\begin{array}{l}\text { Don't do: } \\
\text { Staircase Recruitment maneuvers }\end{array}$ & $\begin{array}{l}1 \\
1 \\
1 \\
1 \\
1\end{array}$ \\
\hline & $\begin{array}{l}1 \\
1 \\
1 \\
1 \\
1 \\
1 \\
1 \\
1 \\
1\end{array}$ & $\begin{array}{l}\text { CONSIDER: } \\
\text { Short course of systemic corticosteroids } \\
\text { ? Uncertain: } \\
\text { Antivirals, chloroquine, anti-IL6 }\end{array}$ & $\begin{array}{c}1 \\
1 \\
1 \\
1 \\
1 \\
1 \\
1\end{array}$ \\
\hline
\end{tabular}

Fig. 3 Summary of recommendations on the management of patients with COVID-19 and ARDS 


\section{Rationale}

There are no clinical trials examining the effect of plateau pressure (Pplat) limitation on COVID-19 induced ARDS. However, there is a large body of indirect evidence in patients with ARDS. Along with low Vt ventilation, Pplat limitation is a lung protective strategy to limit VILI. A systematic review and meta-analysis of RCTs found that using a lung protective strategy including protocolized low Vt and Pplat $<30 \mathrm{cmH}_{2} \mathrm{O}$ (9 RCTs and 1629 patients) reduced the risk of death (RR, 0.80, 95\% CI 0.66-0.98)[92]. A subsequent meta-analysis of RCTs comparing ventilatory strategies with low and high Pplat in patients with ARDS (15 studies) found that short-term mortality was higher in patients with Pplat $>32 \mathrm{cmH}_{2} \mathrm{O}$ during the first week in the ICU (Day 1: RR 0.77, 95\% CI 0.66-0.89; Day 3: RR 0.76, 95\% CI 0.64-0.90; Day 7: RR 0.78, 95\% CI 0.65-0.93)[102].

On the basis of the available body of evidence, several guidelines recommended keeping Pplat $<30 \mathrm{~cm} \mathrm{H}_{2} \mathrm{O}$ in patients with ARDS [99, 100].

The panel judged the magnitude of benefit to be moderate, the cost to be low, the patients' values to be consistent, and the intervention to be acceptable and feasible to implement, and therefore, issued a strong recommendation to keep Pplat $<30 \mathrm{cmH}_{2} \mathrm{O}$ when ventilating patients with ARDS.

\section{Practical considerations}

The ARDSNet study protocol set the initial Vt at $6 \mathrm{~mL} / \mathrm{kg}$, and then measured Pplat (after a $0.5 \mathrm{~s}$ inspiratory pause) [95]. If the Pplat $>30 \mathrm{cmH}_{2} \mathrm{O}, \mathrm{Vt}$ could be reduced in $1 \mathrm{~mL} / \mathrm{kg}$ (to $4 \mathrm{~mL} / \mathrm{kg}$ ) steps until Pplat was within range.

\section{Recommendation}

32. For mechanically ventilated adults with COVID-19 and moderate to severe ARDS, we suggest using a higher PEEP strategy, over a lower PEEP strategy.

Weak recommendation, low-quality evidence.

Remarks: If using a higher PEEP strategy (i.e. PEEP $>10 \mathrm{~cm} \mathrm{H}_{2} \mathrm{O}$ ), clinicians should monitor patients for barotrauma.

\section{Rationale}

In ARDS, extrinsic PEEP is used to prevent repeated opening and closing of alveoli (i.e. atelectotrauma), and therefore to reduce VILI. In addition, PEEP increases and sustains alveolar recruitment, which improves oxygenation and reduces oxygen requirement.

There are no clinical trials examining the effect of PEEP on coronavirus-induced ARDS. However, there is a large body of indirect evidence in patients with ARDS. An individual patient data meta-analysis (IPDMA) of the 3 largest trials (2299 patients) of high PEEP [103-105] found no difference in in-hospital mortality in all patients (RR 0.94, 95\% CI 0.86-1.04) [106]. However, in patients with ARDS, a higher PEEP strategy resulted in lower ICU mortality (RR 0.85, 95\% CI 0.76-0.95), lower in-hospital mortality (RR $0.90,95 \%$ CI $0.81-1.0$ ), and a reduction in the use of rescue therapies (RR 0.63, 95\% CI 0.53-0.75), at the expense of a possible increase in the risk of pneumothorax [106].

A recent systematic review and meta-analysis of 9 RCTs (3612 patients) examined the effect of a higher PEEP strategy on patient-important outcomes [107]. Overall, a higher PEEP strategy did not reduce hospital mortality (RR 0.92, 95\% CI, 0.79-1.07). However, in a subgroup of trials that enrolled patients with oxygenation response to PEEP (6 RCTS, 1888 patients), the use of high PEEP significantly reduced in-hospital mortality, compared with a lower PEEP strategy (RR 0.83, 95\% CI 0.69-0.98). Although the body of evidence suggests a beneficial effect of higher PEEP in selected patients, the results are likely to be confounded by the fact that low Vt ventilation was not used in the control arm of these trials [108].

There is no clear and agreed upon definition of higher PEEP; moreover, the optimal PEEP level in ARDS patients is unknown, and is likely to vary based on the extent of disease, lung compliance, and other factors. In the aforementioned IPDMA, the median PEEP level in the high PEEP arm was 15.3 and $13.3 \mathrm{~cm} \mathrm{H}_{2} \mathrm{O}$ on days 1 and 3, respectively, compared with median values of 9 and $8.2 \mathrm{~cm} \mathrm{H}_{2} \mathrm{O}$ on days 1 and 3 in the low PEEP arm [106]. Although arbitrary, clinicians could consider PEEP levels $>10 \mathrm{~cm} \mathrm{H}_{2} \mathrm{O}$ to constitute a higher PEEP strategy, and PEEP levels $<10 \mathrm{~cm} \mathrm{H}_{2} \mathrm{O}$ as a lower PEEP strategy.

\section{Practical considerations}

Because the IPDMA combined different strategies to set higher PEEP, a reasonable starting point would be to implement a strategy used in the large RCTs that were included (i.e. ALVEOLI, LOV, and ExPRESS) [103-105]. After increasing the PEEP level, clinicians should monitor their patients for evidence of barotrauma. Importantly, higher PEEP may result in higher Pplat, which is associated with its own risks and benefits when Pplat $>30$ $\mathrm{cmH}_{2} \mathrm{O}$. Clinicians can use the ARDS Network protocol strategies to determine the optimal PEEP level. Other available strategies include decremental PEEP strategy, the esophageal balloon technique, and electrical impedance tomography. However, the effect of using these techniques on clinical outcomes is unknown.

\section{Recommendation}

33. For mechanically ventilated adults with COVID-19 and ARDS, we suggest using a conservative fluid strategy over a liberal fluid strategy. Weak recommendation, low-quality evidence. 


\section{Rationale}

The optimal fluid strategy in COVID-19 is not known, however, it is plausible that these patients will respond to fluid similarly to other ARDS patients. The limited data available on COVID-19 show that cardiac failure, alone or in combination with respiratory failure, was the cause of $40 \%$ of COVID-19 deaths [46]. Another study showed that $44 \%$ of COVID-19 patients had arrhythmia [43]. The data suggest the presence of myocardial injury in some patients with COVID-19. Few RCTs have been published that compare conservative or deresuscitative with liberal fluid strategies in ARDS. A recent systematic review included 5 RCTs enrolling 1206 patients with ARDS. The risk of death was similar in both groups: $28 \%$ in the conservative fluid strategy group and $31.1 \%$ in the liberal strategy group (RR 0.91, 95\% CI 0.77-1.07) [52]. This study included RCTs in critically ill patients with or without ARDS, and the authors found that a conservative fluid strategy increased ventilator-free days (MD 1.82 days; 95\% CI 0.53-3.10 days) and reduced ICU length of stay (MD -1.88 days, $95 \%$ CI -0.12 to -3.64 days), compared with a liberal fluid strategy. There was no difference in harm, including renal failure between the two groups. The landmark trial in ARDS patients (FACTT) found a significant reduction in the duration of mechanical ventilation with a conservative fluid strategy [109]. Furthermore, the majority of patients with COVID-19 in the ICU are elderly, and may develop myocardial dysfunction that could limit their ability to handle large fluid volumes [46]. In view of the moderate benefit observed in other ARDS populations, the possible reduced cost of administering less fluids, and the feasibility of the intervention, the panel issued a weak recommendation favoring conservative fluid strategy in patients with COVID-19 and ARDS

\section{Recommendation \\ 34. For mechanically ventilated adults with COVID-19 and moderate \\ to severe ARDS, we suggest prone ventilation for $\mathbf{1 2 - 1 6} \mathbf{h}$, over no \\ prone ventilation. \\ Weak recommendation, low-quality evidence.}

\section{Rationale}

In a series of 81 patients with COVID-19, radiographic features progressed over the first 1-2 weeks after symptom onset from predominant ground glass opacities to a mixed pattern of predominant basilar consolidation. This latter pattern may suggest a role for prone ventilation [110].
Prone positioning theoretically makes ventilation more homogeneous by decreasing ventral alveolar distention and dorsal alveolar collapse [111]. This may reduce the difference between the dorsal and ventral transpulmonary pressures, in addition to reducing lung compression [112] and improving perfusion [113].

A recent study that described the clinical course of COVID-19 in the ICU showed that prone ventilation was used in $11.5 \%$ of patients (6 out of 52) [42]. However, there are no studies available that describe the clinical course of patients with COVID-19 who were ventilated in the prone position.

A recent systematic review and meta-analysis of 9 RCTs (2129 patients) showed that prone ventilation for at least $12 \mathrm{~h}$ in patients with moderate to severe ARDS reduced mortality (5 RCTs; RR 0.74, 95\% CI 0.56-0.99), but had no effect on mortality in studies that used prone ventilation for < 12 h (3 RCTs; RR 1.03, 95\% CI 0.88-1.20). On the other hand, prone ventilation increased the risks of pressure sores (RR 1.22, 95\% CI 1.06-1.41) and endotracheal tube obstruction (RR 1.76, 95\% CI 1.24-2.50) [114]. Other systematic reviews reached similar conclusions [115-117].

We have moderate certainty that prone ventilation for more than $12 \mathrm{~h}$ in patients with moderate to severe ARDS reduces mortality, but may increase the risk of pressure sores and endotracheal tube obstruction. Healthcare workers proning patients with COVID-19 should be trained in the proper technique for proning and take infection control precautions in the event of accidental endotracheal tube disconnection from the ventilator. Proning itself is not associated with significant cost, and we believe that it may provide significant benefit. Further, proning can be implemented in low- and middle-income settings, and efforts should be made to provide the necessary training and education of healthcare workers to facilitate the practice (https://www.youtube.com/watch?v=E_6jT9R7WJs).

\section{Practical considerations}

A protocol for proning should be used at all institutions, based on the available resources and level of training. If prone ventilation is used, healthcare workers should be aware of complications such as pressure sores, vascular line and endotracheal tube displacement, facial edema, transient hemodynamic instability, corneal abrasions, brachial plexus injury, and hemodialysis vascular access flow issues.

In addition, clinicians should be familiar with the absolute contraindications for prone ventilation, such as unstable spine, open abdomen or open chest (i.e. surgery or trauma). Enteral nutrition via nasogastric or nasoduodenal tube can be continued during proning $[118,119]$. 


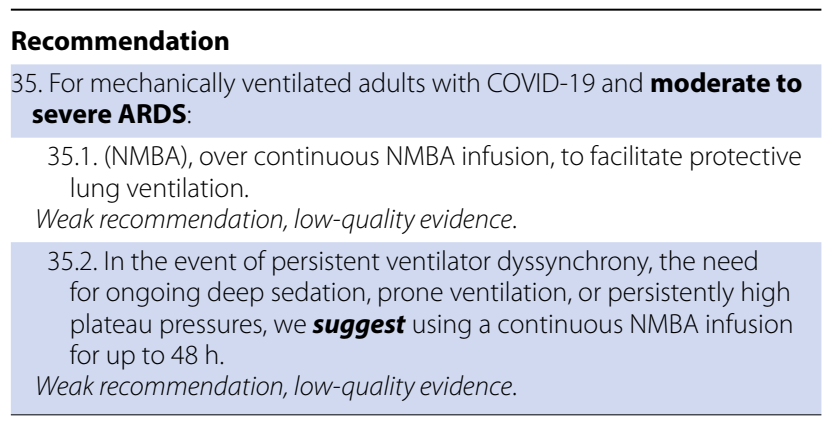

\section{Rationale}

Several professional societies have issued recommendations on the use of NMBAs in ARDS [100, 120-123]. Most issued recommendations favoring the use of an NMBA infusion in patients with moderate to severe ARDS. These recommendations were mostly based on the pooled estimates from 3 RCTs (431 patients) showing a reduction in 90-day mortality with an NMBA infusion as compared with no NMBA infusion [124]. However, the results of the Re-evaluation of Systemic Early Neuromuscular Blockade (ROSE) trial challenged those of previous trials. The ROSE trial investigators randomized 1006 patients with moderate or severe ARDS to receive either an infusion of NMBA for $48 \mathrm{~h}$ or intermittent NMBA boluses on an as needed basis [125]. The ROSE trial showed that a continuous infusion of cisatracurium did not improve any patient important outcomes.

Due to differences in design between the ROSE trial and the earlier trials, we did not perform a meta-analysis for mortality outcome, although the pooled estimate for barotrauma favored continuous NMBA infusion (RR 0.55 , 95\% CI 0.35-0.85). The panel suggests that a continuous NMBA infusion should be reserved for patients who have an indication for ongoing paralysis in which intermittent dosing may not suffice, such as patients with persistent ventilator dyssynchrony, and patients needing ongoing deep sedation prone ventilation, or persistently high plateau pressures. The effect of NMBAs on longterm outcomes is unclear.

\footnotetext{
Recommendations

36. In mechanically ventilated adults with COVID-19 ARDS, we recom-

mend against the routine use of inhaled nitric oxide.

Strong recommendation, low-quality evidence.

37. In mechanically ventilated adults with COVID-19, severe ARDS and

hypoxemia despite optimizing ventilation and other rescue strategies,

we suggest a trial of inhaled pulmonary vasodilator as a rescue-

therapy; if no rapid improvement in oxygenation is observed, the

treatment should be tapered off.

Weak recommendation, low-quality evidence.
}

\section{Rationale}

There are no studies that describe the use of pulmonary vasodilators in COVID-19 patients. A Cochrane review identified 13 RCTs (1243 patients) on inhaled nitric oxide in ARDS; this treatment showed no significant effect on mortality (RR 1.04, 95\% CI 0.9-1.19), and was associated with an increased risk of acute kidney injury (RR 1.59, 95\% CI 1.17-2.16). Inhaled nitric oxide results in a transient improvement in oxygenation. The subgroup of studies reporting $\mathrm{PaO}_{2} / \mathrm{FiO}_{2}(\mathrm{~mm} \mathrm{Hg}$ ) values up to $24 \mathrm{~h}$ after the intervention showed a statistically significant difference in favor of inhaled nitric oxide, which was not present beyond $24 \mathrm{~h}$. No study assessed the use of inhaled nitric oxide as a "rescue" therapy [126]. Because of the possible harm from inhaled nitric oxide and the absence of a clear mortality benefit, the panel issued a strong recommendation against its routine use in patients with ARDS. However, in view of the finding of improved oxygenation, a trial of inhaled nitric oxide as a "rescue" therapy, after trying other options, is reasonable if available. If inhaled nitric oxide is used without a good response in terms of oxygenation, it should be tapered off to avoid rebound the pulmonary vasoconstriction that can occur with prolonged use and abrupt discontinuation.

No adequately powered RCTs have evaluated inhaled prostacyclins such as ilioprost, therefore, we could not recommend against or for their use in severe ARDS.

\section{Recommendations \\ 38. For mechanically ventilated adults with COVID-19 and hypoxemia despite optimizing ventilation, we suggest using recruitment maneu- vers, over not using recruitment maneuvers. Weak recommendation, low-quality evidence. \\ 39. If recruitment maneuvers are used, we recommend against using staircase (incremental PEEP) recruitment maneuvers. Strong recommendation, low-quality evidence.}

\section{Rationale}

No studies have assessed the role of recruitment maneuvers (RMs) in patients with ARDS secondary to COVID19. RMs aim to improve oxygenation by increasing transpulmonary pressure to open atelectatic alveoli [127]. However, exposure to high levels of positive pressure may lead to barotrauma, as well as cause transient hypotension in already critically ill and unstable patients.

We assessed 8 indirect RCTs assessing RMs in ARDS patients, including patients with sepsis due to bacterial or viral pneumonia. Varying strategies were used to help recruit atelectatic lungs, however two strategies, in particular, were common in the 8 RCTs included in this meta-analysis. Traditional RMs are described as prolonged inspiratory holds for a set duration of time on higher levels of CPAP, most commonly 35-40 $\mathrm{cm} \mathrm{H}_{2} \mathrm{O}$ 
for $40 \mathrm{~s}$ [93, 104, 128, 129]. Incremental PEEP titration RMs are described as incremental increases in PEEP from 25 to 35 to $45 \mathrm{~cm} \mathrm{H}_{2} 0$ for 1-2 min each [130-133].

In a systematic review and meta-analysis of 6 RCTs (1423 patients), RMs reduced mortality and the use of rescue interventions, and improved oxygenation at $24 \mathrm{~h}$ without increasing the risk of barotrauma [134]. Similarly, we identified 8 RCTs (2544 patients) that reported on in-hospital mortality. In these studies, RMs were not associated with reduced mortality (RR 0.90 , 95\% CI 0.781.04). However, subgroup analyses suggested that traditional RMs significantly reduced mortality (RR 0.85, 95\% CI 0.75-0.97), whereas incremental PEEP titration RMs increased mortality (RR 1.06, 95\% CI 0.97-1.17). While the effects of RMs on oxygenation may be transient, the studies showed a significant improvement in oxygenation after $24 \mathrm{~h}$. Trials used different PEEP strategies in intervention and control arms; RMs are best combined with a higher PEEP strategy.

Patients with severe ARDS and hypoxemia may benefit from traditional recruitment maneuvers along with higher levels of PEEP, but evidence specific to COVID-19 is needed. Patients receiving RMs should be monitored closely for severe desaturation, hypotension or barotrauma. RMS should be stopped if they lead to patient deterioration.

\section{Recommendation}

40. In mechanically ventilated adults with COVID-19 and refractory hypoxemia despite optimizing ventilation, use of rescue therapies, and proning, we suggest using venovenous (VV) ECMO if available, or referring the patient to an ECMO center.

Weak recommendation, low-quality evidence.

Remark: Due to the resource-intensive nature of ECMO, and the need for experienced centers and healthcare workers, and infrastructure, ECMO should only be considered in carefully selected patients with COVID-19 and severe ARDS.

\section{Rationale}

There are no clinical trials of ECMO in COVID-19 patients. A recent report from China suggested that $11.5 \%$ of COVID-19 cases in the ICU received ECMO [42], but the clinical courses and the outcomes of these patients have not been reported yet.

The Ministry of Health in Saudi Arabia established an ECMO program during the MERS-CoV epidemic. In a retrospective cohort study of 35 patients with MERS$\mathrm{CoV}$ and refractory hypoxemia, the group of patients who received VV ECMO had lower in-hospital mortality (65 vs. $100 \%, p=0.02$ ) [135]. However, this cohort study is at high risk of selection bias given its retrospective design.

Only two RCTs have evaluated ECMO vs. conventional mechanical ventilation in severe ARDS. Guidelines published in 2017 were unable to provide specific guidance on the use of ECMO, and further research was recommended [99]. Although the most recent RCT (EOLIA) was stopped early for futility [136], a re-analysis of this trial using a Bayesian approach provided a more favorable interpretation, suggesting lower mortality with ECMO in severe ARDS [137]. A recent systematic review including two RCTs (429 patients) found a reduction in 60-day mortality with ECMO (RR 0.73, 95\% CI 0.58-0.92), but the risk of major bleeding was higher with ECMO [138].

ECMO is a resource-intensive technique restricted to specialized centers, and it remains an extremely limited resource. Therefore, its use as a rescue therapy should be reserved for carefully selected patients [139]. Future studies describing the outcomes of COVID-19 patients on ECMO and the mechanisms of death will advance our understanding and guide practice.

\section{COVID-19 therapy}

In this section we will discuss possible treatment options for SARS CoV-2 and its complications, including antiviral agents, immunosuppressive agents, immunomodulators and other therapies.

\section{Cytokine storm syndrome}

Cytokine storm syndrome is a hyperinflammatory state that is characterized by fulminant multi-organ failure and elevation of cytokine levels. A recent study from China showed that COVID-19 is associated with a cytokine elevation profile that is reminiscent of secondary hemophagocytic lymphohistiocytosis (HLH) [44]. Some authors even suggest that we screen critically ill COVID-19 patients for secondary HLH using the Hscore [140], and that corticosteroids and other immunosuppressive agents can be used in patients with a high likelihood of HLH [141]. More evidence is needed before we can make recommendations on the treatment options for cytokine storm.

\footnotetext{
Recommendations

41. In mechanically ventilated adults with COVID-19 and respiratory failure (without ARDS), we suggest against the routine use of systemic corticosteroids.

Weak recommendation, low-quality evidence.

42. In mechanically ventilated adults with COVID-19 and ARDS, we suggest using systemic corticosteroids, over not using corticosteroids. Weak recommendation, low-quality evidence.

Remark: The majority of our panel support a weak recommendation (i.e. suggestion) to use steroids in the sickest patients with COVID-19 and ARDS. However, because of the very low-quality evidence, some experts on the panel preferred not to issue a recommendation until higher quality direct evidence is available.
} 


\section{Rationale}

There are no controlled clinical trials on the use of corticosteroids in COVID-19 patients or other coronaviruses. A published, but not peer-reviewed, report of 26 patients with severe COVID-19 reports that the use of methylprednisolone at $1-2 \mathrm{mg} / \mathrm{kg} /$ day for 5-7 days was associated with shorter duration of supplemental oxygen use (8.2 days vs. 13.5 days; $p<0.001)$ and improved radiographic findings [142]. Although interesting, we judged these preliminary reports to be an insufficient basis for formulating recommendations, due to the risk of confounding. Therefore, we used indirect evidence from community acquired pneumonia, ARDS, and other viral infections to inform our recommendation.

There are several RCTs on the use of systemic corticosteroids in hospitalized patients with community-acquired pneumonia, mostly non-ICU patients, some with sepsis or septic shock. A systematic review and meta-analysis of RCTs showed that using corticosteroids may reduce the need for mechanical ventilation (5 RCTs; 1060 patients; RR 0.45, 95\% CI 0.26-0.79), ARDS (4 RCTs; 945 patients; RR 0.24 , 95\% CI 0.10-0.56) and the duration of hospitalization (6 RCTs; 1499 patients; MD -1.00 day, 95\% CI, -1.79 to -0.21 ), but increase the risk of hyperglycemia requiring treatment [143]. However, these trials included different populations, the effect on mortality outcome was unclear, and they used different drugs and dosing regimens. In addition, there are some concerns about corticosteroid use in viral pneumonias. Therefore, the results may not be generalizable to the COVID-19 population.

There are many published observational studies on the use of steroids in viral pneumonias (i.e. influenza virus, coronaviruses, and others), but they are prone to confounding, as sicker patients usually receive corticosteroids. We updated a recent Cochrane review on the use of corticosteroids in influenza [144] and searched for studies on other coronaviruses. We included a total of 15 cohort studies on influenza and 10 on coronaviruses. Our meta-analysis of adjusted ORs showed an association between corticosteroid use and increased mortality (OR 2.76, 95\% CI 2.06-3.69), but the effect in the patients with other coronaviruses was unclear (OR 0.83 , 95\% CI 0.32-2.17). Also, these studies are limited by significant heterogeneity. We found significant homogeneity between observational studies on the use of corticosteroids in ARDS caused by coronaviruses and in general viral ARDS $\left(\mathrm{I}^{2}=82 \%\right.$ and $77 \%$ respectively). Furthermore, in both cases, the summary statistic tended toward harm with the use of steroids.

We updated a recent Cochrane review [145] and identified an additional RCT [146] dealing with ARDS.
Overall, we included 7 RCTs enrolling 851 patients with ARDS. The use of corticosteroids reduced mortality (RR 0.75, 95\% CI 0.59-0.95) and duration of mechanical ventilation (MD -4.93 days, $95 \% \mathrm{CI}-7.81$ to -2.06 ). However, these trials were not focused on viral ARDS, which limits the generalizability of their results to COVID-19 patients. In addition, we reviewed observational studies on corticosteroid use in viral ARDS, and identified 4 cohort studies. Although the point estimate showed increased mortality, the CI included substantial harm and benefit (OR 1.40, 95\% CI 0.76-2.57). In a recent RCT (INTEREST trial), the use of recombinant interferon $\beta 1 b$ (rIFN $\beta 1 b a)$ did not reduce mortality in ARDS patients, but in the subgroup of patients receiving corticosteroids, rIFN $\beta 1$ ba use was associated with increased mortality (OR, 2.53, 95\% CI 1.12-5.72) [147]. The only direct evidence comes from a retrospective cohort study of 201 patients with COVID-19 pneumonia. This study showed an association between corticosteroid use and lower mortality in patients with COVID-19 and ARDS (HR 0.38, 95\% CI 0.20-0.72). However, the estimate was not adjusted for confounding factors [148].

The effect of corticosteroids in COVID-19 patients with sepsis or septic shock may be different. Recent systematic reviews and meta-analyses of RCTs in sepsis showed small improvements in mortality and faster resolution of shock with corticosteroid use, compared with not using corticosteroids $[63,149,150]$ (see the previous section on hemodynamic support).

It is widely recognized that corticosteroids have a range of adverse effects. In viral pneumonia in the ICU, several studies showed increase in viral shedding with corticosteroid use [151-153], potentially indicating viral replication, but the clinical implication of increased viral shedding is uncertain.

Considering the above, the panel issued a suggestion against the routine use of systemic corticosteroids for respiratory failure in COVID-19, and a suggestion to use corticosteroids in the sicker population of COVID19 with ARDS. If clinicians use corticosteroids in ARDS, they should use lower dosing and shorter treatment courses.

\footnotetext{
Recommendation

43. In mechanically ventilated patients with COVID-19 and respiratory failure, we suggest using empiric antimicrobials/antibacterial agents, over no antimicrobials.

Weak recommendation, low-quality evidence.

Remark: if the treating team initiates empiric antimicrobials, they should assess for de-escalation daily, and re-evaluate the duration of therapy and spectrum of coverage based on the microbiology results and the patient's clinical status.
} 


\section{Rationale}

There are no controlled clinical trials evaluating the use of empiric antimicrobials in COVID-19 patients or other coronaviruses. This recommendation is therefore based upon extrapolation of data from other viral pneumonias, particularly influenza [154]. Identifying bacterial coinfection or superinfection in patients with COVID-19 is challenging, as the symptoms may be similar to those of the underlying viral infection. The diagnostic difficulty is reflected in high rates of intravenous antibiotics administered in Wuhan: 53\% with non-severe disease and $>90 \%$ of patients admitted to hospital or the $\operatorname{ICU}[1,42,43]$. Data on the prevalence of bacterial superinfection in patients with COVID-19 are limited, as in larger case studies clinicians were often too overwhelmed to systematically obtain high-quality samples [1].

In critically ill patients with MERS, $18 \%$ had bacterial and 5\% viral co-infections [155]. Co-infection with Staphylococcus aureus is common with influenza pneumonia and can be especially virulent [154]. Recent clinical practice guidelines recommend initiating empiric antibacterial therapy in adults with community-acquired pneumonia who test positive for influenza [154]. Data from critically ill patients demonstrate secondary infection in about $11 \%$ of cases, although the numbers are small. Isolated organisms included gram-negative organisms such as K. pneumoniae, P. aeruganosa, and S. marcescens. On the basis of these limited data it is difficult to determine patterns of superinfection, including the risk of $S$. aureus infection, commonly seen in influenza.

In patients with COVID-19 and hypoxic respiratory failure requiring mechanical ventilation, the panel suggest empiric antimicrobial treatment, on the basis that superinfection is reasonably common in this population and may to lead to a substantial increase in mortality, as in pandemic influenza [156-158]. Therefore, critically ill patients with suspected or confirmed COVID-19 should be treated with empiric antimicrobial therapy in accordance with the clinical syndrome (e.g. community-acquired or hospital-acquired pneumonia). Secondary infections occur in patients with COVID-19, but the incidence is unknown given the very limited data [159]. These infections should be treated according to clinical and microbiological data.

\section{Recommendation}

44. For critically ill adults with COVID-19 who develop fever, we suggest using acetaminophen/paracetamol for temperature control, over no treatment.

Weak recommendation, low-quality evidence.

\section{Rationale}

The majority of patients with COVID-19 develop fever during hospitalization ( $92 \%$ of those with severe disease).
In the largest report from China, the median temperature across 1099 patients was $38.3{ }^{\circ} \mathrm{C}$ (IQR 37.8-38.9) [1]. Data from critically ill patients in general are available. We reviewed the literature and identified 12 RCTs (1785 patients) that examined the effect of fever control in the critically ill population, excluding neurological indication for temperature control [160-171]; active temperature management (pharmacologic or non-pharmacologic) did not reduce the risk of death (RR 1.03, 95\% CI 0.81-1.31), ICU length of stay (MD -0.07 days, 95\% CI $-0.70-$ $0.56)$, but it was effective in reducing body temperature (MD $-0.36{ }^{\circ} \mathrm{C}, 95 \% \mathrm{CI}-0.42$ lower to -0.29$)$. Given the safety of acetaminophen and lack of harm in the body of evidence, increasing patient comfort through fever management maybe important. Therefore, we issued a suggestion for clinicians to consider using pharmacologic agents for controlling fever in COIVD-19 patients.

The use of non-steroidal anti-inflammatory drugs to treat fever in patients with COVID-19 continues to be debated. Until more evidence is available, we suggest using acetaminophen/paracetamol to treat fever.

\section{Recommendation \\ 45. In critically ill adults with COVID-19, we suggest against the routine \\ use of standard intravenous immunoglobulins (IVIG). \\ Weak recommendation, low-quality evidence.}

\section{Rationale}

The use of intravenous immunoglobulin (IVIG) has been reported in several series of COVID-19 patients, but no efficacy data are available [172]. In the absence of adequate titers of neutralizing antibodies, standard intravenous immunoglobulin is unlikely to have a biologic effect in COVID-19. While IVIG may have immunomodulatory actions, its use can, rarely, also be associated with an increased risk of serious adverse events including anaphylactic reactions, aseptic meningitis, renal failure, thromboembolism, hemolytic reactions, transfusion-related lung injury, and other late reactions [173]. Preparations of anti-SARS-CoV-2 polyclonal or monoclonal antibodies are being developed. However, data from recent trials on the use of antibody-based therapies (immune plasma, hyperimmune globulin, monoclonal antibody to hemagglutinin stalk)[173] in hospitalized seasonal influenza patients did not demonstrate improvement in outcomes [174-176].

\section{Recommendation}

46. In critically ill adults with COVID-19, we suggest against the routine use of convalescent plasma.

Weak recommendation, low-quality evidence. 


\section{Rationale}

Convalescent plasma obtained from patients who have recovered from COVID-19 has been suggested as a potential therapy that may provide passive immunity from SARS-CoV2-specific antibodies [177]. Convalescent plasma has been used to treat several other viral infections, including those caused by SARS coronavirus, avian influenza $\mathrm{A}$ ( $\mathrm{H} 5 \mathrm{~N} 1)$ virus, and influenza $\mathrm{A}$ (H1N1) pdm09 virus [178-182]. A recent meta-analysis of observational studies using passive immunotherapy for the treatment of severe acute respiratory infections of viral etiology suggests that convalescent plasma therapy was associated with reduction in mortality (OR 0.25 , 95\% CI 0.14-0.45) [183]. During the current outbreak in China, convalescent plasma was used in some patients with COVID-19 [184]. However, data on the efficacy and safety of convalescent plasma are limited, and the target for sufficient levels of neutralizing antibody titers against SARS-CoV-2 is unknown. A study on MERS concluded that use of convalescent plasma might be feasible but was challenging due to a small pool of potential donors with sufficiently high antibody titers [185]. An RCT in patients with confirmed Ebola virus disease showed that convalescent plasma, with unknown levels of neutralizing antibodies, was not associated with improvement in survival [186]. Another RCT in patients with seasonal influenza treated with high-titer versus low-titer anti-influenza immune plasma was terminated for futility because of the lack of effect on the primary outcome measured by a 6-point ordinal scale of clinical status on Day 7 [187]. Given the lack of convincing evidence from RCTs and the uncertainty surrounding the optimal preparation of convalescent plasma and its safety, we suggest that it should not be routinely used in treating patients with COVID-19 until more evidence is available.

\section{Recommendation \\ 47. In critically ill adults with COVID-19: \\ 47.1. We suggest against the routine use of lopinavir/ritonavir (weak recommendation, low-quality evidence). \\ 47.2. There is insufficient evidence to issue a recommenda- tion on the use of other antiviral agents in critically ill adults with COVID-19.}

\section{Rationale}

The prolonged detection of SARS-CoV-2 RNA in the respiratory tract and sometimes other sites of seriously ill COVID-19 patients provides the rationale for administration of antiviral agents to reduce replication in efforts to improve clinical outcomes [45]. At present, no direct-acting antivirals have been proven to inhibit replication or provide clinical benefit in COVID-19 or MERS patients.

A considerable number of agents approved for other indications have been proposed for use, but the comments below address the most promising ones. Several others are undergoing testing (e.g. arbidol [umifenovir], favipiravir, ribavirin, traditional Chinese medicines, inhaled interferons), alone or in combinations, and in one or more countries.

Lopinavir is an antiretroviral protease inhibitor used in combination with ritonavir to ensure adequate lopinavir exposure for the treatment of human immunodeficiency virus (HIV) infection [188]. Because it was found to show in vitro activity against SARS-CoV, lopinavir/ritonavir was administered, in combination with high-dose oral ribavirin and a tapering course of systemic corticosteroids, in a cohort of 41 patients with SARS, and was found to be associated with significantly fewer adverse clinical outcomes (ARDS or death) compared with ribavirin alone used in 111 historical controls that received ribavirin and corticosteroids [189]. In a high-throughput screening for antiviral compounds, lopinavir inhibited replication of MERS-CoV in vitro [190]. In an animal model of MERS$\mathrm{CoV}$ infection, treatment with lopinavir/ritonavir or IFN$\beta 1 b$ was associated with virologic, histologic and clinical improvement versus placebo [191]. Lopinavir/ritonavir in combination with interferon beta $1-\mathrm{b}$ is being tested in an RCT in MERS-CoV patients [192]. This combination was considered the second candidate in a WHO research prioritization list of therapeutic agents [193]. The drug has a generally good safety profile, but may have interactions with many drugs commonly used in critically ill patients (http://www.covid19-druginteractions.org/).

A recent RCT compared the use of lopinavir/ritonavir to usual care in 199 hospitalized patients with COVID19 in China [194]. In this trial, lopinavir/ritonavir did not significantly reduce 28 -day mortality (RD $-5.8 \%$; 95\% CI -17.3 to 5.7 ) or time to clinical improvement (MD 1.31 days, 95\% CI 0.95-1.80). In addition, lopinavir/ritonavir was associated with more adverse events [194]. This trial is the only available direct evidence on the use of lopinavir/ritonavir in patients with COVID-19, however, it has several limitations. The trial was unblinded and it enrolled a small number of patients $(n=199)$ with a small number of events (44 deaths in total), which limits our confidence in its results. Nevertheless, the routine use of 
lopinavir/ritonavir in critically ill patients is probably not warranted, and a weak recommendation against the routine use of lopinavir/ritonavir in critically ill COVID-19 patients is reasonable.

Lopinavir/ritonavir is one of the arms in a planned WHO core treatment protocol for hospitalized patients with COVID-19, and in the REMAP-CAP (Randomized, Embedded, Multifactorial Adaptive Platform Trial for Community-Acquired Pneumonia) trial (NCT02735707) The results of ongoing trials will help increase the precision of estimates and the certainty in the evidence.

Remdesivir is the prodrug of an adenosine analog, which incorporates into nascent viral RNA chains and results in premature termination. It was considered the most promising drug in an informal consultation on research prioritization of candidate therapeutic agents by WHO [195]. Currently, there are published case reports but no published trials on the use of remdesivir in COVID-19. Remdesivir demonstrated effective inhibition of SARS-CoV-2, MERS-CoV, and SARS-CoV in in vitro studies [196]. Furthermore, studies in animal models of MERS-CoV showed that it was more effective than control and superior to lopinavir/ritonavir combined with systemic IFN- $\beta$ [197, 198]. Although intravenous remdesivir appears to adequately tolerated, a recent RCT showed that it was less effective than several antibody therapies in Ebola virus disease [199]. There are several ongoing RCTs that aim to examine the efficacy and safety of intravenous remdesivir for severe COVID-19 (clinicaltrials.gov NCT04257656) and for mild and moderate COVID-19 (clinicaltrials.gov NCT04252664). Another trial sponsored by the National Institute of Allergy and Infectious Diseases is recruiting patients in USA (clinicaltrials.gov NCT04280705). We will update our guidelines as new evidence emerges.

\section{Recommendation \\ 48. There is insufficient evidence to issue a recommendation on \\ the use of recombinant rIFNs, alone or in combination with antivirals, in critically ill adults with COVID-19.}

\section{Rationale}

Recombinant interferon, often combined with ribavirin therapy, has been used in patients with MERS and SARS $[179,200-202]$. Different preparations of recombinant rIFNs (rIFN- $\alpha 2 a, r I F N-\alpha 2 b$, rIFN- $\beta 1 \mathrm{a}$ and rIFN- $\beta 1 \mathrm{~b}$ ) have shown activity against MERS-CoV in Vero and LLCMK2 cells, and in a rhesus macaque model of MERS-CoV infection [200, 201, 203]. The largest cohort of critically ill patients with MERS showed that rIFN- $\alpha 2 a, r I F N-\alpha 2 b$,
rIFN- $\beta 1 \mathrm{a}$ and ribavirin were not associated with lower mortality (OR 1.03, 95\% CI .73-1.44) or reduced viral clearance when adjusted for time-varying covariables [204]. The relative effectiveness of different interferons against SARS-CoV-2 is unknown at this point.

In vitro data showed that rIFN- $\beta$ displayed the strongest MERS-CoV inhibition among different rIFN preparations (rIFN- $\alpha 2 \mathrm{~b}, \mathrm{rIFN}-\gamma, \mathrm{rIFN}-$ universal, and rIFN- $\alpha 2 \mathrm{a}$, rIFN- $\beta$ ), at 41 times lower than the previously reported $50 \%$ inhibitory concentration (IC50) of rIFN- $\alpha 2 b$ [203, 205]. An RCT to examine the effect of a combination of lopinavir/ritonavir and rIFN- $\beta-1 b$ on mortality of hospitalized patients with MERS is currently recruiting patients [206]. Unpublished data indicate that IFN- $\beta$ inhibits SARS-COV-2 in cell culture, and IFNs have been prioritized for study in COVID-19 by the WHO.

\section{Recommendation \\ 49. There is insufficient evidence to issue a recommendation on \\ the use of chloroquine or hydroxychloroquine in critically ill adults with COVID-19.}

\section{Rationale}

Chloroquine and its metabolite, hydroxychloroquine, are antimalarial agents that have demonstrated antiviral effects on SARS-CoV and SARS-CoV-2 in vitro [196, 207, 208]. Prior studies found inhibitory effects of chloroquine for multiple RNA viruses in vitro, but RCTs in treatment of dengue and chikungunya virus infections and of influenza prophylaxis failed to demonstrate antiviral or clinical benefits [209]. In one non-human primate model of chikungunya infection, it was shown that chloroquine's immunomodulatory effects were associated with delayed immune responses, higher levels of viral replication, and worse illness [210]. A news briefing suggested that its use in more than 100 patients showed "that it was superior to the control in inhibiting the exacerbation of pneumonia, improving lung imaging findings, promoting a virus negative conversion, and shortening the disease course", but the data have not been published yet [211]. A recent consensus document recommended chloroquine phosphate $500 \mathrm{mg}$ twice daily for minimum of 5 days, with dose modifications if severe gastrointestinal side effects occur [212]. Since chloroquine is not available in some countries, hydroxychloroquine is an alternative. A recent study in China explored various dosing regimens of chloroquine and hydroxychloroquine using physiologicallybased pharmacokinetic models [208]. The study found hydroxychloroquine to be more potent than chloroquine in inhibiting SARS-CoV-2 in vitro. Based on these 
models, a hydroxychloroquine loading dose of $400 \mathrm{mg}$ twice daily followed by $200 \mathrm{mg}$ twice daily for 4 days was recommended [208]. A recent systematic review found no published studies in COVID-19 patients [213]. Pending the results of ongoing trials, we were unable to issue a recommendation for or against chloroquine.

\section{Recommendation}

50. There is insufficient evidence to issue a recommendation on the use of tocilizumab in critically ill adults with COVID-19.

\section{Rationale}

Tocilizumab is a humanized immunoglobulin that functions in the immune response and blocks IL-6 receptor binding to IL-6. It has been approved for CRS and other inflammatory conditions related to IL-6 related inflammation, such as rheumatoid arthritis and juvenile idiopathic arthritis [214-217]. Severely ill patients with COVID-19 may have an extreme immune response leading to severe respiratory failure. In such cases, inhibition of IL-6 may help attenuate the cytokine release syndrome by reducing cytokine concentrations and acute phase reactant production [218]. Ongoing trials of tocilizumab will help address the safety and efficacy of this therapy in COVID-19.

From the rheumatoid arthritis literature, a systematic review and meta-analysis of 6 RCTs (3 with 8/mg dose and 3 with $4 \mathrm{mg} / \mathrm{kg}$ dose) showed an increased risk of adverse events compared with control treatment (OR 1.53, 95\% CI 1.26-1.86), and an increased risk of infections (OR 1.30, 95\% CI 1.07-1.58) [219]. Another systematic review and meta-analysis of RCTs on tocilizumab in rheumatoid arthritis found an increased risk of infectious respiratory adverse events (RR 1.53, 95\% CI 1.04-2.25) [220]. Since we have no data on the safety or efficacy of tocilizumab in COVID-19, we were unable to issue a recommendation.

\section{Other agents}

Nafamostat is a synthetic serine protease inhibitor and a potent inhibitor of MERS CoV. Nitazoxanide is an antiprotozoal agent with antiviral potential against several respiratory viruses including influenza, parainfluenza, respiratory syncytial virus, and rhinovirus. An in vitro study showed that both nafamostat and nitazoxanide inhibited SARS-CoV-2 [196]. An RCT in patients with acute uncomplicated influenza demonstrated that the use of nitazoxanide reduced the duration of symptoms [221]. However, in hospitalized patients with severe acute respiratory infection in
Mexico, nitazoxanide was not found to be superior to placebo [222].

\section{Electronic supplementary material}

The online version of this article (https://doi.org/10.1007/s00134-020-06022-5) contains supplementary material, which is available to authorized users.

\section{Author details}

${ }^{1}$ Department of Medicine, McMaster University, Hamilton, Canada. ${ }^{2}$ Department of Health Research Methods, Evidence, and Impact, McMaster University, Hamilton, Canada. ${ }^{3}$ Department of Intensive Care, Copenhagen University Hospital Rigshospitalet, 4131 Copenhagen, Denmark. ${ }^{4}$ Scandinavian Society of Anaesthesiology and Intensive Care Medicine (SSAI), Copenhagen, Denmark. ${ }^{5}$ Intensive Care Department, Ministry of National Guard Health Affairs, King Saud Bin Abdulaziz University for Health Sciences, King Abdullah International Medical Research Center, Riyadh, Kingdom of Saudi Arabia. ${ }^{6}$ Division of Critical Care Medicine, Division of Pulmonary Medicine, Department of Medicine, Montefiore Healthcare System/Albert Einstein College of Medicine, Bronx, NY, USA. ${ }^{7}$ Interdepartmental Division of Critical Care Medicine, Institute of Health Policy, Management and Evaluation, University of Toronto, Toronto, Canada. ${ }^{8}$ Warren Alpert School of Medicine, Brown University, Providence, RI, USA. ${ }^{9}$ Rhode Island Hospital, Providence, RI, USA. ${ }^{10}$ Department of Intensive Care Medicine, University Medical Center Utrecht, Utrecht University, Utrecht, The Netherlands. ${ }^{11}$ Julius Center for Health Sciences and Primary Care, Utrecht, The Netherlands. ${ }^{12}$ Department of Pharmacy, NewYork-Presbyterian Hospital, Columbia University Irving Medical Center, New York, NY, USA. ${ }^{13}$ Medical ICU, Peking Union Medical College Hospital, 1 Shuai Fu Yuan, Beijing 100730, China. ${ }^{14}$ Department of Critical Care Medicine, Sunnybrook Health Sciences Centre, Toronto, ON, Canada. ${ }^{15}$ Department of Anesthesia and Interdepartmental Division of Critical Care Medicine, University of Toronto, Toronto, ON, Canada. ${ }^{16}$ Department of Anesthesia and Intensive Care, Humanitas Clinical and Research Center, Rozzano, Milan, Italy. ${ }^{17}$ Department of Biomedical Science, Humanitas University, Pieve Emanuele, Milan, Italy. ${ }^{18}$ Department of Pulmonary and Critical Care Medicine, Asan Medical Center, University of Ulsan College of Medicine, Seoul, Korea. ${ }^{19}$ Critical Care Medicine Department, National Institutes of Health Clinical Center and Laboratory of Immunoregulation, National Institute of Allergy and Infectious Diseases, Baltimore, USA. ${ }^{20}$ Faculty of Medicine, Imperial College, London, UK. ${ }^{21}$ Department of Internal Medicine, College of Medicine and Health Sciences, United Arab Emirates University, PO Box 17666, Al Ain, United Arab Emirates.

22 Population Health Research Institute, Hamilton, Canada. ${ }^{23}$ Microbiology and Infection Control, St George's University Hospitals NHS Foundation Trust \& St George's University of London, London, UK. ${ }^{24}$ Emory University Hospital, Atlanta, USA. ${ }^{25}$ Division of Infectious Diseases, University of Toronto, Toronto, Canada. ${ }^{26}$ Department of Medicine, Jacobs School of Medicine and Biomedical Sciences, State University of New York at Buffalo, Buffalo, USA. ${ }^{27}$ GUIDE Research Methods Group, Hamilton, Canada. ${ }^{28}$ Houston Children's Hospital, Baylor College of Medicine, Houston, USA. ${ }^{29}$ Department of Anesthesia, McMaster University, Hamilton, Canada. ${ }^{30}$ Department of Medicine and Surgery, Milano-Bicocca University, Milan, Italy. ${ }^{31}$ ASST-Monza, Desio and San Gerardo Hospital, Monza, Italy. ${ }^{32}$ Department of Emergency Medicine, King Abdulaziz Medical City, Riyadh, Saudi Arabia. ${ }^{33}$ Director, Research and Innovation Centre, King Saud Medical City, Ministry of Health, Riyadh, Kingdom of Saudi Arabia. ${ }^{34}$ Critical Care Division, The George Institute for Global Health and UNSW, Sydney, Australia. ${ }^{35}$ Malcolm Fisher Department of Intensive Care, Royal North Shore Hospital, Sydney, Australia. ${ }^{36}$ Division of Infectious Diseases and International Health, Department of Medicine, University, of Virginia, School of Medicine, Charlottesville, VA, USA. ${ }^{37}$ Division of Pulmonary, Critical Care, and Sleep Medicine, University of Washington, Seattle, USA. ${ }^{38}$ Adult Critical Care, St George's University Hospitals NHS Foundation Trust \& St George's University of London, London, UK.

\section{Acknowledgements}

We would like to acknowledge Drs. Zainab Al duhailib, Kimberly Lewis, Malik Farooqi, and Jessica Bartoszko for their support with conducting systematic reviews and meta-analyses for some of the guideline questions.

Funding

There was no dedicated funding for this guideline. 


\section{Compliance with ethical standards}

\section{Conflicts of interest}

Dr. Yaseen Arabi is the principal investigator on a clinical trial for lopinavir/ ritonavir and interferon in Middle East respiratory syndrome (MERS) and he was a nonpaid consultant on antiviral active for MERS-coronavirus (CoV) for Gilead Sciences and SAB Biotherapeutics. He is an investigator on REMAP-CAP trial and is a Board Members of the International Severe Acute Respiratory and Emerging Infection Consortium (ISARIC). Dr. Eddy Fan declared receiving consultancy fees from ALung Technologies and MC3 Cardiopulmonary. Dr. Maurizio Cecconi declared consultancy work with Edwards Lifesciences, Directed Systems, and Cheetah Medical. Dr. Lennie Derde is the NVIC (Dutch National ICU society) chair of Taskforce Infectious Diseases (standing committee), member of ESICM Coronavirus Taskforce (started with this outbreak), chair ESICM Clinical Training Committee, all are unpaid positions. Dr. Frederick Hyden is non-compensated consultant to Gilead Sciences (antivirals for RVIS including remdesivir), Regeneraon (monoclonals for RVIs including MERS), and SAB Biotherapeutics (polyclonal antibodies for RVls including MERS). Other authors declared no conflict of interest.

\section{Publisher's Note}

Springer Nature remains neutral with regard to jurisdictional claims in published maps and institutional affiliations.

Received: 15 March 2020 Accepted: 20 March 2020 Published online: 28 March 2020

\section{References}

1. Guan WJ, Ni ZY, Hu Y, Liang WH, Ou CQ, He JX, Liu L, Shan H, Lei CL, Hui DSC, Du B, Li LJ, Zeng G, Yuen KY, Chen RC, Tang CL, Wang T, Chen PY, Xiang J, Li SY, Wang JL, Liang ZJ, Peng YX, Wei L, Liu Y, Hu YH, Peng P, Wang JM, Liu JY, Chen Z, Li G, Zheng ZJ, Qiu SQ, Luo J, Ye CJ, Zhu SY, Zhong NS, China Medical Treatment Expert Group for C (2020) Clinical characteristics of Coronavirus Disease 2019 in China. N Engl J Med. https://doi.org/10.1056/NEJMoa2002032

2. European Centre for Disease Prevention and Control, Situation update worldwide, 4 March 2020. 2020, March 4. https://www.ecdc.europa.eu/ en/geographical-distribution-2019-ncov-cases

3. Alhazzani W, Lewis K, Jaeschke R, Rochwerg B, Moller MH, Evans L, Wilson KC, Patel S, Coopersmith CM, Cecconi M, Guyatt G, AkI EA (2018) Conflicts of interest disclosure forms and management in critical care clinical practice guidelines. Intensive Care Med 44:1691-1698

4. Vandvik PO, Alhazzani W, Moller MH (2018) Understanding conflicts of interest. Intensive Care Med 44:1738-1740

5. Guyatt GH, Oxman AD, Kunz R, Atkins D, Brozek J, Vist G, Alderson P, Glasziou P, Falck-Ytter Y, Schunemann HJ (2011) GRADE quidelines: 2. Framing the question and deciding on important outcomes. J Clin Epidemiol 64:395-400

6. Akl EA, Johnston BC, Alonso-Coello P, Neumann I, Ebrahim S, Briel M, Cook DJ, Guyatt GH (2013) Addressing dichotomous data for participants excluded from trial analysis: a guide for systematic reviewers. PLOS ONE 8:e57132

7. Guyatt GH, Oxman AD, Vist GE, Kunz R, Falck-Ytter Y, Schunemann P Schunemann HJ, Group GW (2008) GRADE: an emerging consensus on rating quality of evidence and strength of recommendations. BMJ 336:924-926

8. Balshem $H$, Helfand M, Schunemann HJ, Oxman AD, Kunz R, Brozek J, Vist GE, Falck-Ytter Y, Meerpohl J, Norris S, Guyatt GH (2011) GRADE guidelines: 3 . Rating the quality of evidence. J Clin Epidemiol 64:401-406

9. Andrews J, Guyatt G, Oxman AD, Alderson P, Dahm P, Falck-Ytter $Y$, Nasser M, Meerpohl J, Post PN, Kunz R, Brozek J, Vist G, Rind D, Akl EA, Schunemann HJ (2013) GRADE guidelines: 14. Going from evidence to recommendations: the significance and presentation of recommendations. J Clin Epidemiol 66:719-725

10. Guyatt GH, Oxman AD, Santesso N, Helfand M, Vist G, Kunz R, Brozek J, Norris S, Meerpohl J, Djulbegovic B, Alonso-Coello P, Post PN, Busse JW, Glasziou P, Christensen R, Schunemann HJ (2013) GRADE quidelines: 12.
Preparing summary of findings tables-binary outcomes. J Clin Epidemiol 66:158-172

11. Schunemann HJ, Wiercioch W, Brozek J, Etxeandia-lkobaltzeta I, Mustafa RA, Manja V, Brignardello-Petersen R, Neumann I, Falavigna M, Alhazzani W, Santesso N, Zhang Y, Meerpohl JJ, Morgan RL, Rochwerg B, Darzi A, Rojas MX, Carrasco-Labra A, Adi Y, AlRayees Z, Riva J, Bollig C, Moore A, Yepes-Nunez JJ, Cuello C, Waziry R, Akl EA (2017) GRADE evidence to decision (EtD) frameworks for adoption, adaptation, and de novo development of trustworthy recommendations: GRADE-ADOLOPMENT. J Clin Epidemiol 81:101-110

12. Wu Z, McGoogan JM (2020) Characteristics of and important lessons from the Coronavirus Disease 2019 (COVID-19) outbreak in china: summary of a report of 72314 cases from the Chinese center for disease control and prevention. JAMA. https://doi.org/10.1001/jama.2020.2648

13. Livingston E, Bucher K (2020) Coronavirus Disease 2019 (COVID-19) in Italy. JAMA, Dumka

14. Milton DK, Fabian MP, Cowling BJ, Grantham ML, McDevitt JJ (2013) Influenza virus aerosols in human exhaled breath: particle size, culturability, and effect of surgical masks. PLoS Pathog 9:e1003205

15. Twu SJ, Chen TJ, Chen CJ, Olsen SJ, Lee LT, Fisk T, Hsu KH, Chang SC, Chen KT, Chiang IH, Wu YC, Wu JS, Dowell SF (2003) Control measures for severe acute respiratory syndrome (SARS) in Taiwan. Emerg Infect Dis 9:718-720

16. World Health Organization, Clinical management of severe acute respiratory infection (SARI) when COVID-19 disease is suspected. 2020, March 14. https://www.who.int/docs/default-source/coronaviruse/ clinical-management-of-novel-cov.pdf?sfvrsn=bc7da517_10\&downl oad=true

17. Cabrini L, Landoni G, Zangrillo A (2020) Minimise nosocomial spread of 2019-nCoV when treating acute respiratory failure. Lancet 395:685

18. Yam LY, Chen RC, Zhong NS (2003) SARS: ventilatory and intensive care. Respirology 8(Suppl):S31-S35

19. Qian H, Li Y, Sun H, Nielsen PV, Huang X, Zheng X (2010) Particle removal efficiency of the portable HEPA air cleaner in a simulated hospital ward. Build Simul 3:215-224

20. Smith JD, MacDougall CC, Johnstone J, Copes RA, Schwartz B, Garber GE (2016) Effectiveness of N95 respirators versus surgical masks in protecting health care workers from acute respiratory infection: a systematic review and meta-analysis. CMAJ 188:567-574

21. Radonovich $\sqcup \mathrm{Jr}$, Simberkoff MS, Bessesen MT, Brown AC, Cummings DAT, Gaydos CA, Los JG, Krosche AE, Gibert CL, Gorse GJ, Nyquist AC, Reich NG, Rodriguez-Barradas MC, Price CS, Perl TM, Pi R (2019) N95 respirators vs medical masks for preventing influenza among health care personnel: a randomized clinical trial. JAMA 322:824-833

22. Loeb M, Dafoe N, Mahony J, John M, Sarabia A, Glavin V, Webby R, Smieja M, Earn DJ, Chong S, Webb A, Walter SD (2009) Surgical mask vs N95 respirator for preventing influenza among health care workers: a randomized trial. JAMA 302:1865-1871

23. MacIntyre $C R$, Wang $Q$, Cauchemez $S$, Seale $H$, Dwyer $D E$, Yang $P$, Shi W, Gao Z, Pang X, Zhang Y, Wang X, Duan W, Rahman B, Ferguson N (2011) A cluster randomized clinical trial comparing fit-tested and non-fit-tested N95 respirators to medical masks to prevent respiratory virus infection in health care workers. Influenza Other Respir Viruses 5:170-179

24. Maclntyre CR, Wang Q, Rahman B, Seale H, Ridda I, Gao Z, Yang P, Shi W, Pang X, Zhang Y, Moa A, Dwyer DE (2014) Efficacy of face masks and respirators in preventing upper respiratory tract bacterial colonization and co-infection in hospital healthcare workers. Prev Med 62:1-7

25. Maclntyre CR, Wang Q, Seale H, Yang P, Shi W, Gao Z, Rahman B, Zhang Y, Wang X, Newall AT, Heywood A, Dwyer DE (2013) A randomized clinical trial of three options for N95 respirators and medical masks in health workers. Am J Respir Crit Care Med 187:960-966

26. Long Y, Hu T, Liu L, Chen R, Guo Q, Yang L, Cheng Y, Huang J, Du L (2020) Effectiveness of $\mathrm{N} 95$ respirators versus surgical masks against influenza: A systematic review and meta-analysis. J Evid Based Med. https://doi. org/10.1111/jebm.12381

27. Tuite AR, Fisman DN (2020) Reporting, epidemic growth, and reproduction numbers for the 2019 novel coronavirus (2019-nCoV) epidemic. Ann Intern Med. https://doi.org/10.7326/M20-0358

28. Biggerstaff M, Cauchemez S, Reed C, Gambhir M, Finelli L (2014) Estimates of the reproduction number for seasonal, pandemic, and 
zoonotic influenza: a systematic review of the literature. BMC Infect Dis $14: 480$

29. Tran K, Cimon K, Severn M, Pessoa-Silva CL, Conly J (2012) Aerosol generating procedures and risk of transmission of acute respiratory infections to healthcare workers: a systematic review. PLoS ONE 7:e35797

30. Lewis SR, Butler AR, Parker J, Cook TM, Schofield-Robinson OJ, Smith AF (2017) Videolaryngoscopy versus direct laryngoscopy for adult patients requiring tracheal intubation: a Cochrane systematic review. $\mathrm{Br}$ J Anaesth 119:369-383

31. Lewis SR, Butler AR, Parker J, Cook TM, Smith AF (2016) Videolaryngoscopy versus direct laryngoscopy for adult patients requiring tracheal intubation. Cochrane Database Syst Rev 11:CD011136

32. Russell TM, Hormis A, Rotherham NHSFT (2018) Should the Glidescope video laryngoscope be used first line for all oral intubations or only in those with a difficult airway? A review of current literature. J Perioper Pract 28:322-333

33. Center of Disease Control, Interim Guidelines for Collecting, Handling, and Testing Clinical Specimens from Persons Under Investigation (PUIs) for Coronavirus Disease 2019 (COVID-19). 2020, February 14. https:// www.cdc.gov/coronavirus/2019-nCoV/lab/guidelines-clinical-speci mens.html

34. Linton NM, Kobayashi T, Yang Y, Hayashi K, Akhmetzhanov AR, Jung SM, Yuan B, Kinoshita R, Nishiura H (2020) Incubation period and other epidemiological characteristics of 2019 novel coronavirus infections with right truncation: a statistical analysis of publicly available case data. J Clin Med. https://doi.org/10.3390/jcm9020538

35. Corman VM, Landt O, Kaiser M, Molenkamp R, Meijer A, Chu DKW, Bleicker T, Brunink S, Schneider J, Schmidt ML, Mulders D, Haagmans $B L$, van der Veer $B$, van den Brink S, Wijsman L, Goderski G, Romette JL, Ellis J, Zambon M, Peiris M, Goossens H, Reusken C, Koopmans MPG, Drosten C (2020) Detection of 2019 novel coronavirus (2019-nCoV) by real-time RT-PCR. Euro Surveill. https://doi.org/10.2807/1560-7917. ES.2020.25.3.2000045

36. Chu DKW, Pan Y, Cheng SMS, Hui KPY, Krishnan P, Liu Y, Ng DYM, Wan CKC, Yang P, Wang Q, Peiris M, Poon LLM (2020) Molecular diagnosis of a novel coronavirus (2019-nCoV) causing an outbreak of pneumonia. Clin Chem. https://doi.org/10.1093/clinchem/hvaa029

37. Xie C, Jiang L, Huang G, Pu H, Gong B, Lin H, Ma S, Chen X, Long B, Si G, Yu H, Jiang L, Yang X, Shi Y, Yang Z (2020) Comparison of different samples for 2019 novel coronavirus detection by nucleic acid amplification tests. Int J Infect Dis. https://doi.org/10.1016/j.ijid.2020.02.050

38. Yam WC, Chan KH, Poon LL, Guan Y, Yuen KY, Seto WH, Peiris JS (2003) Evaluation of reverse transcription-PCR assays for rapid diagnosis of severe acute respiratory syndrome associated with a novel coronavirus. J Clin Microbiol 41:4521-4524

39. Ai T, Yang Z, Hou H, Zhan C, Chen C, Lv W, Tao Q, Sun Z, Xia L (2020) Correlation of chest CT and RT-PCR testing in Coronavirus Disease 2019 (COVID-19) in China: a report of 1014 cases. Radiology. https://doi. org/10.1148/radiol.2020200642

40. Wu X, Cai Y, Huang X, Yu X, Zhao L, Wang F, Li Q, Gu S, Xu T, Li Y, Lu B, Zhan Q (2020) Co-infection with SARS-CoV-2 and influenza A virus in patient with pneumonia, China. Emerg Infect Dis. https://doi. org/10.3201/eid2606.200299

41. Chan PK, To WK, Ng KC, Lam RK, Ng TK, Chan RC, Wu A, Yu WC, Lee N, Hui DS, Lai ST, Hon EK, Li CK, Sung JJ, Tam JS (2004) Laboratory diagnosis of SARS. Emerg Infect Dis 10:825-831

42. Yang $X, Y u Y, X u$ J, Shu $H$, Xia J, Liu H, Wu Y, Zhang L, Yu Z, Fang M, Yu T, Wang Y, Pan S, Zou X, Yuan S, Shang Y (2020) Clinical course and outcomes of critically ill patients with SARS-CoV-2 pneumonia in Wuhan, China: a single-centered, retrospective, observational study. Lancet Respir Med. https://doi.org/10.1016/S2213-2600(20)30079-5

43. Wang D, Hu B, Hu C, Zhu F, Liu X, Zhang J, Wang B, Xiang H, Cheng Z, Xiong Y, Zhao Y, Li Y, Wang X, Peng Z (2020) Clinical characteristics of 138 Hospitalized patients With 2019 novel coronavirus-infected pneumonia in Wuhan, China. JAMA 45:50. https://doi.org/10.1001/ jama.2020.1585

44. Huang C, Wang Y, Li X, Ren L, Zhao J, Hu Y, Zhang L, Fan G, Xu J, Gu X, Cheng Z, Yu T, Xia J, Wei Y, Wu W, Xie X, Yin W, Li H, Liu M, Xiao Y, Gao H, Guo L, Xie J, Wang G, Jiang R, Gao Z, Jin Q, Wang J, Cao B (2020) Clinical features of patients infected with 2019 novel coronavirus in Wuhan, China. Lancet 395:497-506
45. Zhou F, Yu T, Du R, Fan G, Liu Y, Liu Z, Xiang J, Wang Y, Song B, Gu X, Guan L, Wei Y, Li H, Wu X, Xu J, Tu S, Zhang Y, Chen H, Cao B (2020) Clinical course and risk factors for mortality of adult inpatients with COVID-19 in Wuhan, China: a retrospective cohort study. Lancet. https //doi.org/10.1016/S0140-6736(20)30566-3

46. Ruan Q, Yang K, Wang W, Jiang L, Song J (2020) Clinical predictors of mortality due to COVID-19 based on an analysis of data of 150 patients from Wuhan. Intensive Care Med, China. https://doi.org/10.1007/s0013 4-020-05991-x

47. Bednarczyk JM, Fridfinnson JA, Kumar A, Blanchard L, Rabbani R, Bell D, Funk D, Turgeon AF, Abou-Setta AM, Zarychanski R (2017) Incorporating dynamic assessment of fluid responsiveness into goal-directed therapy: a systematic review and meta-analysis. Crit Care Med 45:1538-1545

48. Bentzer P, Griesdale DE, Boyd J, MacLean K, Sirounis D, Ayas NT (2016) Will this hemodynamically unstable patient respond to a bolus of intravenous fluids? JAMA 316:1298-1309

49. Pan J, Peng M, Liao C, Hu X, Wang A, Li X (2019) Relative efficacy and safety of early lactate clearance-quided therapy resuscitation in patients with sepsis: a meta-analysis. Medicine (Baltimore) 98:e14453

50. Hernandez G, Ospina-Tascon GA, Damiani LP, Estenssoro E, Dubin A Hurtado J, Friedman G, Castro R, Alegria L, Teboul JL, Cecconi M, Ferri G, Jibaja M, Pairumani R, Fernandez P, Barahona D, Granda-Luna V, Cavalcanti AB, Bakker J, The ASI, the Latin America Intensive Care N, Hernandez G, Ospina-Tascon G, Petri Damiani L, Estenssoro E, Dubin A, Hurtado J, Friedman G, Castro R, Alegria L, Teboul JL, Cecconi M, Cecconi M, Ferri G, Jibaja M, Pairumani R, Fernandez P, Barahona D, Cavalcanti AB, Bakker J, Hernandez G, Alegria L, Ferri G, Rodriguez N, Holger P, Soto N, Pozo M, Bakker J, Cook D, Vincent JL, Rhodes A, Kavanagh BP, Dellinger P, Rietdijk W, Carpio D, Pavez N, Henriquez E, Bravo S, Valenzuela ED, Vera M, Dreyse J, Oviedo V, Cid MA, Larroulet M, Petruska E, Sarabia C, Gallardo D, Sanchez JE, Gonzalez H, Arancibia JM, Munoz A, Ramirez G, Aravena F, Aquevedo A, Zambrano F, Bozinovic M, Valle F, Ramirez M, Rossel V, Munoz P, Ceballos C, Esveile C, Carmona C, Candia E, Mendoza D, Sanchez A, Ponce D, Ponce D, Lastra J, Nahuelpan B, Fasce F, Luengo C, Medel N, Cortes C, Campassi L, Rubatto P, Horna N, Furche M, Pendino JC, Bettini L, Lovesio C, Gonzalez MC, Rodruguez J, Canales H, Caminos F, Galletti C, Minoldo E, Aramburu MJ, Olmos D, Nin N, Tenzi J, Quiroga C, Lacuesta P, Gaudin A, Pais R, Silvestre A, Olivera G, Rieppi G, Berrutti D, Ochoa M, Cobos P, Vintimilla F, Ramirez V, Tobar M, Garcia F, Picoita F, Remache N, Granda V, Paredes F, Barzallo E, Garces P, Guerrero F, Salazar S, Torres G, Tana C, Calahorrano J, Solis F, Torres P, Herrera L, Ornes A, Perez V, Delgado G, Lopez A, Espinosa E, Moreira J, Salcedo B, Villacres I, Suing J, Lopez M, Gomez L, Toctaquiza G, Cadena Zapata M, Orazabal MA, Pardo Espejo R, Jimenez J, Calderon A, Paredes G, Barberan JL, Moya T, Atehortua H, Sabogal R, Ortiz G, Lara A, Sanchez F, Hernan Portilla A, Davila H, Mora JA, Calderon LE, Alvarez I, Escobar E, Bejarano A, Bustamante LA, Aldana JL (2019) Effect of a resuscitation strategy targeting peripheral perfusion status vs serum lactate levels on 28-day mortality among patients with septic shock: the ANDROMEDASHOCK randomized clinical trial. JAMA 321:654-664

51. Meyhoff TS, Moller MH, Hjortrup PB, Cronhjort M, Perner A, Wetterslev $J$ (2020) Lower versus higher fluid volumes during initial management of sepsis: a systematic review with meta-analysis and trial sequential analysis. Chest. https://doi.org/10.1016/j.chest.2019.11.050

52. Silversides JA, Major E, Ferguson AJ, Mann EE, McAuley DF, Marshall JC, Blackwood B, Fan E (2017) Conservative fluid management or deresuscitation for patients with sepsis or acute respiratory distress syndrome following the resuscitation phase of critical illness: a systematic review and meta-analysis. Intensive Care Med 43:155-170

53. Maitland K, Kiguli S, Opoka RO, Engoru C, Olupot-Olupot P, Akech SO, Nyeko R, Mtove G, Reyburn H, Lang T, Brent B, Evans JA, Tibenderana JK, Crawley J, Russell EC, Levin M, Babiker AG, Gibb DM, Group FT (2011) Mortality after fluid bolus in African children with severe infection. N Engl J Med 364:2483-2495

54. Lewis SR, Pritchard MW, Evans DJ, Butler AR, Alderson P, Smith AF, Roberts I (2018) Colloids versus crystalloids for fluid resuscitation in critically ill people. Cochrane Database Syst Rev 8:CD000567

55. Antequera Martin AM, Barea Mendoza JA, Muriel A, Saez I, ChicoFernandez M, Estrada-Lorenzo JM, Plana MN (2019) Buffered solutions versus 09\% saline for resuscitation in critically ill adults and children. Cochrane Database Syst Rev 7:CD012247 
56. Moller MH, Claudius C, Junttila E, Haney M, Oscarsson-Tibblin A, Haavind A, Perner A (2016) Scandinavian SSAI clinical practice guideline on choice of first-line vasopressor for patients with acute circulatory failure. Acta Anaesthesiol Scand 60:1347-1366

57. Gamper G, Havel C, Arrich J, Losert H, Pace NL, Mullner M, Herkner H (2016) Vasopressors for hypotensive shock. Cochrane Database Syst Rev 2:CD003709

58. Honarmand K, Um KJ, Belley-Cote EP, Alhazzani W, Farley C, Fernando SM, Fiest K, Grey D, Hajdini E, Herridge M, Hrymak C, Moller MH, Kanji S, Lamontagne F, Lauzier F, Mehta S, Paunovic B, Singal R, Tsang JL, Wynne C, Rochwerg B (2020) Canadian Critical Care Society clinical practice guideline: the use of vasopressin and vasopressin analogues in critically ill adults with distributive shock. Can J Anaesth 67:369-376

59. Mclntyre WF, Um KJ, Alhazzani W, Lengyel AP, Hajjar L, Gordon AC, Lamontagne F, Healey JS, Whitlock RP, Belley-Cote EP (2018) Association of vasopressin plus catecholamine vasopressors vs catecholamines alone with atrial fibrillation in patients with distributive shock: a systematic review and meta-analysis. JAMA 319:1889-1900

60. Lamontagne F, Day AG, Meade MO, Cook DJ, Guyatt GH, Hylands M, Radermacher P, Chretien JM, Beaudoin N, Hebert P, D'Aragon F, Meziani F, Asfar P (2018) Pooled analysis of higher versus lower blood pressure targets for vasopressor therapy septic and vasodilatory shock. Intensive Care Med 44:12-21

61. Lamontagne F, Richards-Belle A, Thomas K, Harrison DA, Sadique MZ, Grieve RD, Camsooksai J, Darnell R, Gordon AC, Henry D, Hudson N, Mason AJ, Saull M, Whitman C, Young JD, Rowan KM, Mouncey PR, trial i, (2020) Effect of reduced exposure to vasopressors on 90-day mortality in older critically ill patients with vasodilatory hypotension: a randomized clinical trial. JAMA. https://doi.org/10.1001/jama.2020.0930

62. Moller MH, Granholm A, Junttila E, Haney M, Oscarsson-Tibblin A, Haavind A, Laake JH, Wilkman E, Sverrisson KO, Perner A (2018) Scandinavian SSAI clinical practice guideline on choice of inotropic agent for patients with acute circulatory failure. Acta Anaesthesiol Scand 62:420-450

63. Rygard SL, Butler E, Granholm A, Moller MH, Cohen J, Finfer S, Perner A, Myburgh J, Venkatesh B, Delaney A (2018) Low-dose corticosteroids for adult patients with septic shock: a systematic review with meta-analysis and trial sequential analysis. Intensive Care Med 44:1003-1016

64. Lamontagne F, Rochwerg B, Lytvyn L, Guyatt GH, Moller MH, Annane D, Kho ME, Adhikari NKJ, Machado F, Vandvik PO, Dodek P, Leboeuf R, Briel M, Hashmi M, Camsooksai J, Shankar-Hari M, Baraki MK, Fugate K, Chua S, Marti C, Cohen D, Botton E, Agoritsas T, Siemieniuk RAC (2018) Corticosteroid therapy for sepsis: a clinical practice guideline. BMJ 362:k3284

65. Chen N, Zhou M, Dong X, Qu J, Gong F, Han Y, Qiu Y, Wang J, Liu Y, Wei Y, Xia J, Yu T, Zhang X, Zhang L (2020) Epidemiological and clinical characteristics of 99 cases of 2019 novel coronavirus pneumonia in Wuhan, China: a descriptive study. Lancet 395:507-513

66. van den Boom W, Hoy M, Sankaran J, Liu M, Chahed H, Feng M, See KC (2020) The search for optimal oxygen saturation targets in critically ill patients: observational data from large ICU databases. Chest 157:566-573

67. Chu DK, Kim LH, Young PJ, Zamiri N, Almenawer SA, Jaeschke R, SzCzeklik W, Schunemann HJ, Neary JD, Alhazzani W (2018) Mortality and morbidity in acutely ill adults treated with liberal versus conservative oxygen therapy (IOTA): a systematic review and meta-analysis. Lancet 391:1693-1705

68. Siemieniuk RAC, Chu DK, Kim LH, Guell-Rous MR, Alhazzani W, Soccal PM, Karanicolas PJ, Farhoumand PD, Siemieniuk JLK, Satia I, Irusen EM, Refaat MM, Mikita JS, Smith M, Cohen DN, Vandvik PO, Agoritsas T, Lytvyn L, Guyatt GH (2018) Oxygen therapy for acutely ill medical patients: a clinical practice guideline. BMJ 363:k4169

69. Investigators I-R, the A, New Zealand Intensive Care Society Clinical Trials G, Mackle D, Bellomo R, Bailey M, Beasley R, Deane A, Eastwood G, Finfer S, Freebairn R, King V, Linke N, Litton E, McArthur C, McGuinness S, Panwar R, Young P (2019) Conservative oxygen therapy during mechanical ventilation in the ICU. N Engl J Med 382:989

70. Barrot L, Asfar P, Mauny F, Winiszewski H, Montini F, Badie J, Quenot JP, Pili-Floury S, Bouhemad B, Louis G, Souweine B, Collange O, Pottecher J, Levy B, Puyraveau M, Vettoretti L, Constantin JM, Capellier G, Investigators L, Network RR, Investigators L, Network RR (2020) Liberal or conservative oxygen therapy for acute respiratory distress syndrome. N Engl J Med 382:999

71. Frat JP, Thille AW, Mercat A, Girault C, Ragot S, Perbet S, Prat G, Boulain T, Morawiec E, Cottereau A, Devaquet J, Nseir S, Razazi K, Mira JP, Argaud L, Chakarian JC, Ricard JD, Wittebole X, Chevalier S, Herbland A, Fartoukh M, Constantin JM, Tonnelier JM, Pierrot M, Mathonnet A, Beduneau G, Deletage-Metreau C, Richard JC, Brochard L, Robert R, Group FS, Network R (2015) High-flow oxygen through nasal cannula in acute hypoxemic respiratory failure. N Engl J Med 372:2185-2196

72. Ni YN, Luo J, Yu H, Liu D, Liang BM, Liang ZA (2018) The effect of highflow nasal cannula in reducing the mortality and the rate of endotracheal intubation when used before mechanical ventilation compared with conventional oxygen therapy and noninvasive positive pressure ventilation. A systematic review and meta-analysis. Am J Emerg Med 36:226-233

73. Ou X, Hua Y, Liu J, Gong C, Zhao W (2017) Effect of high-flow nasal cannula oxygen therapy in adults with acute hypoxemic respiratory failure: a meta-analysis of randomized controlled trials. CMAJ 189:E260-E267

74. Rochwerg B, Granton D, Wang DX, Helviz Y, Einav S, Frat JP, MekontsoDessap A, Schreiber A, Azoulay E, Mercat A, Demoule A, Lemiale V, Pesenti A, Riviello ED, Mauri T, Mancebo J, Brochard L, Burns K (2019) High flow nasal cannula compared with conventional oxygen therapy for acute hypoxemic respiratory failure: a systematic review and metaanalysis. Intensive Care Med 45:563-572

75. Raboud J, Shigayeva A, McGeer A, Bontovics E, Chapman M, Gravel D, Henry B, Lapinsky S, Loeb M, McDonald LC, Ofner M, Paton S, Reynolds D, Scales D, Shen S, Simor A, Stewart T, Vearncombe M, Zoutman D, Green K (2010) Risk factors for SARS transmission from patients requiring intubation: a multicentre investigation in Toronto, Canada. PLoS ONE 5:e10717

76. Fowler RA, Guest CB, Lapinsky SE, Sibbald WJ, Louie M, Tang P, Simor AE, Stewart TE (2004) Transmission of severe acute respiratory syndrome during intubation and mechanical ventilation. Am J Respir Crit Care Med 169:1198-1202

77. Leung CCH, Joynt GM, Gomersall CD, Wong WT, Lee A, Ling L, Chan PKS Lui PCW, Tsoi PCY, Ling CM, Hui M (2019) Comparison of high-flow nasal cannula versus oxygen face mask for environmental bacterial contamination in critically ill pneumonia patients: a randomized controlled crossover trial. J Hosp Infect 101:84-87

78. Cheung JC, Ho LT, Cheng JV, Cham EYK, Lam KN (2020) Staff safety during emergency airway management for COVID-19 in Hong Kong. Lancet Respir Med. https://doi.org/10.1016/S2213-2600(20)30084-9

79. Alraddadi BM, Qushmaq I, Al-Hameed FM, Mandourah Y, Almekhlafi GA, Jose J, Al-Omari A, Kharaba A, Almotairi A, Al Khatib K, Shalhoub S, Abdulmomen A, Mady A, Solaiman O, Al-Aithan AM, Al-Raddadi R, Ragab A, Balkhy HH, Al Harthy A, Sadat M, Tlayjeh H, Merson L, Hayden FG, Fowler RA, Arabi YM, Saudi Critical Care Trials G (2019) Noninvasive ventilation in critically ill patients with the Middle East respiratory syndrome. Influenza Other Respir Viruses 13:382-390

80. Arabi YM, Arifi AA, Balkhy HH, Najm H, Aldawood AS, Ghabashi A, Hawa H, Alothman A, Khaldi A, Al Raiy B (2014) Clinical course and outcomes of critically ill patients with Middle East respiratory syndrome coronavirus infection. Ann Intern Med 160:389-397

81. Zayed Y, Banifadel M, Barbarawi M, Kheiri B, Chahine A, Rashdan L, Haykal T, Samji V, Armstrong E, Bachuwa G, Al-Sanouri I, Seedahmed E, Hernandez DA (2019) Noninvasive oxygenation strategies in immunocompromised patients with acute hypoxemic respiratory failure: a pairwise and network meta-analysis of randomized controlled trials. J Intensive Care Med 2:885066619844713

82. Xu XP, Zhang XC, Hu SL, Xu JY, Xie JF, Liu SQ, Liu L, Huang YZ, Guo FM, Yang Y, Qiu HB (2017) noninvasive ventilation in acute hypoxemic nonhypercapnic respiratory failure: a systematic review and meta-analysis. Crit Care Med 45:e727-e733

83. Wang T, Zhang L, Luo K, He J, Ma Y, Li Z, Zhao N, Xu Q, Li Y, Yu X (2016) Noninvasive versus invasive mechanical ventilation for immunocompromised patients with acute respiratory failure: a systematic review and meta-analysis. BMC Pulm Med 16:129

84. Esquinas AM, Egbert Pravinkumar S, Scala R, Gay P, Soroksky A, Girault C, Han F, Hui DS, Papadakos PJ, Ambrosino N, International NIVN (2014) Noninvasive mechanical ventilation in high-risk pulmonary infections: a clinical review. Eur Respir Rev 23:427-438 
85. Brochard L, Lefebvre JC, Cordioli RL, Akoumianaki E, Richard JC (2014) Noninvasive ventilation for patients with hypoxemic acute respiratory failure. Semin Respir Crit Care Med 35:492-500

86. Slutsky AS, Ranieri VM (2013) Ventilator-induced lung injury. N Engl J Med 369:2126-2136

87. Hui DSC, Zumla A (2019) Severe acute respiratory syndrome: historical, epidemiologic, and clinical features. Infect Dis Clin N Am 33:869-889

88. Brochard L, Mancebo J, Wysocki M, Lofaso F, Conti G, Rauss A, Simonneau G, Benito S, Gasparetto A, Lemaire F et al (1995) Noninvasive ventilation for acute exacerbations of chronic obstructive pulmonary disease. N Engl J Med 333:817-822

89. Rochwerg B, Brochard L, Elliott MW, Hess D, Hill NS, Nava S, Navalesi PMOTSC, Antonelli M, Brozek J, Conti G, Ferrer M, Guntupalli K, Jaber S, Keenan S, Mancebo J, Mehta S, Raoof SMOTTF (2017) Official ERS/ATS clinical practice guidelines: noninvasive ventilation for acute respiratory failure. Eur Respir J. https://doi.org/10.1183/13993003.02426-2016

90. Patel BK, Wolfe KS, Pohlman AS, Hall JB, Kress JP (2016) Effect of noninvasive ventilation delivered by helmet vs face mask on the rate of endotracheal intubation in patients with acute respiratory distress syndrome: a randomized clinical trial. JAMA 315:2435-2441

91. Hui DS, Chow BK, Lo T, Ng SS, Ko FW, Gin T, Chan MTV (2015) Exhaled air dispersion during noninvasive ventilation via helmets and a total facemask. Chest 147:1336-1343

92. Walkey AJ, Goligher EC, Del Sorbo L, Hodgson CL, Adhikari NKJ, Wunsch $H$, Meade MO, Uleryk E, Hess D, Talmor DS, Thompson BT, Brower RG, Fan E (2017) Low tidal volume versus non-volume-limited strategies for patients with acute respiratory distress syndrome. a systematic review and meta-analysis. Ann Am Thorac Soc 14:S271-S279

93. Amato MB, Barbas CS, Medeiros DM, Magaldi RB, Schettino GP, LorenziFilho G, Kairalla RA, Deheinzelin D, Munoz C, Oliveira R, Takagaki TY, Carvalho CR (1998) Effect of a protective-ventilation strategy on mortality in the acute respiratory distress syndrome. N Engl J Med 338:347-354

94. Villar J, Kacmarek RM, Perez-Mendez L, Aguirre-Jaime A (2006) A high positive end-expiratory pressure, low tidal volume ventilatory strategy improves outcome in persistent acute respiratory distress syndrome: a randomized, controlled trial. Crit Care Med 34:1311-1318

95. Acute Respiratory Distress Syndrome N, Brower RG, Matthay MA, Morris A, Schoenfeld D, Thompson BT, Wheeler A (2000) Ventilation with lower tidal volumes as compared with traditional tidal volumes for acute lung injury and the acute respiratory distress syndrome. N Engl J Med 342:1301-1308

96. Brower RG, Shanholtz CB, Fessler HE, Shade DM, White P Jr, Wiener CM Teeter JG, Dodd-o JM, Almog Y, Piantadosi S (1999) Prospective, randomized, controlled clinical trial comparing traditional versus reduced tidal volume ventilation in acute respiratory distress syndrome patients. Crit Care Med 27:1492-1498

97. Orme J Jr, Romney JS, Hopkins RO, Pope D, Chan KJ, Thomsen G, Crapo RO, Weaver LK (2003) Pulmonary function and health-related quality of life in survivors of acute respiratory distress syndrome. Am J Respir Crit Care Med 167:690-694

98. Wu G, Lu B (1998) The application of low tidal volume pressure-controlled ventilation in patients with acute respiratory distress syndrome. Hunan Yi Ke Da Xue Xue Bao 23:57-58

99. Fan E, Del Sorbo L, Goligher EC, Hodgson CL, Munshi L, Walkey AJ, Adhikari NKJ, Amato MBP, Branson R, Brower RG, Ferguson ND, Gajic O, Gattinoni L, Hess D, Mancebo J, Meade MO, McAuley DF, Pesenti A, Ranieri VM, Rubenfeld GD, Rubin E, Seckel M, Slutsky AS, Talmor D, Thompson BT, Wunsch H, Uleryk E, Brozek J, Brochard L, American Thoracic Society ESolCM, Society of Critical Care M (2017) An Official American Thoracic Society/European Society of Intensive Care Medicine/Society of critical care medicine clinical practice guideline: mechanical ventilation in adult patients with acute respiratory distress syndrome. Am J Respir Crit Care Med 195:1253-1263

100. Rhodes A, Evans LE, Alhazzani W, Levy MM, Antonelli M, Ferrer R, Kumar A, Sevransky JE, Sprung CL, Nunnally ME, Rochwerg B, Rubenfeld GD, Angus DC, Annane D, Beale RJ, Bellinghan GJ, Bernard GR, Chiche JD, Coopersmith C, De Backer DP, French CJ, Fujishima S, Gerlach H, Hidalgo JL, Hollenberg SM, Jones AE, Karnad DR, Kleinpell RM, Koh Y, Lisboa TC, Machado FR, Marini JJ, Marshall JC, Mazuski JE, Mclntyre LA, McLean AS, Mehta S, Moreno RP, Myburgh J, Navalesi P, Nishida O, Osborn TM, Perner A, Plunkett CM, Ranieri M, Schorr CA, Seckel MA,
Seymour CW, Shieh L, Shukri KA, Simpson SQ, Singer M, Thompson BT, Townsend SR, Van der Poll T, Vincent JL, Wiersinga WJ, Zimmerman JL, Dellinger RP (2017) Surviving sepsis campaign: international guidelines for management of sepsis and septic shock-2016. Intensive Care Med 43:304-377

101. Thille AW, Rodriguez P, Cabello B, Lellouche F, Brochard L (2006) Patientventilator asynchrony during assisted mechanical ventilation. Intensive Care Med 32:1515-1522

102. Yasuda H, Nishimura T, Kamo T, Sanui M, Nango E, Abe T, Takebayashi T, Lefor AK, Hashimoto S (2017) Optimal plateau pressure for patients with acute respiratory distress syndrome: a protocol for a systematic review and meta-analysis with meta-regression. BMJ Open 7:e015091

103. Brower RG, Lanken PN, MacIntyre N, Matthay MA, Morris A, Ancukiewicz M, Schoenfeld D, Thompson BT, National Heart L, Blood Institute ACTN (2004) Higher versus lower positive end-expiratory pressures in patients with the acute respiratory distress syndrome. N Engl J Med 351:327-336

104. Meade MO, Cook DJ, Guyatt GH, Slutsky AS, Arabi YM, Cooper DJ, Davies AR, Hand LE, Zhou Q, Thabane L, Austin P, Lapinsky S, Baxter A, Russell J, Skrobik Y, Ronco JJ, Stewart TE, Lung Open Ventilation Study I (2008) Ventilation strategy using low tidal volumes, recruitment maneuvers, and high positive end-expiratory pressure for acute lung injury and acute respiratory distress syndrome: a randomized controlled trial. JAMA 299:637-664

105. Mercat A, Richard JC, Vielle B, Jaber S, Osman D, Diehl JL, Lefrant JY, Prat G, Richecoeur J, Nieszkowska A, Gervais C, Baudot J, Bouadma L, Brochard L, Expiratory Pressure Study G (2008) Positive end-expiratory pressure setting in adults with acute lung injury and acute respiratory distress syndrome: a randomized controlled trial. JAMA 299:646-655

106. Briel M, Meade M, Mercat A, Brower RG, Talmor D, Walter SD, Slutsky AS, Pullenayegum E, Zhou Q, Cook D, Brochard L, Richard JC, Lamontagne F, Bhatnagar N, Stewart TE, Guyatt G (2010) Higher vs lower positive end-expiratory pressure in patients with acute lung injury and acute respiratory distress syndrome: systematic review and meta-analysis. JAMA 303:865-873

107. Guo L, Xie J, Huang Y, Pan C, Yang Y, Qiu H, Liu L (2018) Higher PEEP improves outcomes in ARDS patients with clinically objective positive oxygenation response to PEEP: a systematic review and meta-analysis. BMC Anesthesiol 18:172

108. Walkey AJ, Del Sorbo L, Hodgson CL, Adhikari NKJ, Wunsch $H$, Meade MO, Uleryk E, Hess D, Talmor DS, Thompson BT, Brower RG, Fan E (2017) Higher PEEP versus lower PEEP strategies for patients with acute respiratory distress syndrome. A systematic review and meta-analysis. Ann Am Thorac Soc 14:S297-S303

109. National Heart L, Blood Institute Acute Respiratory Distress Syndrome Clinical Trials N, Wiedemann HP, Wheeler AP, Bernard GR, Thompson BT, Hayden D, deBoisblanc B, Connors AF Jr, Hite RD, Harabin AL (2006) Comparison of two fluid-management strategies in acute lung injury. $N$ Engl J Med 354:2564-2575

110. Shi H, Han X, Jiang N, Cao Y, Alwalid O, Gu J, Fan Y, Zheng C (2020) Radiological findings from 81 patients with COVID-19 pneumonia in Wuhan, China: a descriptive study. Lancet Infect Dis. https://doi. org/10.1016/S1473-3099(20)30086-4

111. Cornejo RA, Diaz JC, Tobar EA, Bruhn AR, Ramos CA, Gonzalez RA, Repetto CA, Romero CM, Galvez LR, Llanos O, Arellano DH, Neira WR, Diaz GA, Zamorano AJ, Pereira GL (2013) Effects of prone positioning on lung protection in patients with acute respiratory distress syndrome. Am J Respir Crit Care Med 188:440-448

112. Albert RK, Hubmayr RD (2000) The prone position eliminates compression of the lungs by the heart. Am J Respir Crit Care Med 161:1660-1665

113. Nyren S, Radell P, Lindahl SG, Mure M, Petersson J, Larsson SA Jacobsson H, Sanchez-Crespo A (2010) Lung ventilation and perfusion in prone and supine postures with reference to anesthetized and mechanically ventilated healthy volunteers. Anesthesiology 112:682-687

114. Munshi L, Del Sorbo L, Adhikari NKJ, Hodgson CL, Wunsch H, Meade MO, Uleryk E, Mancebo J, Pesenti A, Ranieri VM, Fan E (2017) Prone position for acute respiratory distress syndrome. A systematic review and meta-analysis. Ann Am Thorac Soc 14:S280-S288 
115. Bloomfield R, Noble DW, Sudlow A (2015) Prone position for acute respiratory failure in adults. Cochrane Database Syst Rev 11:CD008095

116. Mora-Arteaga JA, Bernal-Ramirez OJ, Rodriguez SJ (2015) The effects of prone position ventilation in patients with acute respiratory distress syndrome. A systematic review and metaanalysis. Med Intensiva 39:359-372

117. Lee JM, Bae W, Lee YJ, Cho YJ (2014) The efficacy and safety of prone positional ventilation in acute respiratory distress syndrome: updated study-level meta-analysis of 11 randomized controlled trials. Crit Care Med 42:1252-1262

118. van der Voort PH, Zandstra DF (2001) Enteral feeding in the critically ill: comparison between the supine and prone positions: a prospective crossover study in mechanically ventilated patients. Crit Care 5:216-220

119. Reintam Blaser A, Starkopf J, Alhazzani W, Berger MM, Casaer MP, Deane AM, Fruhwald S, Hiesmayr M, Ichai C, Jakob SM, Loudet Cl, Malbrain ML, Montejo Gonzalez JC, Paugam-Burtz C, Poeze M, Preiser JC, Singer P, van Zanten AR, De Waele J, Wendon J, Wernerman J, Whitehouse T, Wilmer A, Oudemans-van Straaten HM, Function EWGoG (2017) Early enteral nutrition in critically ill patients: ESICM clinical practice guidelines. Intensive Care Med 43:380-398

120. Murray MJ, DeBlock H, Erstad B, Gray A, Jacobi J, Jordan C, McGee W, McManus C, Meade M, Nix S, Patterson A, Sands MK, Pino R, Tescher A, Arbour R, Rochwerg B, Murray CF, Mehta S (2016) Clinical practice guidelines for sustained neuromuscular blockade in the adult critically III patient. Crit Care Med 44:2079-2103

121. Griffiths M, Fan E, Baudouin SV (2019) New UK guidelines for the management of adult patients with ARDS. Thorax 74:931-933

122. Claesson J, Freundlich M, Gunnarsson I, Laake JH, Moller MH, Vandvik PO, Varpula T, Aasmundstad TA (2016) Scandinavian clinical practice guideline on fluid and drug therapy in adults with acute respiratory distress syndrome. Acta Anaesthesiol Scand 60:697-709

123. Papazian L, Aubron C, Brochard L, Chiche JD, Combes A, Dreyfuss D, Forel JM, Guerin C, Jaber S, Mekontso-Dessap A, Mercat A, Richard JC, Roux D, Vieillard-Baron A, Faure H (2019) Formal guidelines: management of acute respiratory distress syndrome. Ann Intensive Care 9:69

124. Alhazzani W, Alshahrani M, Jaeschke R, Forel JM, Papazian L, Sevransky J, Meade MO (2013) Neuromuscular blocking agents in acute respiratory distress syndrome: a systematic review and meta-analysis of randomized controlled trials. Crit Care 17:R43

125. National Heart L, Blood Institute PCTN, Moss M, Huang DT, Brower RG, Ferguson ND, Ginde AA, Gong MN, Grissom CK, Gundel S, Hayden D, Hite RD, Hou PC, Hough CL, Iwashyna TJ, Khan A, Liu KD, Talmor D, Thompson BT, Ulysse CA, Yealy DM, Angus DC (2019) Early neuromuscular blockade in the acute respiratory distress syndrome. N Engl J Med 380:1997-2008

126. Gebistorf F, Karam O, Wetterslev J, Afshari A (2016) Inhaled nitric oxide for acute respiratory distress syndrome (ARDS) in children and adults. Cochrane Database Syst Rev 6:CD002787

127. Gattinoni L, Caironi P, Cressoni M, Chiumello D, Ranieri VM, Quintel M, Russo S, Patroniti N, Cornejo R, Bugedo G (2006) Lung recruitment in patients with the acute respiratory distress syndrome. N Engl J Med 354:1775-1786

128. Kacmarek RM, Villar J, Sulemanji D, Montiel R, Ferrando C, Blanco J, Koh Y, Soler JA, Martinez D, Hernandez M, Tucci M, Borges JB, Lubillo S, Santos A, Araujo JB, Amato MB, Suarez-Sipmann F, Open Lung Approach N (2016) Open lung approach for the acute respiratory distress syndrome: a pilot, randomized controlled trial. Crit Care Med 44:32-42

129. Xi XM, Jiang L, Zhu B, group RM, (2010) Clinical efficacy and safety of recruitment maneuver in patients with acute respiratory distress syndrome using low tidal volume ventilation: a multicenter randomized controlled clinical trial. Chin Med J (Engl) 123:3100-3105

130. Writing Group for the Alveolar Recruitment for Acute Respiratory Distress Syndrome Trial I, Cavalcanti AB, Suzumura EA, Laranjeira LN, Paisani DM, Damiani LP, Guimaraes HP, Romano ER, Regenga MM, Taniguchi LNT, Teixeira C, Pinheiro de Oliveira R, Machado FR, Diaz-Quijano FA, Filho MSA, Maia IS, Caser EB, Filho WO, Borges MC, Martins PA, Matsui M, Ospina-Tascon GA, Giancursi TS, Giraldo-Ramirez ND, Vieira SRR, Assef M, Hasan MS, SzczeklikW, Rios F, Amato MBP, Berwanger O, Ribeiro de Carvalho CR (2017) Effect of lung recruitment and titrated positive endexpiratory pressure (PEEP) vs low PEEP on mortality in patients with acute respiratory distress syndrome: a randomized clinical trial. JAMA 318:1335-1345

131. Hodgson CL, Tuxen DV, Davies AR, Bailey MJ, Higgins AM, Holland AE, Keating JL, Pilcher DV, Westbrook AJ, Cooper DJ, Nichol AD (2011) A randomised controlled trial of an open lung strategy with staircase recruitment, titrated PEEP and targeted low airway pressures in patients with acute respiratory distress syndrome. Crit Care 15:R133

132. Hodgson CL, Cooper DJ, Arabi Y, King V, Bersten A, Bihari S, Brickell K, Davies A, Fahey C, Fraser J, McGuinness S, Murray L, Parke R, Paul E, Tuxen D, Vallance S, Young M, Nichol A (2019) Maximal recruitment open lung ventilation in acute respiratory distress syndrome (PHARLAP). A phase II, multicenter randomized controlled clinical trial. Am J Respir Crit Care Med 200:1363-1372

133. Huh JW, Jung H, Choi HS, Hong SB, Lim CM, Koh Y (2009) Efficacy of positive end-expiratory pressure titration after the alveolar recruitment manoeuvre in patients with acute respiratory distress syndrome. Crit Care 13:R22

134. Goligher EC, Hodgson CL, Adhikari NKJ, Meade MO, Wunsch H, Uleryk E, Gajic O, Amato MPB, Ferguson ND, Rubenfeld GD, Fan E (2017) Lung recruitment maneuvers for adult patients with acute respiratory distress syndrome. A systematic review and meta-analysis. Ann Am Thorac Soc 14:S304-S311

135. Alshahrani MS, Sindi A, Alshamsi F, Al-Omari A, El Tahan M, Alahmadi B, Zein A, Khatani N, Al-Hameed F, Alamri S, Abdelzaher M, Alghamdi A, Alfousan F, Tash A, Tashkandi W, Alraddadi R, Lewis K, Badawee M, Arabi YM, Fan E, Alhazzani W (2018) Extracorporeal membrane oxygenation for severe Middle East respiratory syndrome coronavirus. Ann Intensive Care 8:3

136. Combes A, Hajage D, Capellier G, Demoule A, Lavoue S, Guervilly C, Da Silva D, Zafrani L, Tirot P, Veber B, Maury E, Levy B, Cohen Y, Richard C, Kalfon P, Bouadma L, Mehdaoui H, Beduneau G, Lebreton G, Brochard L, Ferguson ND, Fan E, Slutsky AS, Brodie D, Mercat A, Eolia Trial Group $\mathrm{R}$, Ecmonet (2018) Extracorporeal membrane oxygenation for severe acute respiratory distress syndrome. N Engl J Med 378:1965-1975

137. Goligher EC, Tomlinson G, Hajage D, Wijeysundera DN, Fan E, Juni P, Brodie D, Slutsky AS, Combes A (2018) Extracorporeal membrane oxygenation for severe acute respiratory distress syndrome and posterior probability of mortality benefit in a post hoc bayesian analysis of a randomized clinical trial. JAMA 320:2251-2259

138. Munshi L, Walkey A, Goligher E, Pham T, Uleryk EM, Fan E (2019) Venovenous extracorporeal membrane oxygenation for acute respiratory distress syndrome: a systematic review and meta-analysis. Lancet Respir Med 7:163-172

139. MacLaren G, Fisher D, Brodie D (2020) Preparing for the most critically ill patients with COVID-19: the potential role of extracorporeal membrane oxygenation. JAMA. https://doi.org/10.1001/jama.2020.2342

140. Fardet L, Galicier L, Lambotte O, Marzac C, Aumont C, Chahwan D, Coppo P, Hejblum G (2014) Development and validation of the HScore, a score for the diagnosis of reactive hemophagocytic syndrome. Arthritis Rheumatol 66:2613-2620

141. Mehta P, McAuley DF, Brown M, Sanchez E, Tattersall RS, Manson JJ (2020) COVID-19: consider cytokine storm syndromes and immunosuppression. Lancet. https://doi.org/10.1016/S0140-6736(20)30628-0

142. Wang Y, Jiang W, He Q, Wang C, Wang B, Zhou P, Dong N, Tong Q, (2020) Early, low-dose and short-term application of corticosteroid treatment in patients with severe COVID-19 pneumonia: single-center experience from Wuhan, China. medRxiv: 2020.2003.2006.20032342

143. Siemieniuk RA, Meade MO, Alonso-Coello P, Briel M, Evaniew N, Prasad M, Alexander PE, Fei Y, Vandvik PO, Loeb M, Guyatt GH (2015) Corticosteroid therapy for patients hospitalized with community-acquired pneumonia: a systematic review and meta-analysis. Ann Intern Med 163:519-528

144. Lansbury L, Rodrigo C, Leonardi-Bee J, Nguyen-Van-Tam J, Lim WS (2019) Corticosteroids as adjunctive therapy in the treatment of influenza. Cochrane Database Syst Rev 2:CD010406

145. Lewis SR, Pritchard MW, Thomas CM, Smith AF (2019) Pharmacological agents for adults with acute respiratory distress syndrome. Cochrane Database Syst Rev 7:CD004477

146. Villar J, Ferrando C, Martinez D, Ambros A, Munoz T, Soler JA, Aguilar G, Alba F, Gonzalez-Higueras E, Conesa LA, Martin-Rodriguez C, DiazDominguez FJ, Serna-Grande P, Rivas R, Ferreres J, Belda J, Capilla L, 
Tallet A, Anon JM, Fernandez RL, Gonzalez-Martin JM, dexamethasone in An, (2020) Dexamethasone treatment for the acute respiratory distress syndrome: a multicentre, randomised controlled trial. Lancet Respir Med 8:267-276

147. Ranieri VM, Pettila V, Karvonen MK, Jalkanen J, Nightingale P, Brealey D, Mancebo J, Ferrer R, Mercat A, Patroniti N, Quintel M, Vincent JL, Okkonen M, Meziani F, Bellani G, MacCallum N, Creteur J, Kluge S, Artigas-Raventos A, Maksimow M, Piippo I, Elima K, Jalkanen S, Jalkanen M, Bellingan G, Group IS (2020) Effect of Intravenous Interferon beta-1a on death and days free from mechanical ventilation among patients with moderate to severe acute respiratory distress syndrome: a randomized clinical trial. JAMA. https://doi.org/10.1001/jama.2019.22525

148. Wu C, Chen X, Cai Y, Xia J, Zhou X, Xu S, Huang H, Zhang L, Zhou X, Du C, Zhang Y, Song J, Wang S, Chao Y, Yang Z, Xu J, Zhou X, Chen D, Xiong W, Xu L, Zhou F, Jiang J, Bai C, Zheng J, Song Y (2020) Risk factors associated with acute respiratory distress syndrome and death in patients with Coronavirus Disease 2019 pneumonia in Wuhan. JAMA Intern Med, China. https://doi.org/10.1001/jamainternmed.2020.0994

149. Rochwerg B, Oczkowski SJ, Siemieniuk RAC, Agoritsas T, Belley-Cote E, D'Aragon F, Duan E, English S, Gossack-Keenan K, Alghuroba M, Szczeklik W, Menon K, Alhazzani W, Sevransky J, Vandvik PO, Annane D, Guyatt G (2018) Corticosteroids in sepsis: an updated systematic review and meta-analysis. Crit Care Med 46:1411-1420

150. Lian XJ, Huang DZ, Cao YS, Wei YX, Lian ZZ, Qin TH, He PC, Liu YH, Wang SH (2019) Reevaluating the role of corticosteroids in septic shock: an updated meta-analysis of randomized controlled trials. Biomed Res Int 2019:3175047

151. Arabi YM, Mandourah Y, Al-Hameed F, Sindi AA, Almekhlafi GA, Hussein MA, Jose J, Pinto R, Al-Omari A, Kharaba A, Almotairi A, Al Khatib K, Alraddadi B, Shalhoub S, Abdulmomen A, Qushmaq I, Mady A, Solaiman O, Al-Aithan AM, Al-Raddadi R, Ragab A, Balkhy HH, Al Harthy A, Deeb AM, Al Mutairi H, Al-Dawood A, Merson L, Hayden FG, Fowler RA, Saudi Critical Care Trial G (2018) Corticosteroid therapy for critically ill patients with middle east respiratory syndrome. Am J Respir Crit Care Med 197:757-767

152. Hui DS (2018) Systemic corticosteroid therapy may delay viral clearance in patients with middle east respiratory syndrome coronavirus infection. Am J Respir Crit Care Med 197:700-701

153. Lee N, Allen Chan KC, Hui DS, Ng EK, Wu A, Chiu RW, Wong VW, Chan PK, Wong KT, Wong E, Cockram CS, Tam JS, Sung JJ, Lo YM (2004) Effects of early corticosteroid treatment on plasma SARS-associated Coronavirus RNA concentrations in adult patients. J Clin Virol 31:304-309

154. Uyeki TM, Bernstein HH, Bradley JS, Englund JA, File TM, Fry AM, Gravenstein S, Hayden FG, Harper SA, Hirshon JM, Ison MG, Johnston BL, Knight SL, McGeer A, Riley LE, Wolfe CR, Alexander PE, Pavia AT (2019) Clinical Practice Guidelines by the Infectious Diseases Society of America: 2018 Update on diagnosis, treatment, chemoprophylaxis, and institutional outbreak management of seasonal influenzaa. Clin Inf Dis 68:895-902

155. Arabi YM, Al-Omari A, Mandourah Y, Al-Hameed F, Sindi AA, Alraddadi B, Shalhoub S, Almotairi A, Al Khatib K, Abdulmomen A, Qushmaq I, Mady A, Solaiman O, Al-Aithan AM, Al-Raddadi R, Ragab A, Al Mekhlafi GA, Al Harthy A, Kharaba A, Ahmadi MA, Sadat M, Mutairi HA, Qasim EA, Jose J, Nasim M, Al-Dawood A, Merson L, Fowler R, Hayden FG, Balkhy HH, Saudi Critical Care Trials G (2017) Critically ill patients with the middle east respiratory syndrome: a multicenter retrospective cohort study. Crit Care Med 45:1683-1695

156. Rice TW, Rubinson L, Uyeki TM, Vaughn FL, John BB, Miller RR 3rd, Higgs E, Randolph AG, Smoot BE, Thompson BT, Network NA (2012) Critical illness from 2009 pandemic influenza A virus and bacterial coinfection in the United States. Crit Care Med 40:1487-1498

157. Shieh WJ, Blau DM, Denison AM, Deleon-Carnes M, Adem P, Bhatnagar J, Sumner J, Liu L, Patel M, Batten B, Greer P, Jones T, Smith C, Bartlett J, Montague J, White E, Rollin D, Gao R, Seales C, Jost H, Metcalfe M, Goldsmith CS, Humphrey C, Schmitz A, Drew C, Paddock C, Uyeki TM, Zaki SR (2010) 2009 Pandemic influenza A (H1N1): pathology and pathogenesis of 100 fatal cases in the United States. Am J Pathol 177:166-175

158. McCullers JA (2013) Do specific virus-bacteria pairings drive clinical outcomes of pneumonia? Clin Microbiol Infect 19:113-118

159. Rodriquez-Morales AJ, Cardona-Ospina JA, Gutiérrez-Ocampo E, Villamizar-Peña R, Holguin-Rivera Y, Escalera-Antezana JP, Alvarado-Arnez
LE, Katterine Bonilla-Aldana D, Franco-Paredes C, Henao-Martinez AF, Paniz-Mondolfi A, Lagos-Grisales GJ, Ramírez-Vallejo E, Suárez JA, Zambrano LI, Villamil-Gómez WE, Balbin-Ramon GJ, Rabaan AA, Harapan H, Dhama K, Nishiura H, Kataoka H, Ahmad T, Sah R (2020) Clinical, laboratory and imaging features of COVID-19: a systematic review and meta-analysis. Travel Med Inf Dis 45:50

160. Schulman Cl, Namias N, Doherty J, Manning RJ, Li P, Elhaddad A, Lasko D, Amortegui J, Dy CJ, Dlugasch L, Baracco G, Cohn SM (2005) The effect of antipyretic therapy upon outcomes in critically ill patients: a randomized, prospective study. Surg Infect (Larchmt) 6:369-375

161. Young P, Saxena M, Bellomo R, Freebairn R, Hammond N, van Haren F, Holliday M, Henderson S, Mackle D, McArthur C, McGuinness S, Myburgh J, Weatherall M, Webb S, Beasley R, Investigators H, Australian, New Zealand Intensive Care Society Clinical Trials G (2015) Acetaminophen for fever in critically ill patients with suspected infection. N Engl J Med 373:2215-2224

162. Haupt MT, Jastremski MS, Clemmer TP, Metz CA, Goris GB (1991) Effect of ibuprofen in patients with severe sepsis: a randomized, doubleblind, multicenter study. The Ibuprofen Study Group. Crit Care Med 19:1339-1347

163. Bernard GR, Wheeler AP, Russell JA, Schein R, Summer WR, Steinberg KP, Fulkerson WJ, Wright PE, Christman BW, Dupont WD, Higgins SB, Swindell BB (1997) The effects of ibuprofen on the physiology and survival of patients with sepsis. The Ibuprofen in Sepsis Study Group. N Engl J Med 336:912-918

164. Gozzoli V, Schottker P, Suter PM, Ricou B (2001) Is it worth treating fever in intensive care unit patients? Preliminary results from a randomized trial of the effect of external cooling. Arch Intern Med 161:121-123

165. Memis D, Karamanlioglu B, Turan A, Koyuncu O, Pamukcu Z (2004) Effects of lornoxicam on the physiology of severe sepsis. Crit Care 8:R474-R482

166. Honarmand H, Abdollahi M, Ahmadi A, Javadi MR, Khoshayand MR, Tabeefar H, Mousavi S, Mahmoudi L, Radfar M, Najafi A, Mojtahedzadeh M (2012) Randomized trial of the effect of intravenous paracetamol on inflammatory biomarkers and outcome in febrile critically ill adults. Daru 20:12

167. Schortgen F, Clabault K, Katsahian S, Devaquet J, Mercat A, Deye N, Dellamonica J, Bouadma L, Cook F, Beji O, Brun-Buisson C, Lemaire F, Brochard L (2012) Fever control using external cooling in septic shock: a randomized controlled trial. Am J Respir Crit Care Med 185:1088-1095

168. Niven DJ, Stelfox HT, Leger C, Kubes P, Laupland KB (2013) Assessment of the safety and feasibility of administering antipyretic therapy in critically ill adults: a pilot randomized clinical trial. J Crit Care 28:296-302

169. Yang YL, Liu DW, Wang XT, Long Y, Zhou X, Chai WZ (2013) Body temperature control in patients with refractory septic shock: too much may be harmful. Chin Med J (Engl) 126:1809-1813

170. Janz DR, Bastarache JA, Rice TW, Bernard GR, Warren MA, Wickersham $N$, Sills $G$, Oates $J A$, Roberts $L J$ 2nd, Ware LB, Acetaminophen for the Reduction of Oxidative Injury in Severe Sepsis Study G (2015) Randomized, placebo-controlled trial of acetaminophen for the reduction of oxidative injury in severe sepsis: the Acetaminophen for the Reduction of Oxidative Injury in Severe Sepsis trial. Crit Care Med 43:534-541

171. Schortgen F, Charles-Nelson A, Bouadma L, Bizouard G, Brochard L, Katsahian S (2015) Respective impact of lowering body temperature and heart rate on mortality in septic shock: mediation analysis of a randomized trial. Intensive Care Med 41:1800-1808

172. Wu J, Liu J, Zhao X, Liu C, Wang W, Wang D, Xu W, Zhang C, Yu J, Jiang B, Cao H, Li L (2020) Clinical characteristics of imported cases of COVID-19 in Jiangsu Province: a multicenter descriptive study. Clin Inf Dis. https:// doi.org/10.1093/cid/ciaa199

173. Stiehm ER (2013) Adverse effects of human immunoglobulin therapy. Transfus Med Rev 27:171-178

174. Davey RT Jr, Fernández-Cruz E, Markowitz N, Pett S, Babiker AG, Wentworth D, Khurana S, Engen N, Gordin F, Jain MK, Kan V, Polizzotto MN, Riska P, Ruxrungtham K, Temesgen Z, Lundgren J, Beigel JH, Lane HC, Neaton JD, Davey RT, Fernández-Cruz E, Markowitz N, Pett S, Babiker AG, Wentworth D, Khurana S, Engen N, Gordin F, Jain MK, Kan V, Polizzotto MN, Riska P, Ruxrungtham K, Temesgen Z, Lundgren J, Beigel JH, Lane HC, Neaton JD, Butts J, Denning E, DuChene A, Krum E, Harrison M, Meger S, Peterson R, Quan K, Shaughnessy M, Thompson G, Vock D, Metcalf J, Dewar R, Rehman T, Natarajan V, McConnell R, Flowers E, 
Smith K, Hoover M, Coyle EM, Munroe D, Aagaard B, Pearson M, Cursley A, Webb H, Hudson F, Russell C, Sy A, Purvis C, Jackson B, CollacoMoraes Y, Carey D, Robson R, Sánchez A, Finley E, Conwell D, Losso MH, Gambardella L, Abela C, Lopez P, Alonso H, Touloumi G, Gioukari $V$, Anagnostou O, Avihingsanon A, Pussadee K, Ubolyam S, Omotosho B, Solórzano C, Petersen T, Vysyaraju K, Rizza SA, Whitaker JA, Nahra R, Baxter J, Coburn P, Gardner EM, Scott JA, Faber L, Pastor E, Makohon L, MacArthur RA, Hillman LM, Farrough MJ, Polenakovik HM, Clark LA, Colon RJ, Kunisaki KM, DeConcini M, Johnson SA, Wolfe CR, Mkumba L, Carbonneau JY, Morris A, Fitzpatrick ME, Kessinger CJ, Salata RA, Arters KA, Tasi CM, Panos RJ, Lach LA, Glesby MJ, Ham KA, Hughes VG, Schooley RT, Crouch D, Muttera L, Novak RM, Bleasdale SC, Zuckerman AE, Manosuthi W, Thaonyen S, Chiewcharn T, Suwanpimolkul G, Gatechumpol S, Bunpasang S, Angus BJ, Anderson M, Morgan M, Minton J, Gkamaletsou MN, Hambleton J, Price DA, Llewelyn MJ, Sweetman J, Carbone J, Arribas JR, Montejano R, Lobo Beristain JL, Martinez IZ, Barberan J, Hernandez P, Dwyer DE, Kok J, Borges A, Brandt CT, Knudsen LS, Sypsas N, Constantinou C, Markogiannakis A, Zakynthinos S, Katsaounou P, Kalomenidis I, Mykietiuk A, Alzogaray MF, Obed M, Macias LM, Ebensrtejin J, Burgoa P, Nannini E, Lahitte M, Perez-Patrigeon S, Martínez-Orozco JA, Ramírez-Hinojosa JP (2019) Anti-influenza hyperimmune intravenous immunoglobulin for adults with influenza A or B infection (FLU-IVIG): a double-blind, randomised, placebo-controlled trial. Lancet Respir Med 7:951-963

175. Beigel JH, Nam HH, Adams PL, Krafft A, Ince WL, El-Kamary SS, Sims AC (2019) Advances in respiratory virus therapeutics: a meeting report from the 6th isirv antiviral group conference. Antiviral Res 167:45-67

176. Arabi YM, Fowler R, Hayden FG (2020) Critical care management of adults with community-acquired severe respiratory viral infection. Intensive Care Med 46:315-328

177. Casadevall A, Pirofski L-a (2020) The convalescent sera option for containing COVID-19. J Clin Investig. https://doi.org/10.1172/JCl138003

178. Hung IF, To KK, Lee CK, Lee KL, Yan WW, Chan K, Chan WM, Ngai CW, Law Kl, Chow FL, Liu R, Lai KY, Lau CC, Liu SH, Chan KH, Lin CK, Yuen KY (2013) Hyperimmune IV immunoglobulin treatment: a multicenter double-blind randomized controlled trial for patients with severe 2009 influenza $A(\mathrm{H} 1 \mathrm{~N} 1)$ infection. Chest 144:464-473

179. Stockman LJ, Bellamy R, Garner P (2006) SARS: systematic review of treatment effects. PLoS Med 3:e343

180. Hung IF, To KK, Lee CK, Lee KL, Chan K, Yan WW, Liu R, Watt CL, Chan WM, Lai KY, Koo CK, Buckley T, Chow FL, Wong KK, Chan HS, Ching CK, Tang BS, Lau CC, Li IW, Liu SH, Chan KH, Lin CK, Yuen KY (2011) Convalescent plasma treatment reduced mortality in patients with severe pandemic influenza A (H1N1) 2009 virus infection. Clin Inf Dis $52: 447-456$

181. Luke TC, Kilbane EM, Jackson JL, Hoffman SL (2006) Meta-analysis: convalescent blood products for Spanish influenza pneumonia: a future H5N1 treatment? Ann Intern Med 145:599-609

182. Kong LK, Zhou BP (2006) Successful treatment of avian influenza with convalescent plasma. Hong Kong Med J 12:489

183. Mair-Jenkins J, Saavedra-Campos M, Baillie K, Cleary P, Khaw FM, Lim WS, Makki S, Rooney KD, Nguyen-Van-Tam JS, Beck CR (2014) The effectiveness of convalescent plasma and hyperimmune immunoglobulin for the treatment of severe acute respiratory infections of viral aetiology: a systematic review and exploratory meta-analysis. J Infect Dis 211:80-90

184. China puts 245 COVID-19 patients on convalescent plasma therapy (2020). News release. Xinhua. February 28, 2020. http://www.xinhuanet. com/english/2020-02/28/c_138828177.htm. Accessed 13 March 2020

185. Arabi YM, Hajeer AH, Luke T, Raviprakash K, Balkhy H, Johani S, AlDawood A, Al-Qahtani S, Al-Omari A, Al-Hameed F, Hayden FG, Fowler R, Bouchama A, Shindo N, Al-Khairy K, Carson G, Taha Y, Sadat M Alahmadi M (2016) Feasibility of using convalescent plasma immunotherapy for MERS-CoV infection, Saudi Arabia. Emerg Infect Dis 22:1554-1561

186. van Griensven J, Edwards T, de Lamballerie X, Semple MG, Gallian P, Baize S, Horby PW, Raoul H, Magassouba N, Antierens A, Lomas C, Faye $\mathrm{O}$, Sall AA, Fransen K, Buyze J, Ravinetto R, Tiberghien P, Claeys Y, De Crop M, Lynen L, Bah El, Smith PG, Delamou A, De Weggheleire A, Haba N, Ebola-Tx C (2016) Evaluation of convalescent plasma for ebola virus disease in Guinea. N Engl J Med 374:33-42
187. Beigel JH, Aga E, Elie-Turenne M-C, Cho J, Tebas P, Clark CL, Metcalf JP, Ozment C, Raviprakash K, Beeler J, Holley HP Jr, Warner S, Chorley C, Lane HC, Hughes MD, Davey RT Jr, Beigel JH, Aga E, Elie-Turenne M-C, Cho J, Tebas P, Clark CL, Metcalf JP, Ozment C, Raviprakash K, Beeler J, Holley HP Jr, Warner S, Chorley C, Lane HC, Hughes MD, Davey RT, Barron M, Bastani A, Bauer P, Borkowsky W, Cairns C, Deville J, Elie M-C, Fichtenbaum C, Finberg R, Jain M, Kaufman D, Lin M, Lin J, Maves R, Morrow L, Nguyen M-H, Park P, Polk C, Randolph A, Rao S, Rubinson L, Schofield C, Shoham S, Stalets E, Stapleton RD (2019) Anti-influenza immune plasma for the treatment of patients with severe influenza A: a randomised, double-blind, phase 3 trial. Lancet Respir Med. https://doi. org/10.1016/s2213-2600(19)30199-7

188. Huang $X, X u$ Y, Yang Q, Chen J, Zhang T, Li Z, Guo C, Chen H, Wu H, Li N (2015) Efficacy and biological safety of lopinavir/ritonavir based anti-retroviral therapy in HIV-1-infected patients: a meta-analysis of randomized controlled trials. Sci Rep 5:8528

189. Chu CM, Cheng VC, Hung IF, Wong MM, Chan KH, Chan KS, Kao RY, Poon LL, Wong CL, Guan Y, Peiris JS, Yuen KY, Group HUSS (2004) Role of lopinavir/ritonavir in the treatment of SARS: initial virological and clinical findings. Thorax 59:252-256

190. de Wilde AH, Jochmans D, Posthuma CC, Zevenhoven-Dobbe JC, van Nieuwkoop S, Bestebroer TM, van den Hoogen BG, Neyts J, Snijder EJ (2014) Screening of an FDA-approved compound library identifies four small-molecule inhibitors of Middle East respiratory syndrome coronavirus replication in cell culture. Antimicrob Agents Chemother 58:4875-4884

191. Chan JF, Yao Y, Yeung ML, Deng W, Bao L, Jia L, Li F, Xiao C, Gao H, Yu P, Cai JP, Chu H, Zhou J, Chen H, Qin C, Yuen KY (2015) Treatment With lopinavir/ritonavir or interferon-beta $1 \mathrm{~b}$ improves outcome of MERSCoV infection in a nonhuman primate model of common marmoset. J Infect Dis 212:1904-1913

192. Arabi YM, Asiri AY, Assiri AM, Aziz Jokhdar HA, Alothman A, Balkhy HH, AlJohani S, Al Harbi S, Kojan S, Al Jeraisy M, Deeb AM, Memish ZA, Ghazal S, Al Faraj S, Al-Hameed F, AlSaedi A, Mandourah Y, Al Mekhlafi GA, Sherbeeni NM, Elzein FE, Almotairi A, Al Bshabshe A, Kharaba A, Jose J, Al Harthy A, Al Sulaiman M, Mady A, Fowler RA, Hayden FG, AlDawood A, Abdelzaher M, Bajhmom W, Hussein MA, the Saudi Critical Care Trials g (2020) Treatment of Middle East respiratory syndrome with a combination of lopinavir/ritonavir and interferon-beta $1 \mathrm{~b}$ (MIRACLE trial): statistical analysis plan for a recursive two-stage group sequential randomized controlled trial. Trials 21:8

193. World Health Organization Informal consultation on prioritization of candidate therapeutic agents for use in novel coronavirus 2019 infection. In: Editor (ed) Book Informal consultation on prioritization of candidate therapeutic agents for use in novel coronavirus 2019 infection

194. Cao B, Wang Y, Wen D, Liu W, Wang J, Fan G, Ruan L, Song B, Cai Y, Wei M, Li X, Xia J, Chen N, Xiang J, Yu T, Bai T, Xie X, Zhang L, Li C, Yuan Y, Chen $H$, Li H, Huang H, Tu S, Gong F, Liu Y, Wei Y, Dong C, Zhou F, Gu X, Xu J, Liu Z, Zhang Y, Li H, Shang L, Wang K, Li K, Zhou X, Dong X, Qu Z, Lu S, Hu X, Ruan S, Luo S, Wu J, Peng L, Cheng F, Pan L, Zou J, Jia C, Wang J, Liu X, Wang S, Wu X, Ge Q, He J, Zhan H, Qiu F, Guo L, Huang C, Jaki T, Hayden FG, Horby PW, Zhang D, Wang C (2020) A trial of lopinavir-ritonavir in adults hospitalized with severe Covid-19. N Engl J Med. https:// doi.org/10.1056/nejmoa2001282

195. World Health Organization (2020) Informal consultation on prioritization of candidate therapeutic agents for use in novel coronavirus 2019 infection. Jan 24 2020. https://apps.who.int/iris/bitstream/handl e/10665/330680/WHO-HEO-RDBlueprint\%28nCoV\%29-2020.1-eng.pdf. Accessed 10 March 2020

196. Wang M, Cao R, Zhang L, Yang X, Liu J, Xu M, Shi Z, Hu Z, Zhong W, Xiao $G$ (2020) Remdesivir and chloroquine effectively inhibit the recently emerged novel coronavirus (2019-nCoV) in vitro. Cell Res 30:269-271

197. Sheahan TP, Sims AC, Leist SR, Schafer A, Won J, Brown AJ, Montgomery SA, Hogg A, Babusis D, Clarke MO, Spahn JE, Bauer L, Sellers S, Porter D, Feng JY, Cihlar T, Jordan R, Denison MR, Baric RS (2020) Comparative therapeutic efficacy of remdesivir and combination lopinavir, ritonavir, and interferon beta against MERS-CoV. Nat Commun 11:222

198. de Wit E, Feldmann F, Cronin J, Jordan R, Okumura A, Thomas T, Scott D, Cihlar T, Feldmann H (2020) Prophylactic and therapeutic remdesivir (GS-5734) treatment in the rhesus macaque model of MERS-CoV infection. Proc Nat Acad Sci USA. https://doi.org/10.1073/pnas.1922083117 
199. Mulangu S, Dodd LE, Davey RT Jr, Tshiani Mbaya O, Proschan M, Mukadi D, Lusakibanza Manzo M, Nzolo D, Tshomba Oloma A, Ibanda A, Ali R, Coulibaly S, Levine AC, Grais R, Diaz J, Lane HC, Muyembe-Tamfum JJ, Group TW, Sivahera B, Camara M, Kojan R, Walker R, Dighero-Kemp B, Cao H, Mukumbayi P, Mbala-Kingebeni P, Ahuka S, Albert S, Bonnett T, Crozier I, Duvenhage M, Proffitt C, Teitelbaum M, Moench T, Aboulhab J, Barrett K, Cahill K, Cone K, Eckes R, Hensley L, Herpin B, Higgs E, Ledgerwood J, Pierson J, Smolskis M, Sow Y, Tierney J, Sivapalasingam S. Holman W, Gettinger N, Vallee D, Nordwall J, Team PCS (2019) A randomized, controlled trial of ebola virus disease therapeutics. N Engl J Med 381:2293-2303

200. Falzarano D, de Wit E, Martellaro C, Callison J, Munster VJ, Feldmann H (2013) Inhibition of novel beta coronavirus replication by a combination of interferon-alpha2b and ribavirin. Sci Rep 3:1686

201. Falzarano D, de Wit E, Rasmussen AL, Feldmann F, Okumura A, Scott DP, Brining D, Bushmaker T, Martellaro C, Baseler L, Benecke AG, Katze MG, Munster VJ, Feldmann H (2013) Treatment with interferon-alpha2b and ribavirin improves outcome in MERS-CoV-infected rhesus macaques. Nat Med 19:1313-1317

202. Momattin H, Mohammed K, Zumla A, Memish ZA, Al-Tawfiq JA (2013) Therapeutic options for Middle East respiratory syndrome coronavirus (MERS-CoV)-possible lessons from a systematic review of SARS-CoV therapy. IJID 17:e792-e798

203. Hart BJ, Dyall J, Postnikova E, Zhou H, Kindrachuk J, Johnson RF, Olinger GG Jr, Frieman MB, Holbrook MR, Jahrling PB, Hensley L (2014) Interferon-beta and mycophenolic acid are potent inhibitors of Middle East respiratory syndrome coronavirus in cell-based assays. J Gener Virol 95:571-577

204. Arabi YM, Shalhoub S, Mandourah Y, Al-Hameed F, Al-Omari A, Al Qasim E, Jose J, Alraddadi B, Almotairi A, Al Khatib K, Abdulmomen A, Qushmaq I, Sindi AA, Mady A, Solaiman O, Al-Raddadi R, Maghrabi K, Ragab A, Al Mekhlafi GA, Balkhy HH, Al Harthy A, Kharaba A, Gramish JA, Al-Aithan AM, Al-Dawood A, Merson L, Hayden FG, Fowler R (2019) Ribavirin and interferon therapy for critically ill patients with middle east respiratory syndrome: a multicenter observational study. Clin Inf Dis 45:50. https://doi.org/10.1093/cid/ciz544

205. Chan JF, Chan KH, Kao RY, To KK, Zheng BJ, Li CP, Li PT, Dai J, Mok FK, Chen H, Hayden FG, Yuen KY (2013) Broad-spectrum antivirals for the emerging Middle East respiratory syndrome coronavirus. J Inf 67:606-616

206. Arabi YM, Alothman A, Balkhy HH, Al-Dawood A, AlJohani S, Al Harbi S, Kojan S, Al Jeraisy M, Deeb AM, Assiri AM, Al-Hameed F, AlSaedi A, Mandourah Y, Almekhlafi GA, Sherbeeni NM, Elzein FE, Memon J, Taha Y, Almotairi A, Maghrabi KA, Qushmaq I, Al Bshabshe A, Kharaba A, Shalhoub S, Jose J, Fowler RA, Hayden FG, Hussein MA, the Mtg, (2018) Treatment of Middle East Respiratory Syndrome with a combination of lopinavir-ritonavir and interferon-beta1b (MIRACLE trial): study protocol for a randomized controlled trial. Trials 19:81

207. Vincent MJ, Bergeron E, Benjannet S, Erickson BR, Rollin PE, Ksiazek TG, Seidah NG, Nichol ST (2005) Chloroquine is a potent inhibitor of SARS coronavirus infection and spread. Virol I 2:69

208. Yao X, Ye F, Zhang M, Cui C, Huang B, Niu P, Liu X, Zhao L, Dong E, Song C, Zhan S, Lu R, Li H, Tan W, Liu D (2020) In vitro antiviral activity and projection of optimized dosing design of hydroxychloroquine for the treatment of severe acute respiratory syndrome coronavirus 2 (SARSCoV-2). Clin Infect Dis. https://doi.org/10.1093/cid/ciaa237

209. Touret $F$, de Lamballerie X (2020) Of chloroquine and COVID-19. Antiviral Res 177:104762

210. Roques P, Thiberville SD, Dupuis-Maguiraga L, Lum FM, Labadie K, Martinon F, Gras G, Lebon P, Ng LFP, de Lamballerie X, Le Grand R (2018) Paradoxical effect of chloroquine treatment in enhancing chikungunya virus infection. Viruses. https://doi.org/10.3390/v10050268

211. Gao J, Tian Z, Yang X (2020) Breakthrough: Chloroquine phosphate has shown apparent efficacy in treatment of COVID-19 associated pneumonia in clinical studies. Biosci Trends 4:72-73
212. multicenter collaboration group of Department of S, Technology of Guangdong P, Health Commission of Guangdong Province for chloroquine in the treatment of novel coronavirus p (2020) Expert consensus on chloroquine phosphate for the treatment of novel coronavirus pneumonia. Zhonghua Jie He He Hu Xi Za Zhi 43:E019

213. Cortegiani A, Ingoglia G, Ippolito M, Giarratano A, Einav S (2020) A systematic review on the efficacy and safety of chloroquine for the treatment of COVID-19. J Crit Care 45:50. https://doi.org/10.1016/j. jerc.2020.03.005

214. Brunner HI, Ruperto N, Zuber Z, Keane C, Harari O, Kenwright A, Lu P, Cuttica R, Keltsev V, Xavier RM, Calvo I, Nikishina I, Rubio-Perez N, Alexeeva E, Chasnyk V, Horneff G, Opoka-Winiarska V, Quartier P, Silva CA, Silverman E, Spindler A, Baildam E, Gamir ML, Martin A, Rietschel C, Siri D, Smolewska E, Lovell D, Martini A, De Benedetti F, Paediatric Rheumatology International Trials Organisation P, Pediatric Rheumatology Collaborative Study G (2015) Efficacy and safety of tocilizumab in patients with polyarticular-course juvenile idiopathic arthritis: results from a phase 3, randomised, double-blind withdrawal trial. Ann Rheum Dis 74:1110-1117

215. Genovese MC, van Adelsberg J, Fan C, Graham NMH, van Hoogstraten H, Parrino J, Mangan EK, Spindler A, Huizinga TWJ, van der Heijde D, Investigators Es (2018) Two years of sarilumab in patients with rheumatoid arthritis and an inadequate response to MTX: safety, efficacy and radiographic outcomes. Rheumatology (Oxford) 57:1423-1431

216. Yokota S, Imagawa T, Mori M, Miyamae T, Aihara Y, Takei S, Iwata N, Umebayashi H, Murata T, Miyoshi M, Tomiita M, Nishimoto N, Kishimoto T (2008) Efficacy and safety of tocilizumab in patients with systemiconset juvenile idiopathic arthritis: a randomised, double-blind, placebocontrolled, withdrawal phase III trial. Lancet 371:998-1006

217. Le RQ, Li L, Yuan W, Shord SS, Nie L, Habtemariam BA, Przepiorka D, Farrell AT, Pazdur R (2018) FDA approval summary: tocilizumab for treatment of chimeric antigen receptor T cell-induced severe or lifethreatening cytokine release syndrome. Oncologist 23:943

218. Chen X, Zhao B, Qu Y, Chen Y, Xiong J, Feng Y, Men D, Huang Q, Liu $Y$, Yang B, Ding J, Li F, (2020) Detectable serum SARS-CoV-2 viral load (RNAaemia) is closely associated with drastically elevated interleukin 6 (IL-6) level in critically ill COVID-19 patients. medRxiv: 2020.2002.2029.20029520

219. Campbell L, Chen C, Bhagat SS, Parker RA, Ostor AJ (2011) Risk of adverse events including serious infections in rheumatoid arthritis patients treated with tocilizumab: a systematic literature review and meta-analysis of randomized controlled trials. Rheumatology (Oxford) 50:552-562

220. Geng Z, Yu Y, Hu S, Dong L, Ye C (2019) Tocilizumab and the risk of respiratory adverse events in patients with rheumatoid arthritis: a systematic review and meta-analysis of randomised controlled trials. Clin Exp Rheumatol 37:318-323

221. Haffizulla J, Hartman A, Hoppers M, Resnick H, Samudrala S, Ginocchio C, Bardin M, Rossignol JF, Group USNICS (2014) Effect of nitazoxanide in adults and adolescents with acute uncomplicated influenza: a doubleblind, randomised, placebo-controlled, phase $2 \mathrm{~b} / 3$ trial. Lancet Inf Dis 14:609-618

222. Gamino-Arroyo AE, Guerrero ML, McCarthy S, Ramirez-Venegas A, Llamosas-Gallardo B, Galindo-Fraga A, Moreno-Espinosa S, Roldan-Aragon Y, Araujo-Melendez J, Hunsberger S, Ibarra-Gonzalez V, Martinez-Lopez J, Garcia-Andrade LA, Kapushoc H, Holley HP Jr, Smolskis MC, RuizPalacios GM, Beigel JH, Mexico Emerging Infectious Diseases Clinical Research N (2019) Efficacy and safety of nitazoxanide in addition to standard of care for the treatment of severe acute respiratory illness. Clin Inf Dis 69:1903-1911 